Cochrane Database of Systematic Reviews

\title{
Antioxidant vitamin and mineral supplements for slowing the progression of age-related macular degeneration (Review)
}

Evans JR, Lawrenson JG

Evans JR, Lawrenson JG.

Antioxidant vitamin and mineral supplements for slowing the progression of age-related macular degeneration.

Cochrane Database of Systematic Reviews 2017, Issue 7. Art. No.: CD000254.

DOI: 10.1002/14651858.CD000254.pub4.

www.cochranelibrary.com 
TABLE OF CONTENTS

ABSTRACT

PLAIN LANGUAGE SUMMARY

SUMMARY OF FINDINGS

BACKGROUND

OBJECTIVES

METHODS

RESULTS

Figure 1.

Figure 2.

Figure 3.

DISCUSSION

AUTHORS' CONCLUSIONS

ACKNOWLEDGEMENTS

REFERENCES

CHARACTERISTICS OF STUDIES

DATA AND ANALYSES

Analysis 1.1. Comparison 1 Antioxidant multivitamin and mineral supplement versus placebo, Outcome 1 Progression to late AMD (neovascular AMD or geographic atrophy).

Analysis 1.2. Comparison 1 Antioxidant multivitamin and mineral supplement versus placebo, Outcome 2 Progression to neovascular AMD.

Analysis 1.3. Comparison 1 Antioxidant multivitamin and mineral supplement versus placebo, Outcome 3 Progression to geographic atrophy.

Analysis 1.4. Comparison 1 Antioxidant multivitamin and mineral supplement versus placebo, Outcome 4 Progression to visual loss (loss of 3 or more lines on logMAR chart).

Analysis 1.5. Comparison 1 Antioxidant multivitamin and mineral supplement versus placebo, Outcome 5 Mean visual acuity. . Analysis 1.6. Comparison 1 Antioxidant multivitamin and mineral supplement versus placebo, Outcome 6 Quality of life. ....... Analysis 2.1. Comparison 2 Lutein and/or zeaxanthin versus placebo, Outcome 1 Progression to late AMD (neovascular AMD and/or geographic atrophy.

Analysis 2.2. Comparison 2 Lutein and/or zeaxanthin versus placebo, Outcome 2 Progression to neovascular AMD. ................ Analysis 2.3. Comparison 2 Lutein and/or zeaxanthin versus placebo, Outcome 3 Progression to geographic atrophy. ............ Analysis 2.4. Comparison 2 Lutein and/or zeaxanthin versus placebo, Outcome 4 Progression to visual loss (loss of 3 or more lines on logMAR chart).

Analysis 2.5. Comparison 2 Lutein and/or zeaxanthin versus placebo, Outcome 5 Distance visual acuity: mean. .....................

Analysis 2.6. Comparison 2 Lutein and/or zeaxanthin versus placebo, Outcome 6 Visual Function Quality (VFQ).

Analysis 3.1. Comparison 3 Vitamin E versus placebo, Outcome 1 Progression to late AMD (neovascular AMD and/or geographic atrophy.

Analysis 3.2. Comparison 3 Vitamin E versus placebo, Outcome 2 Progression to visual loss (loss of 3 or more lines on logMAR chart).

Analysis 4.1. Comparison 4 Zinc versus placebo, Outcome 1 Progression to late AMD (neovascular AMD or geographic atrophy).

Analysis 4.2. Comparison 4 Zinc versus placebo, Outcome 2 Progression to neovascular AMD.

Analysis 4.3. Comparison 4 Zinc versus placebo, Outcome 3 Progression to geographic atrophy.

Analysis 4.4. Comparison 4 Zinc versus placebo, Outcome 4 Progression to visual loss (loss of 3 or more lines on logMAR chart).

Analysis 4.5. Comparison 4 Zinc versus placebo, Outcome 5 Distance visual acuity: mean.

ADDITIONAL TABLES

APPENDICES

WHAT'S NEW

HISTORY

CONTRIBUTIONS OF AUTHORS

DECLARATIONS OF INTEREST

SOURCES OF SUPPORT

DIFFERENCES BETWEEN PROTOCOL AND REVIEW 
[Intervention Review]

\section{Antioxidant vitamin and mineral supplements for slowing the progression of age-related macular degeneration}

Jennifer R Evans ${ }^{1}$, John G Lawrenson²

1Cochrane Eyes and Vision, ICEH, London School of Hygiene \& Tropical Medicine, London, UK. 2Centre for Applied Vision Research, School of Health Sciences, City University of London, London, UK

Contact: Jennifer R Evans, Cochrane Eyes and Vision, ICEH, London School of Hygiene \& Tropical Medicine, Keppel Street, London, WC1E 7HT, UK. jennifer.evans@lshtm.ac.uk.

Editorial group: Cochrane Eyes and Vision Group.

Publication status and date: Edited (no change to conclusions), published in Issue 9, 2017.

Citation: Evans JR, Lawrenson JG. Antioxidant vitamin and mineral supplements for slowing the progression of age-related macular degeneration. Cochrane Database of Systematic Reviews 2017, Issue 7. Art. No.: CD000254. DOI: 10.1002/14651858.CD000254.pub4.

Copyright ( 2017 The Cochrane Collaboration. Published by John Wiley \& Sons, Ltd.

\section{A B S T R A C T}

\section{Background}

It has been proposed that antioxidants may prevent cellular damage in the retina by reacting with free radicals that are produced in the process of light absorption. Higher dietary levels of antioxidant vitamins and minerals may reduce the risk of progression of age-related macular degeneration (AMD).

\section{Objectives}

The objective of this review was to assess the effects of antioxidant vitamin or mineral supplementation on the progression of AMD in people with AMD.

\section{Search methods}

We searched CENTRAL (2017, Issue 2), MEDLINE Ovid (1946 to March 2017), Embase Ovid (1947 to March 2017), AMED (1985 to March 2017), OpenGrey (System for Information on Grey Literature in Europe, the ISRCTN registry (www.isrctn.com/editAdvancedSearch), ClinicalTrials.gov (www.clinicaltrials.gov) and the WHO International Clinical Trials Registry Platform (ICTRP) (www.who.int/ictrp/search/ en). We did not use any date or language restrictions in the electronic searches for trials. We last searched the electronic databases on 29 March 2017.

\section{Selection criteria}

We included randomised controlled trials (RCTs) that compared antioxidant vitamin or mineral supplementation (alone or in combination) to placebo or no intervention, in people with AMD.

\section{Data collection and analysis}

Both review authors independently assessed risk of bias in the included studies and extracted data. One author entered data into RevMan 5; the other author checked the data entry. We graded the certainty of the evidence using GRADE.

\section{Main results}

We included 19 studies conducted in USA, Europe, China, and Australia. We judged the trials that contributed data to the review to be at low or unclear risk of bias.

Nine studies compared multivitamins with placebo (7 studies) or no treatment ( 2 studies) in people with early and moderate AMD. The duration of supplementation and follow-up ranged from nine months to six years; one trial followed up beyond two years. Most evidence 
came from the Age-Related Eye Disease Study (AREDS) in the USA. People taking antioxidant vitamins were less likely to progress to late AMD (odds ratio (OR) $0.72,95 \%$ confidence interval (CI) 0.58 to $0.90 ; 2445$ participants; 3 RCTs; moderate-certainty evidence). In people with very early signs of AMD, who are at low risk of progression, this would mean that there would be approximately 4 fewer cases of progression to late AMD for every 1000 people taking vitamins ( 1 fewer to 6 fewer cases). In people at high risk of progression (i.e. people with moderate AMD) this would correspond to approximately 8 fewer cases of progression for every 100 people taking vitamins ( 3 fewer to 13 fewer). In one study of 1206 people, there was a lower risk of progression for both neovascular AMD (OR $0.62,95 \% \mathrm{Cl} 0.47$ to 0.82 ; moderate-certainty evidence) and geographic atrophy (OR $0.75,95 \% \mathrm{Cl} 0.51$ to 1.10; moderate-certainty evidence) and a lower risk of losing 3 or more lines of visual acuity (OR $0.77,95 \% \mathrm{Cl} 0.62$ to $0.96 ; 1791$ participants; moderate-certainty evidence). Low-certainty evidence from one study of 110 people suggested higher quality of life scores (National Eye Institute Visual Function Questionnaire) in treated compared with the nontreated people after 24 months (mean difference (MD) 12.30, 95\% Cl 4.24 to 20.36).

Six studies compared lutein (with or without zeaxanthin) with placebo. The duration of supplementation and follow-up ranged from six months to five years. Most evidence came from the AREDS2 study in the USA. People taking lutein or zeaxanthin may have similar or slightly reduced risk of progression to late AMD (RR $0.94,95 \% \mathrm{CI} 0.87$ to $1.01 ; 6891$ eyes; low-certainty evidence), neovascular $\mathrm{AMD}$ (RR $0.92,95 \% \mathrm{Cl}$ 0.84 to 1.02; 6891 eyes; low-certainty evidence), and geographic atrophy (RR 0.92, $95 \% \mathrm{Cl} 0.80$ to $1.05 ; 6891$ eyes; low-certainty evidence). A similar risk of progression to visual loss of 15 or more letters was seen in the lutein and control groups ( $\mathrm{RR} 0.98,95 \% \mathrm{Cl} 0.91$ to $1.05 ; 6656$ eyes; low-certainty evidence). Quality of life (measured with Visual Function Questionnaire) was similar between groups in one study of 108 participants (MD 1.48, 95\% -5.53 to 8.49, moderate-certainty evidence).

One study, conducted in Australia, compared vitamin E with placebo. This study randomised 1204 people to vitamin E or placebo, and followed up for four years. Participants were enrolled from the general population; $19 \%$ had AMD. The number of late AMD events was low $(\mathrm{N}=7)$ and the estimate of effect was uncertain (RR $1.36,95 \% \mathrm{Cl} 0.31$ to 6.05 , very low-certainty evidence). There were no data on neovascular AMD or geographic atrophy.There was no evidence of any effect of treatment on visual loss (RR $1.04,95 \% \mathrm{Cl} 0.74$ to 1.47 , lowcertainty evidence). There were no data on quality of life.

Five studies compared zinc with placebo. The duration of supplementation and follow-up ranged from six months to seven years. People taking zinc supplements may be less likely to progress to late AMD (OR 0.83, 95\% Cl 0.70 to $0.98 ; 3790$ participants; 3 RCTs; low-certainty evidence), neovascular AMD (OR 0.76, 95\% Cl 0.62 to $0.93 ; 2442$ participants; 1 RCT; moderate-certainty evidence), geographic atrophy (OR $0.84,95 \% \mathrm{Cl} 0.64$ to $1.10 ; 2442$ participants; $1 \mathrm{RCT}$; moderate-certainty evidence), or visual loss (OR $0.87,95 \% \mathrm{Cl} 0.75$ to $1.00 ; 3791$ participants; 2 RCTs; moderate-certainty evidence). There were no data reported on quality of life.

Very low-certainty evidence was available on adverse effects because the included studies were underpowered and adverse effects inconsistently reported.

\section{Authors' conclusions}

People with AMD may experience some delay in progression of the disease with multivitamin antioxidant vitamin and mineral supplementation. This finding was largely drawn from one large trial, conducted in a relatively well-nourished American population. We do not know the generalisability of these findings to other populations. Although generally regarded as safe, vitamin supplements may have harmful effects. A systematic review of the evidence on harms of vitamin supplements is needed. Supplements containing lutein and zeaxanthin are heavily marketed for people with age-related macular degeneration but our review shows they may have little or no effect on the progression of AMD.

\section{PLAIN LANGUAGE SUMMARY}

\section{Antioxidant vitamin and mineral supplements to slow down the progression of age-related macular degeneration (AMD)}

\section{What is the aim of this review?}

The aim of this Cochrane Review was to find out whether taking antioxidant vitamin and mineral supplements slows down the progression of AMD and prevents visual loss. Cochrane researchers collected and analysed all relevant studies to answer this question and found 19 studies.

\section{Key messages}

Taking an antioxidant multivitamin supplement may slow down the progression of AMD. Most benefit will be seen in people who have a higher chance of progression. Although vitamin supplements are generally regarded as safe, the studies included in this review did not provide good evidence as to safety as they were generally too small.

\section{What was studied in the review?}

AMD is a condition of the central area (macula) of the back of the eye (retina). The macula degenerates with age. In some people, this deterioration happens more quickly, and is associated with a particular appearance at the back of the eye. In its earliest stage (early AMD), yellow spots (drusen) can be seen under the retina by an eye health professional on examining the eye. The affected person will probably be unaware that they a problem. As AMD progresses, it can lead to the loss of the cells in the back of the eye, which are needed for vision. This is known as geographic atrophy. Sometimes, new (harmful) blood vessels grow in the macula. These new blood vessels may bleed 
and cause scarring. This is known as neovascular or wet AMD. Any damage to the macula can affect vision, particularly central vision. Neovascular AMD and geographic atrophy are known as late AMD.

It is possible that antioxidant vitamins may help to protect the macula against this deterioration and loss of vision. Vitamin C, E, betacarotene, lutein, zeaxanthin, and zinc are examples of antioxidant vitamins commonly found in vitamin supplements.

The Cochrane researchers only looked at the effects of these supplements in people with AMD. There is another Cochrane Review on the effects of these supplements in people who do not already have AMD.

\section{What are the main results of the review?}

The Cochrane researchers found 19 relevant studies. Ten studies were from Europe, six from USA, two from China, and one from Australia. These studies compared multivitamin supplements, zinc, vitamin E and lutein and zeaxanthin with placebo.

-Taking antioxidant vitamins plus zinc probably slows down the progression to late AMD and vision loss (moderate-certainty evidence). This may result in a small improvement in quality of life (low-certainty evidence).

-Taking lutein alone (or combined with zeaxanthin) may have little or no effect on progression to late AMD and vision loss (low-certainty evidence).

-Taking vitamin E alone may have little or no effect on the progression to late AMD and vision loss (low-certainty evidence).

Although vitamin supplements are generally regarded as safe, the studies included in this review did not provide good evidence as to safety as they were generally too small and adverse effects were reported inconsistently.

\section{How up-to-date is this review?}

The Cochrane researchers searched for studies that had been published up to 29th March 2017. 


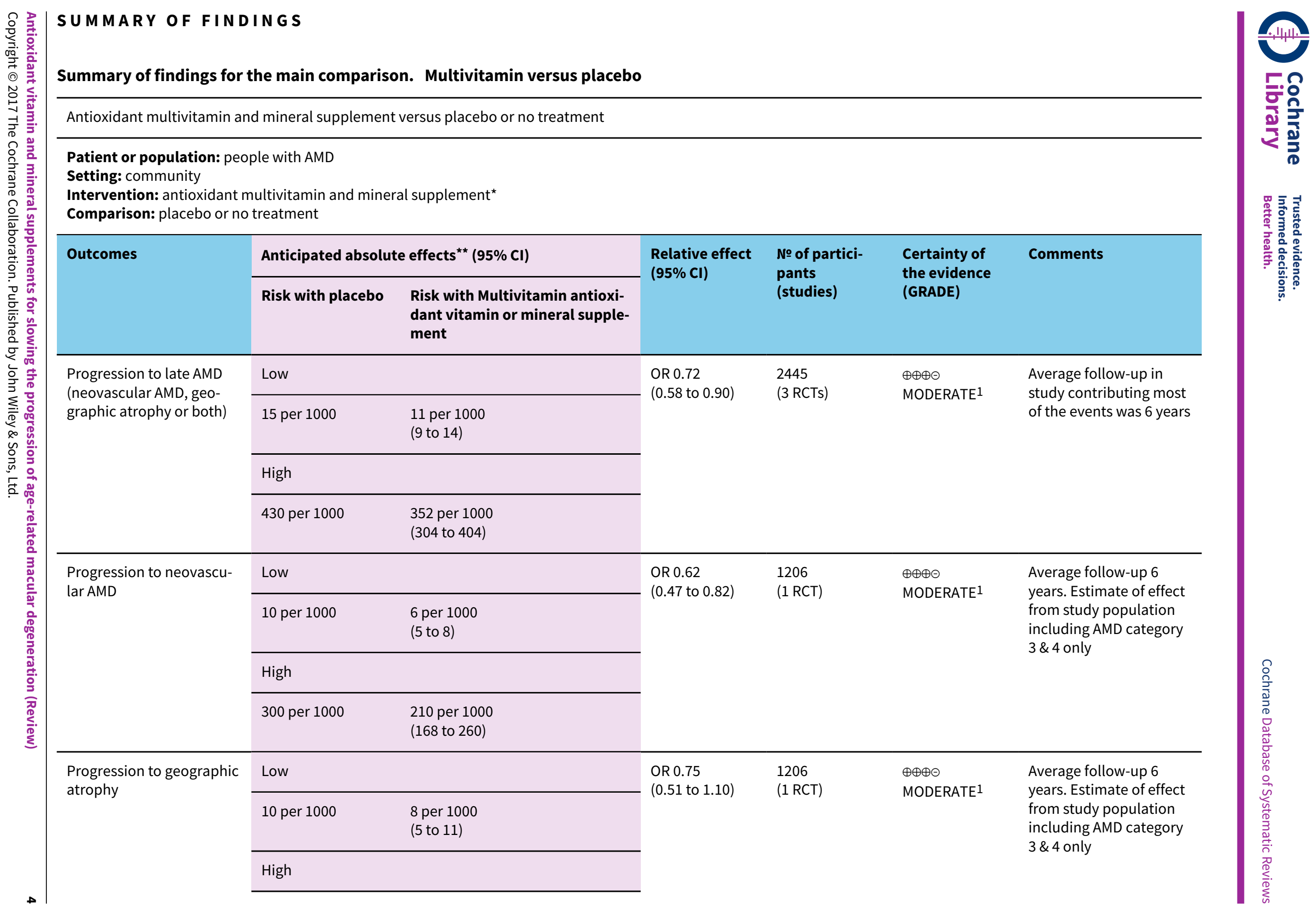




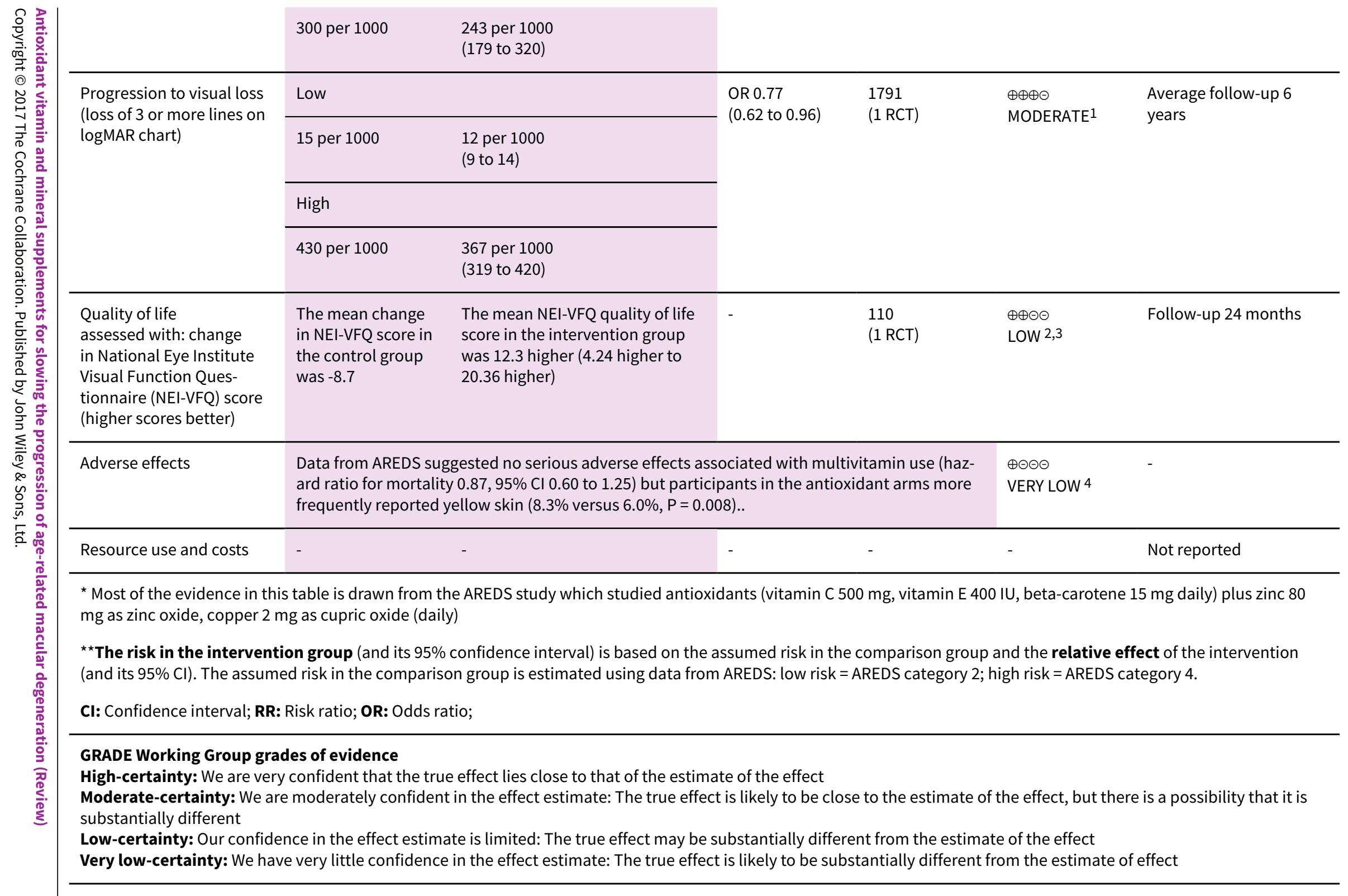

1 Downgraded one level for imprecision because upper confidence interval crosses line of minimum important difference (0.8 to 1.25$)$

2 Downgraded one level for risk of bias because study was not placebo-controlled and at high risk of performance and detection bias

3 Downgraded one level for imprecision because confidence intervals included clinically insignificant effect 
4 Downgraded for one level for imprecision (as included studies were underpowered to look at adverse effects), one level for risk of bias (adverse effects were inconsistently reported) and one level for inconsistency (inconsistent results reported).

\section{Summary of findings 2 . Lutein or zeaxanthin versus placebo}

Lutein and/or zeaxanthin versus placebo

Patient or population: people with AMD

Setting: community

Intervention: lutein and zeaxanthin ${ }^{*}$

Comparison: placebo

\begin{tabular}{|c|c|c|c|c|c|c|}
\hline \multirow[t]{2}{*}{ Outcomes } & \multicolumn{2}{|c|}{ Anticipated absolute effects ${ }^{\star \star}(95 \% \mathrm{Cl})$} & \multirow{2}{*}{$\begin{array}{l}\text { Relative effect } \\
(95 \% \mathrm{Cl})\end{array}$} & \multirow{2}{*}{$\begin{array}{l}\text { № of partici- } \\
\text { pants } \\
\text { (studies) }\end{array}$} & \multirow{2}{*}{$\begin{array}{l}\text { certainty of } \\
\text { the evidence } \\
\text { (GRADE) }\end{array}$} & \multirow[t]{2}{*}{ Comments } \\
\hline & Risk with placebo & Risk with Lutein and zeaxanthin & & & & \\
\hline \multirow{2}{*}{$\begin{array}{l}\text { Progression to late AMD (neo- } \\
\text { vascular AMD, geographic at- } \\
\text { rophy, or both) }\end{array}$} & 15 per 1000 & $\begin{array}{l}14 \text { per } 1000 \\
(13 \text { to } 15)\end{array}$ & \multirow{2}{*}{$\begin{array}{l}\text { RR } 0.94 \\
(0.87 \text { to } 1.01)\end{array}$} & \multirow{2}{*}{$\begin{array}{l}6891 \text { eyes } \\
(1 \mathrm{RCT})\end{array}$} & \multirow{2}{*}{$\begin{array}{l}\oplus \oplus \Theta \Theta \\
\operatorname{LOW} 1,2\end{array}$} & \multirow{2}{*}{$\begin{array}{l}\text { Average fol- } \\
\text { low-up } 5 \text { years }\end{array}$} \\
\hline & 430 per 1000 & $\begin{array}{l}404 \text { per } 1000 \\
\text { ( } 374 \text { to } 434)\end{array}$ & & & & \\
\hline \multirow{3}{*}{$\begin{array}{l}\text { Progression to neovascular } \\
\text { AMD }\end{array}$} & Low & & \multirow{3}{*}{$\begin{array}{l}\text { RR } 0.92 \\
\text { (0.84 to } 1.02 \text { ) }\end{array}$} & \multirow{3}{*}{$\begin{array}{l}6891 \text { eyes } \\
(1 \mathrm{RCT})\end{array}$} & \multirow{3}{*}{$\begin{array}{l}\oplus \oplus \Theta \Theta \\
\operatorname{LOW} 1,2\end{array}$} & \multirow{3}{*}{$\begin{array}{l}\text { Average fol- } \\
\text { low-up } 5 \text { years }\end{array}$} \\
\hline & 10 per 1000 & $\begin{array}{l}9 \text { per } 1000 \\
(8 \text { to } 10)\end{array}$ & & & & \\
\hline & 300 per 1000 & $\begin{array}{l}276 \text { per } 1000 \\
(252 \text { to } 306)\end{array}$ & & & & \\
\hline \multirow{3}{*}{$\begin{array}{l}\text { Progression to geographic at- } \\
\text { rophy }\end{array}$} & Low & & \multirow{3}{*}{$\begin{array}{l}\text { RR } 0.92 \\
\text { (0.80 to } 1.05)\end{array}$} & \multirow{3}{*}{$\begin{array}{l}6891 \text { eyes } \\
\text { (1 study) }\end{array}$} & \multirow{3}{*}{$\begin{array}{l}\oplus \oplus \odot \odot \\
\operatorname{LOW} 1,2\end{array}$} & \multirow{3}{*}{$\begin{array}{l}\text { Average fol- } \\
\text { low-up } 5 \text { years }\end{array}$} \\
\hline & 10 per 1000 & $\begin{array}{l}9 \text { per } 1000 \\
(8 \text { to } 11)\end{array}$ & & & & \\
\hline & High & & & & & \\
\hline
\end{tabular}




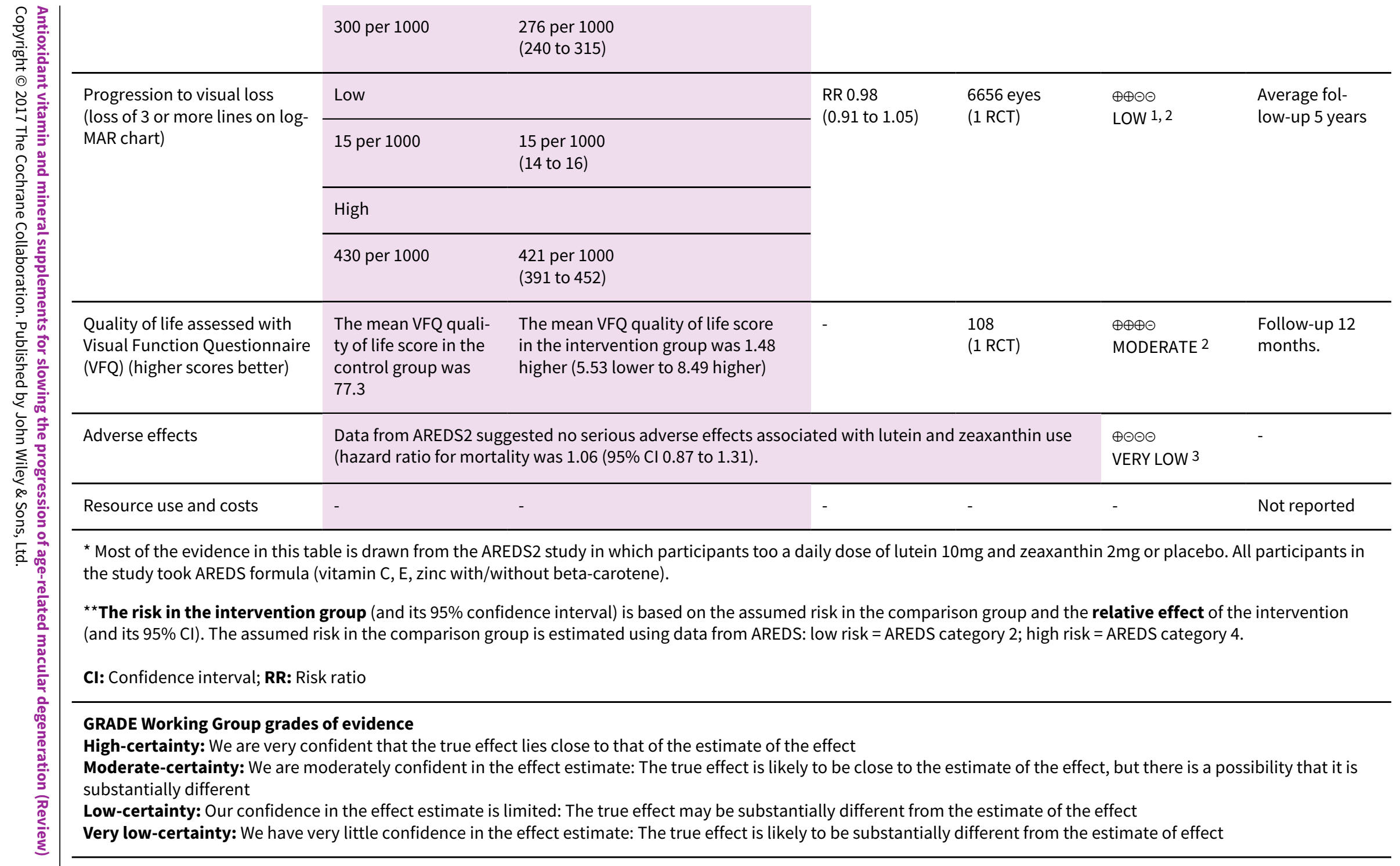

1 Downgraded one level for indirectness, as everyone in trial took AREDS formula, which may have affected the estimate of effect

2 Downgraded one level for imprecision, as confidence intervals crossed line of minimum important difference.

3 Downgraded for one level for imprecision (as included studies were underpowered to look at adverse effects), one level for risk of bias (adverse effects were inconsistently reported) and one level for inconsistency (inconsistent results reported). 


\begin{tabular}{|c|c|c|c|c|c|c|}
\hline \multicolumn{7}{|l|}{ Vitamin E versus placebo } \\
\hline \multicolumn{7}{|c|}{$\begin{array}{l}\text { Patient or population: people with AMD } \\
\text { Setting: community } \\
\text { Intervention: vitamin } E^{\star} \\
\text { Comparison: placebo }\end{array}$} \\
\hline \multirow[t]{2}{*}{ Outcomes } & \multicolumn{2}{|c|}{ Anticipated absolute effects $^{\star \star}(95 \% \mathrm{Cl})$} & \multirow{2}{*}{$\begin{array}{l}\text { Relative effect } \\
(95 \% \mathrm{Cl})\end{array}$} & \multirow{2}{*}{$\begin{array}{l}\text { № of partici- } \\
\text { pants } \\
\text { (studies) }\end{array}$} & \multirow{2}{*}{$\begin{array}{l}\text { Certainty of } \\
\text { the evidence } \\
\text { (GRADE) }\end{array}$} & \multirow[t]{2}{*}{ Comments } \\
\hline & Risk with placebo & $\begin{array}{l}\text { Risk with Multivitamin an- } \\
\text { tioxidant vitamin or mineral } \\
\text { supplement }\end{array}$ & & & & \\
\hline \multirow{4}{*}{$\begin{array}{l}\text { Progression to late AMD (neovas- } \\
\text { cular AMD, geographic atrophy or } \\
\text { both) }\end{array}$} & \multicolumn{2}{|l|}{ Low } & \multirow{4}{*}{$\begin{array}{l}\text { RR } 1.36 \text { (0.31 to } \\
6.05\end{array}$} & \multirow{4}{*}{$\begin{array}{l}998 \\
(1 \mathrm{RCT})\end{array}$} & \multirow{4}{*}{$\begin{array}{l}\oplus \oplus \odot \odot \\
\text { VERY LOW1,2 }\end{array}$} & \multirow{4}{*}{$\begin{array}{l}\text { Average fol- } \\
\text { low-up } 4 \text { years }\end{array}$} \\
\hline & 15 per 1000 & $\begin{array}{l}20 \text { per } 1000 \\
(5 \text { to } 91)\end{array}$ & & & & \\
\hline & \multicolumn{2}{|l|}{ High } & & & & \\
\hline & 430 per 1000 & $\begin{array}{l}585 \text { per } 1000 \\
(133 \text { to } 1000)\end{array}$ & & & & \\
\hline Progression to neovascular AMD & \multicolumn{6}{|l|}{ Not reported } \\
\hline Progression to geographic atrophy & \multicolumn{6}{|l|}{ Not reported } \\
\hline \multirow{4}{*}{$\begin{array}{l}\text { Progression to visual loss (loss of } 3 \\
\text { or more lines on logMAR chart) }\end{array}$} & \multicolumn{2}{|l|}{ Low } & \multirow{4}{*}{$\begin{array}{l}\text { RR } 1.04 \\
\text { (0.74 to } 1.47)\end{array}$} & \multirow{4}{*}{$\begin{array}{l}1179 \\
(1 \mathrm{RCT})\end{array}$} & \multirow{4}{*}{$\begin{array}{l}\oplus \oplus \ominus \ominus \\
\mathrm{LOW} 1,2\end{array}$} & \multirow{4}{*}{$\begin{array}{l}\text { Average fol- } \\
\text { low-up } 4 \text { years }\end{array}$} \\
\hline & 15 per 1000 & $\begin{array}{l}16 \text { per } 1000 \\
(11 \text { to } 22)\end{array}$ & & & & \\
\hline & \multicolumn{2}{|l|}{ High } & & & & \\
\hline & 430 per 1000 & $\begin{array}{l}447 \text { per } 1000 \\
\text { (318 to } 632 \text { ) }\end{array}$ & & & & \\
\hline Quality of life & \multicolumn{6}{|l|}{ Not reported } \\
\hline Adverse effects & \multicolumn{4}{|c|}{$\begin{array}{l}\text { No serious adverse effects were seen. Similar numbers of people in the vitamin E and place- } \\
\text { bo groups withdrew due to adverse effects (four versus seven), reported any adverse effect ( } 91 \\
\text { versus } 83 \text { ), or ocular adverse effect (105 versus } 90 \text { ). }\end{array}$} & $\begin{array}{l}\oplus \ominus \odot \odot \\
\text { VERY LOW } 3\end{array}$ & - \\
\hline
\end{tabular}


*Vitamin E 500 IU per day: natural vitamin E in soybean oil medium

${ }^{\star \star}$ The risk in the intervention group (and its $95 \%$ confidence interval) is based on the assumed risk in the comparison group and the relative effect of the intervention (and its $95 \% \mathrm{CI}$ ). The assumed risk in the comparison group is estimated using data from AREDS: low risk = AREDS category 2; high risk = AREDS category 4.

Cl: Confidence interval; RR: Risk ratio; OR: Odds ratio;

\section{GRADE Working Group grades of evidence}

High-certainty: We are very confident that the true effect lies close to that of the estimate of the effect

Moderate-certainty: We are moderately confident in the effect estimate: The true effect is likely to be close to the estimate of the effect, but there is a possibility that it is substantially different

Low-certainty: Our confidence in the effect estimate is limited: The true effect may be substantially different from the estimate of the effect

Very low-certainty: We have very little confidence in the effect estimate: The true effect is likely to be substantially different from the estimate of effect

1 Downgraded two levels for imprecision as only 7 events.

2 Downgraded one level for indirectness as over $80 \%$ of the participants in this trial had no signs of AMD at baseline.

3 Downgraded three levels for imprecision as study was underpowered to look at rare adverse effects.

\section{Summary of findings 4. Zinc versus placebo}

Zinc versus placebo

Patient or population: people with AMD

Setting: community

Intervention: zinc*

Comparison: placebo

\begin{tabular}{|c|c|c|c|c|c|c|}
\hline \multirow[t]{2}{*}{ Outcomes } & \multicolumn{2}{|c|}{ Anticipated absolute effects ${ }^{\star \star}(95 \% \mathrm{Cl})$} & \multirow{2}{*}{$\begin{array}{l}\text { Relative effect } \\
(95 \% \mathrm{CI})\end{array}$} & \multirow{2}{*}{$\begin{array}{l}\text { № of participants } \\
\text { (studies) }\end{array}$} & \multirow{2}{*}{$\begin{array}{l}\text { certainty of } \\
\text { the evidence } \\
\text { (GRADE) }\end{array}$} & \multirow[t]{2}{*}{ Comments } \\
\hline & Risk with placebo & Risk with Zinc & & & & \\
\hline \multirow{4}{*}{$\begin{array}{l}\text { Progression to late } \\
\text { AMD (neovascular } \\
\text { AMD, geographic } \\
\text { atrophy or both) }\end{array}$} & Low & & \multirow{4}{*}{$\begin{array}{l}\text { OR } 0.83 \\
(0.70 \text { to } 0.98)\end{array}$} & \multirow{4}{*}{$\begin{array}{l}3790 \\
\text { (3 RCTs) }\end{array}$} & \multirow{4}{*}{$\begin{array}{l}\oplus \oplus \Theta \Theta \\
\text { LOW } 1,2\end{array}$} & \multirow{4}{*}{$\begin{array}{l}\text { Average fol- } \\
\text { low-up in study } \\
\text { contributing } \\
\text { most of the } \\
\text { events was } 6 \\
\text { years }\end{array}$} \\
\hline & 15 per 1000 & $\begin{array}{l}12 \text { per } 1000 \\
(11 \text { to } 15)\end{array}$ & & & & \\
\hline & High & & & & & \\
\hline & 430 per 1000 & $\begin{array}{l}385 \text { per } 1000 \\
(346 \text { to } 425)\end{array}$ & & & & \\
\hline
\end{tabular}




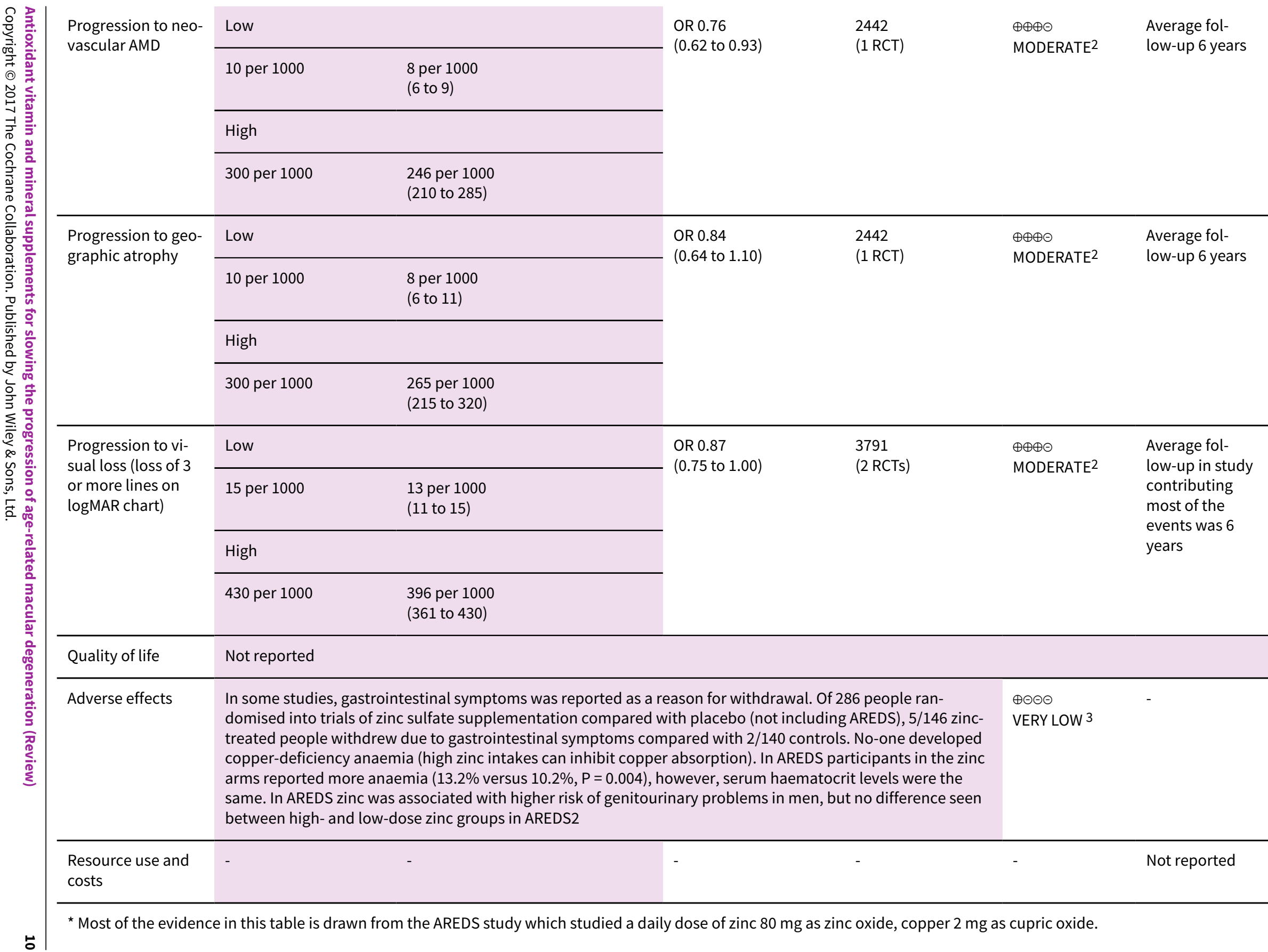




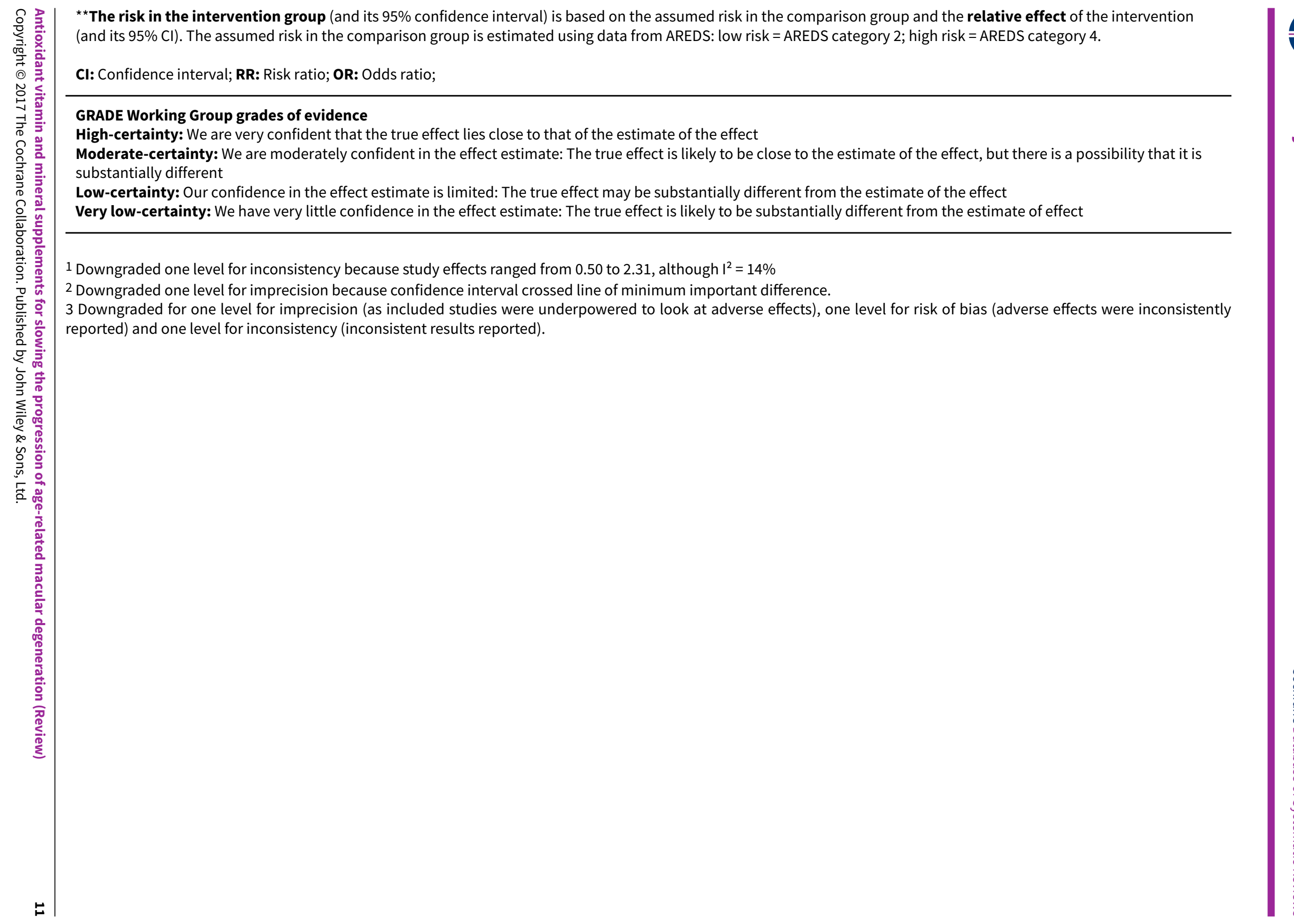




\section{B A C K G R O U N D}

\section{Description of the condition}

Age-related macular degeneration (AMD) is a disease affecting the central area of the retina (macula). In the early stages of the disease, lipid material accumulates in deposits underneath the retinal pigment epithelium. These deposits are known as drusen, and can be seen as pale yellow spots on the retina. The pigment of the retinal pigment epithelium may become disturbed, with areas of hyperpigmentation and hypopigmentation. In the later stages of the disease, the retinal pigment epithelium may atrophy completely. This loss can occur in small focal areas, or can be widespread (geographic). In some cases, new blood vessels grow under the retinal pigment epithelium and occasionally, into the subretinal space (exudative or neovascular AMD). Haemorrhage can occur, which often results in increased scarring of the retina.

In general, the early stages of the disease are asymptomatic. In the later stages, there may be considerable distortion of vision and complete loss of visual function, particularly in the central area of vision. Population-based studies suggest that in older people $(80$ years and above), approximately one in three people have early signs of the disease (Klein 1992). The estimated prevalence of late AMD is $1.4 \%$ (95\% Credible Interval (Crl), $1.0 \%$ to $2.0 \%$ ) at 70 years of age, $5.6 \%$ (95\% Crl, $3.9 \%$ to $7.7 \%$ ) at age 80 , and $20 \%$ (95\% Crl, $14 \%$ to $27 \%$ ) at age 90 (Rudnicka 2012). It is the most common cause of blindness and visual impairment in industrialised countries (Bunce 2010).

\section{Description of the intervention}

Photoreceptors in the retina are subject to oxidative stress throughout life, due to combined exposures to light and oxygen. It has been proposed that antioxidants may prevent cellular damage in the retina by reacting with free radicals produced in the process of light absorption (Christen 1996). Antioxidants are any vitamin or mineral that is known to have antioxidant properties in vivo, or that has been shown to be an important component of an antioxidant enzyme present in the retina. The following vitamins and minerals are usually considered to be 'antioxidant': vitamin C, vitamin E, carotenoids, selenium, and zinc.

There are a number of non-experimental studies that have examined the possible association between antioxidant micronutrients and AMD, although few studies have examined supplementation specifically. Data on vitamin intake in observational studies should be considered cautiously, as people who have a diet rich in antioxidant vitamins and minerals, or who choose to take supplements regularly, are different in many ways from those who do not; these differences may not be adequately controlled by statistical analysis. The results of these observational studies have been inconclusive.

\section{How the intervention might work}

Photoreceptors in the retina are subject to oxidative stress throughout life, due to combined exposures to light and oxygen. It has been proposed that antioxidants may prevent cellular damage in the retina by limiting the damaging effects of free radicals produced in the process of light absorption (for a review see Christen 1996). Antioxidant vitamin and mineral supplements are increasingly being marketed for use in age-related eye disease, including AMD.

\section{Why it is important to do this review}

People with AMD need to have reliable information, in order to decide whether or not to take vitamin supplements.

\section{O B JECTIVES}

The objective of this review was to assess the effects of antioxidant vitamin or mineral supplementation on the progression of AMD in people with AMD.

\section{METHODS}

\section{Criteria for considering studies for this review}

\section{Types of studies}

This review included randomised controlled trials.

\section{Types of participants}

Participants in the trials were people with AMD in one or both eyes.

\section{Types of interventions}

We included trials in which antioxidant vitamin or mineral supplementation, alone or in combination, was compared with placebo or no intervention. Antioxidants were defined as any vitamin or mineral that was known to have antioxidant properties in vivo, or that was known to be an important component of an antioxidant enzyme present in the retina. The following were considered: vitamin C, vitamin E, carotenoids (including the macular pigment carotenoids lutein and zeaxanthin), selenium, and zinc.

The overall objective of the review was to assess the impact of antioxidant vitamin and mineral supplements on the progression of AMD. Trials in this area fall into two broad categories: those evaluating a single vitamin or mineral (for example, vitamin $E$ or zinc), and those investigating a multivitamin formulation (for example, Ocuguard). The following comparisons were considered in this review.

1. Multivitamin formulation versus placebo. All the formulations which include two or more antioxidant vitamins or minerals fall into this category.

2. Single-component formulations versus placebo. Currently, only vitamin $E$, zinc and lutein have been studied as single formulations, however, in principle any of the antioxidant vitamins or minerals could be assessed as individual components.

\section{Types of outcome measures}

We modified our protocol for the current update (2017) to include outcomes specified by the UK NICE macular degeneration guideline panel (NICE 2016); see Differences between protocol and review.

We considered the following outcomes:

- Progression to late AMD (neovascular AMD, geographic atrophy, or both);

- Progression to neovascular AMD;

- Progression to geographic atrophy;

- Progression to visual loss (loss of 3 or more lines on logMAR chart) ${ }^{*}$; 
- Quality of life;

- Resource use and costs.

*As visual acuity is also commonly reported as a 'mean score' we also include mean visual acuity as a continuous outcome.

Follow-up:

We considered the maximum follow-up identified in the studies at any point in time.

\section{Adverse effects}

We considered any adverse effects reported by the included studies.

\section{Search methods for identification of studies}

\section{Electronic searches}

The Cochrane Eyes and Vision Information Specialist conducted systematic searches in the following databases for randomised controlled trials and controlled clinical trials. There were no language or publication year restrictions. The date of the search was 29 March 2017.

- Cochrane Central Register of Controlled Trials (CENTRAL; 2017, Issue 2) (which contains the Cochrane Eyes and Vision Trials Register) in the Cochrane Library (searched 29 March 2017) (Appendix 1);

- MEDLINE Ovid (1946 to 29 March 2017) (Appendix 2);

- Embase Ovid (1980 to 29 March 2017) (Appendix 3);

- AMED (Allied and Complementary Medicine Database) (1985 to 29 March 2017) (Appendix 4);

- OpenGrey (System for Information on Grey Literature in Europe) (www.opengrey.eu/; searched 29 March 2017) (Appendix 5);

- ISRCTN registry (www.isrctn.com/editAdvancedSearch; searched 29 March 2017) (Appendix 6);

- US National Institutes of Health Ongoing Trials Register ClinicalTrials.gov (www.clinicaltrials.gov; searched 29 March 2017) (Appendix 7);

- World Health Organization International Clinical Trials Registry Platform (www.who.int/ictrp; searched 29 March 2017) (Appendix 8).

For the 2012 and 2017 updates, we specifically looked for adverse effects, using a simple search aimed to identify systematic reviews of adverse effects of vitamin supplements, see Appendix 9 for search strategy.

\section{Searching other resources}

We searched the reference lists of identified trial reports to find additional trials. We used the Science Citation Index to find studies that cited the identified trials. We contacted investigators of included studies to identify additional published and unpublished studies.

\section{Data collection and analysis}

\section{Selection of studies}

Both authors independently assessed the titles and abstracts of all reports of trials identified by the electronic searches. We obtained the full texts of possibly relevant trials. We selected relevant studies according to the definitions in the Criteria for considering studies for this review.

\section{Data extraction and management}

We extracted data using a standardised form, developed by Cochrane Eyes and Vision. For the initial review, we sent these data for verification to the trial investigators of all studies included in the review. In the 2012 and current updates, data were independently extracted by both authors, compared, disagreements resolved by discussion, and data cut and pasted into Review Manager (Review Manager 5 2014) by one author and checked by the other. In the current update, citations were screened and duplicate data extracted using web-based review management software (Covidence).

\section{Assessment of risk of bias in included studies}

We assessed risk of bias using Cochrane's tool for assessing the risk of bias as described in Chapter 8 of the Cochrane Handbook for Systematic Reviews of Interventions (Higgins 2011).

\section{Measures of treatment effect}

We used the risk ratio (RR) for dichotomous outcomes where possible. As one of the main large trials reported odds ratios (OR) and their confidence intervals only (derived from repeated measures logistic regression), we used the OR as the measure of effect for analyses that included this trial (AREDS 2001).

For continuous outcomes, we used the mean difference (MD) where possible, and the standardised mean difference (SMD) when visual acuity was measured on different scales. In this case, we corrected for differences in direction between Snellen and logMAR scales by multiplying the Snellen decimal values by -1 . Where possible, we checked for skewness using methods outlined in Chapter 9 of the Cochrane Handbook for Systematic Reviews of Interventions (Deeks 2011).

\section{Unit of analysis issues}

The main study design method in this area is the parallel-group randomised controlled trial. Cluster-randomised trials are unlikely, but would still be considered. Cross-over studies would not be appropriate in this area because of the uncertain and complex natural history of AMD. Currently, no such studies have been identified, but if they are in the future, we will only use data from the first phase.

As the intervention is applied to the individual, the unit of randomisation is the individual person. As people have two eyes, it is possible for there to be a unit of analysis issue if eyes are reported, rather than results for the person. For each included trial we documented whether the unit of analysis was the same as the unit of randomisation and noted any implications for the analysis. For studies reporting right and left eyes separately, we extracted data for the right eye.

\section{Dealing with missing data}

The data included in the review represent an 'available case analysis'. The majority of the data in the current review came from two large trials with high (over 95\%) follow-up.

Two studies specifically excluded people who experienced a neovascular event (one component of late-stage AMD) from the 
analyses (CARMA 2013; Stur 1996). The published reports did not give enough information to include these people in the analyses.

\section{Assessment of heterogeneity}

We assessed heterogeneity by looking at the forest plots to see whether the effect measures for the different studies were in the same direction and of a similar order of effect. An $I^{2}$ statistic value of $50 \%$ or more was taken to indicate considerable inconsistency of results, such that a pooled result may be inaccurate and should not be reported.

The main clinical heterogeneity was the type of supplement. This was incorporated into the analysis strategy by considering the formulations by type.

\section{Assessment of reporting biases}

In future versions of this review, when sufficient trials are included in the meta-analyses (10 or more), we plan to examine the funnel plot to assess whether there is any evidence that smaller studies are reporting larger effects, which may indicate publication bias.

\section{Data synthesis}

We planned to pool data using a random-effects model (because it was likely that the effects of antioxidant vitamin and mineral supplementation may vary in different population groups) but with the proviso that if there were three or fewer trials we would use the fixed-effects model. In the event most of our analyses fell into the latter category and so we largely used a fixed-effects model.

\section{Subgroup analysis and investigation of heterogeneity}

Currently, there are not enough studies to perform useful subgroup analyses, and these are not proposed for this version of the review. Characteristics that may be important are the type and severity of AMD. Subgroup analyses on type or severity of AMD may be considered in future.

\section{Sensitivity analysis}

A sensitivity analysis was not planned.

\section{Summary of findings tables}

We prepared separate 'Summary of findings' tables for the different types of vitamin supplement.

We assessed the certainty of the evidence (GRADE) for each outcome using customised software (GRADEpro 2014). JE did the initial assessment, which was checked by JL. We considered risk of bias, inconsistency, indirectness, imprecision, and publication bias when judging the certainty of the evidence (Schünemann 2011).

The 'Summary of findings' tables include an estimate of the risk of each outcome in the general population. We used data from AREDS to estimate the risk in the control group in low risk (AREDS category 2) and high risk (AREDS category 4) populations.

\section{RES U L T S}

\section{Description of studies}

Results of the search

Summary of searches for previous versions of this review

\begin{tabular}{llllll}
\hline $\begin{array}{l}\text { Date re- } \\
\text { view pub- }\end{array}$ & $\begin{array}{l}\text { Date } \\
\text { searches } \\
\text { lished }\end{array}$ & Newly included trials & $\begin{array}{l}\text { Total num- } \\
\text { ber of tri- } \\
\text { als includ- } \\
\text { ed in the } \\
\text { review }\end{array}$ & $\begin{array}{l}\text { Total num- } \\
\text { ber of ex- } \\
\text { cluded tri- } \\
\text { als }\end{array}$ & $\begin{array}{l}\text { Trials awaiting as- } \\
\text { sessment }\end{array}$
\end{tabular}

\begin{tabular}{|c|c|c|c|c|c|c|}
\hline $\begin{array}{l}\text { November } \\
1997\end{array}$ & $\begin{array}{l}\text { August } \\
1997\end{array}$ & $\begin{array}{l}\text { AMDSG 1996; Newsome } \\
\text { 1988; Stur } 1996\end{array}$ & 3 & 1 & $\begin{array}{l}\text { Holz } 1993 \text { (included } \\
\text { February 2002) }\end{array}$ & $\begin{array}{l}\text { AREDS 2001; VECAT } \\
2002\end{array}$ \\
\hline $\begin{array}{l}\text { November } \\
1998\end{array}$ & $\begin{array}{l}\text { October } \\
1998\end{array}$ & Kaiser 1995 & 4 & 1 & $\begin{array}{l}\text { France } 1998 \text { (unpub- } \\
\text { lished but included } \\
\text { in current update) }\end{array}$ & - \\
\hline
\end{tabular}

\begin{tabular}{llllll}
\hline $\begin{array}{l}\text { February } \\
2002\end{array}$ & $\begin{array}{l}\text { November } \\
2001\end{array}$ & $\begin{array}{l}\text { AREDS 2001; Holz 1993; } \\
\text { VECAT 2002 }\end{array}$ & 1 & - & - \\
\hline
\end{tabular}

\begin{tabular}{llllll}
\hline $\begin{array}{l}\text { February } \\
2006\end{array}$ & January & $\begin{array}{l}\text { Veterans LAST study } \\
2006\end{array}$ & 8 & 1 & $\begin{array}{l}\text { Wang 2004 (included } \\
\text { November 2007) }\end{array}$
\end{tabular}

\begin{tabular}{|c|c|c|c|c|c|c|}
\hline $\begin{array}{l}\text { November } \\
2007\end{array}$ & $\begin{array}{l}\text { August } \\
2007\end{array}$ & Wang 2004 & 9 & 25 & - & - \\
\hline $\begin{array}{l}\text { October } \\
2012\end{array}$ & $\begin{array}{l}\text { August } \\
2012\end{array}$ & $\begin{array}{l}\text { Bartlett 2007; CARMIS } \\
\text { 2011; LISA 2011; New- } \\
\text { some } 2008\end{array}$ & 13 & 41 & $\begin{array}{l}\text { CARMA } 2013 \text { (includ- } \\
\text { ed current update) } \\
\text { LUTEGA } 2013 \text { and } \\
\text { Falsini } 2010 \text { (both ex- }\end{array}$ & $\begin{array}{l}\text { AREDS2 } 2013 \text { and } \\
\text { NCT91948476 (Ma } \\
\text { 2012) (both includ- } \\
\text { ed current update): } \\
\text { NCT00879671 (this is } \\
\text { the same trial as LISA }\end{array}$ \\
\hline
\end{tabular}


cluded current update)
2011 included in October 2012)

NCT00893724 (excluded current update)

\begin{tabular}{|c|c|c|c|c|c|}
\hline $\begin{array}{l}\text { June } 2017 \\
\text { (current } \\
\text { update) }\end{array}$ & March 2017 & $\begin{array}{l}\text { AREDS2 2013; Berrow } \\
\text { 2013; CARMA 2013; } \\
\text { CLEAR 2013; France } \\
\text { 1998*; Ma } 2012\end{array}$ & 19 & 55 & $\begin{array}{l}\text { NCT01694680; } \\
\text { NCT02625376 }\end{array}$ \\
\hline
\end{tabular}

* This is an unpublished trial for which we are unlikely to be able to obtain the data. We originally excluded this, but following more recent guidelines (see MECIR standard C12; methods.cochrane.org/ mecir), we are including this study in the current review.

\section{Searches for current update (2017)}

Update searches run in March 2017 yielded a further 872 records (Figure 1). After 157 duplicate were removed, the Cochrane Information Specialist (CIS; formerly the Trial Search Co-ordinator) screened the remaining 715 records and removed 562 references that were not relevant to the scope of the review. We screened the remaining 153 references and obtained 38 full-text reports for further assessment. We identified 18 reports of six new studies for further details; see Characteristics of included studies. France 1998, which had previously been excluded, has now been reassessed and added to the review as an included study. We excluded 18 reports of 15 studies and identified two new ongoing studies; see Characteristics of excluded studies. In the previous version of this review, there were five reports of studies awaiting classification. For this update, we assessed these reports; two have now been included and three were excluded. The previous ongoing studies were reassessed and those studies that had been completed were either included or excluded in this update. 


\section{Figure 1. Study flow diagram.}

\begin{abstract}
13 studies included in previous version of the review (searches as of January 2012)
\end{abstract}

872 records identified through database searching (January 2012 to March 2017)

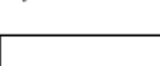

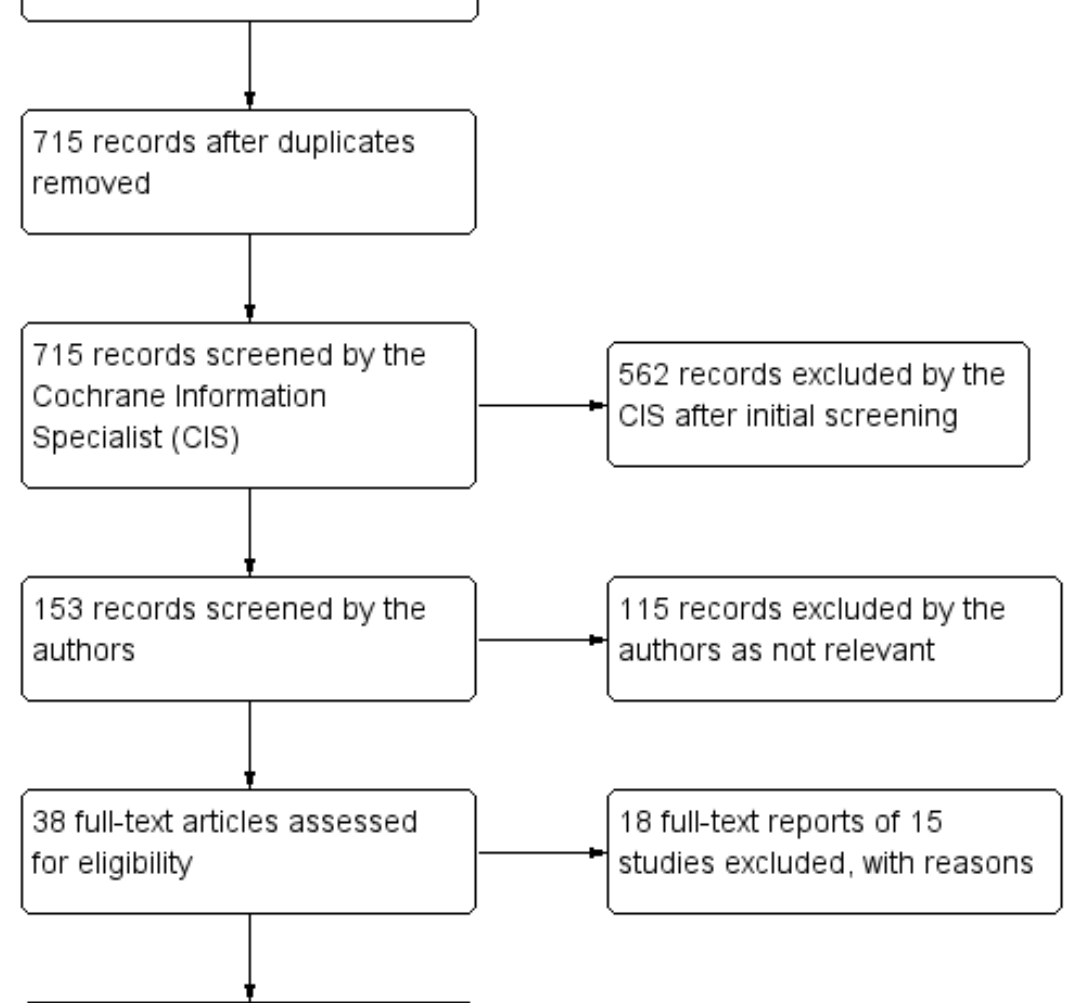

1 study (France 1998) that was previously excluded has now been included

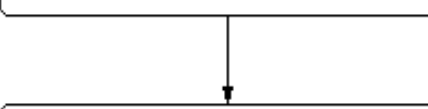

2 ongoing studies identified

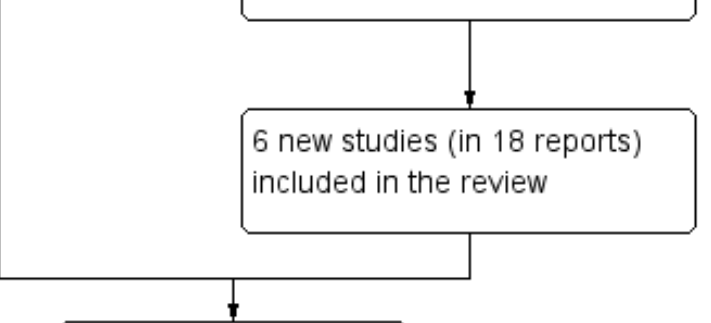

19 studies included in qualitative synthesis

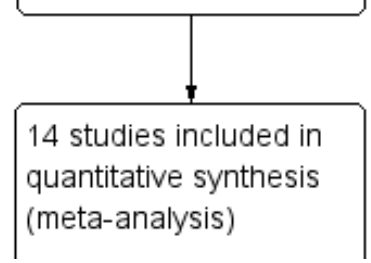


Figure 1. (Continued)

$$
\text { (meta-analysis) }
$$

\section{Included studies}

Below is a summary of the 19 trials included in this review. See Characteristics of included studies for detailed information on individual trials.

\section{Multivitamin supplements}

Seven studies compared multivitamin supplements with placebo (AMDSG 1996; AREDS 2001; Bartlett 2007; CARMA 2013; Kaiser 1995; Veterans LAST study 2004; Wang 2004), and two studies compared multivitamin supplements with no treatment (Berrow 2013; CARMIS 2011). Table 1 summarises the daily dose of key antioxidant vitamin and mineral supplements considered. These studies were conducted in USA (AMDSG 1996; AREDS 2001; Veterans LAST study 2004), Europe (Bartlett 2007; CARMA 2013; Kaiser 1995), and China (Wang 2004).

AMDSG 1996, Bartlett 2007, Berrow 2013, CARMIS 2011, and Veterans LAST study 2004 only enrolled people with early AMD. Wang 2004 recruited people with both early and late-stage disease. In AREDS 2001, participants had a range of disease, from mild or borderline features to late AMD. CARMA 2013 enrolled people with either late AMD in one eye and any AMD in the other, or people with AMD features of "sufficient severity" in both eyes, i.e. either more than 20 drusen, or a combination of drusen and pigmentary abnormalities. Kaiser 1995 recruited people with "nonserous" AMD.

People taking part in the trials were identified by referral from local ophthalmologists (Kaiser 1995), from people attending Department of Veterans Medical Centers (AMDSG 1996; Veterans LAST study 2004), from retinal specialty clinics and general population volunteers (AREDS 2001), from an eye outpatient clinic (Berrow 2013; Wang 2004), and from regional tertiary referral centres (CARMA 2013). Bartlett 2007 recruited participants by sending letters to "local optometrists, ophthalmologists, and a specialist centre for rehabilitation of people with sight loss"; participants were then seen at the University research centre. In CARMIS 2011, it was not clear how they identified participants.

The number of participants enrolled ranged from 14 (Berrow 2013), to 3640 (AREDS 2001). Apart from AREDS 2001, all these trials recruited fewer than 500 people; the median number randomised was 90 . The average age of participants ranged from 66 to 75 years; the median percentage of women was 55\%, two trials recruited mainly men (AMDSG 1996; Veterans LAST study 2004).

The duration of supplementation and follow-up ranged from nine months (Bartlett 2007), to six years (AREDS 2001). Only one trial followed up beyond two years (AREDS 2001).

\section{Lutein and zeaxanthin supplements}

Five studies compared lutein supplements with placebo (AREDS2 2013; CLEAR 2013; LISA 2011; Ma 2012; Veterans LAST study 2004). In AREDS2 2013, all participants also took the AREDS formula (Table 1).
The daily dose of lutein used in all these studies was $10 \mathrm{mg}$; two studies considered additional doses of $20 \mathrm{mg}$ (LISA 2011; Ma 2012). Two studies combined lutein with zeaxanthin, either a dose of $2 \mathrm{mg}$ (AREDS2 2013), or $10 \mathrm{mg}$ (Ma 2012). These studies were conducted in USA (AREDS2 2013; Veterans LAST study 2004), Europe (CLEAR 2013; LISA 2011), and China (Ma 2012).

CLEAR 2013, Ma 2012, and Veterans LAST study 2004 only considered people with early macular degeneration. AREDS2 2013 enrolled people "at risk for progression to advanced AMD, with bilateral large drusen, or large drusen in one eye and advanced AMD in the fellow eye". LISA 2011 recruited individuals in categories 2, 3 , and 4 according to AREDS criteria (similar to the participants in AREDS 2001).

People taking part in the trials were identified from people attending Department of Veterans Medical Centers (Veterans LAST study 2004), from "clinical centers" (AREDS2 2013), and "local communities" (Ma 2012). In CLEAR 2013, "An advertising campaign was conducted within the universities and in local newspapers". In LISA 2011, it was not clear how they identified participants.

The number of participants enrolled ranged from 84 (CLEAR 2013), to 4203 (AREDS2 2013). Apart from AREDS2 2013, all of these trials recruited fewer than 150 people; the median number randomised was 110 . The average age of participants ranged from 69 to 75 years; the median percentage of women was $57 \%$; one trial recruited mainly men (Veterans LAST study 2004).

The duration of supplementation and follow-up ranged from six months (LISA 2011), to five years (AREDS2 2013). The majority of trials followed up to 12 months, only one trial followed up to two years (Ma 2012).

\section{Vitamin E}

One study, conducted in Australia, compared vitamin E with placebo (VECAT 2002). This study randomised 1204 people to vitamin E 400 IU daily or placebo, and followed up for four years. Participants were enrolled from the general population and only $19 \%$ had AMD, mainly early AMD. Average age was 66 years, and $56 \%$ were women.

\section{Zinc}

Six studies compared zinc with placebo (AREDS 2001; France 1998; Holz 1993; Newsome 1988; Newsome 2008; Stur 1996).

In France 1998, 170 people with neovascular AMD in one eye and drusen in the other were randomised to receive zinc $30 \mathrm{mg}$ or placebo. This study was unpublished and we have no further information.

Three studies considered zinc sulfate 200 mg daily (Holz 1993; Newsome 2008; Stur 1996), one study investigated zinc oxide $80 \mathrm{mg}$ daily (AREDS 2001), and one study used zinc monocysteine $50 \mathrm{mg}$ daily (Newsome 2008). 
Holz 1993 and Newsome 2008 only enrolled people with early macular degeneration; in AREDS 2001, participants had a range of disease, from mild or borderline features to late AMD; Newsome 1988 recruited people with both early and late-stage disease; Stur 1996 only enrolled people with late-stage disease in one eye.

The number of participants enrolled ranged from 58 (Holz 1993), to 3640 (AREDS 2001). Apart from AREDS2 2013, all of these trials recruited fewer than 500 people; the median number randomised was 141 . The average age of people participating in the trials ranged from 65 to 74 years; median percentage of women was $57 \%$.

People taking part in the trials were identified by referral from local ophthalmologists (Newsome 1988), eye outpatient clinics (Stur 1996), and from retinal specialty clinics and general population volunteers (AREDS 2001). In Holz 1993 and Newsome 2008, it was not clear how they identified participants.
The duration of supplementation and follow-up in these trials ranged from six months to seven years.

\section{Excluded studies}

Details of excluded studies are provided in 'Characteristics of excluded studies'.

\section{Risk of bias in included studies}

Figure 2 and Figure 3 summarise the 'Risk of bias' assessment. Overall, we considered the trials to be at low risk of bias for the main types of bias, in particular, selection bias (allocation sequence generation and concealment) and performance and detection bias. This is because all trials, except Berrow 2013 and CARMIS 2011, had a placebo control. Three trials were not well reported $(\mathrm{Holz}$ 1993; LISA 2011; Wang 2004), and one trial was unpublished (France 1998).

\section{Figure 2. 'Risk of bias' graph: review authors' judgements about each risk of bias item presented as percentages across all included studies.}

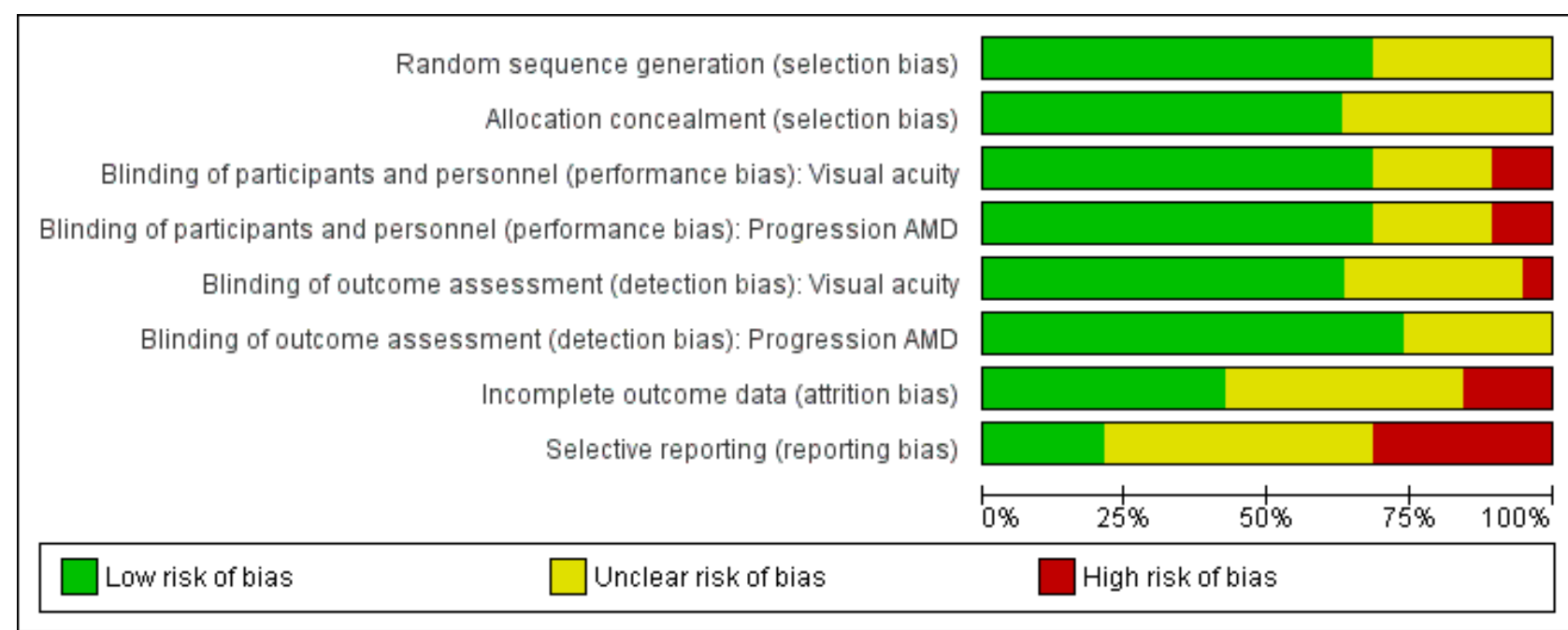


Figure 3. 'Risk of bias' summary: review authors' judgements about each risk of bias item for each included study.

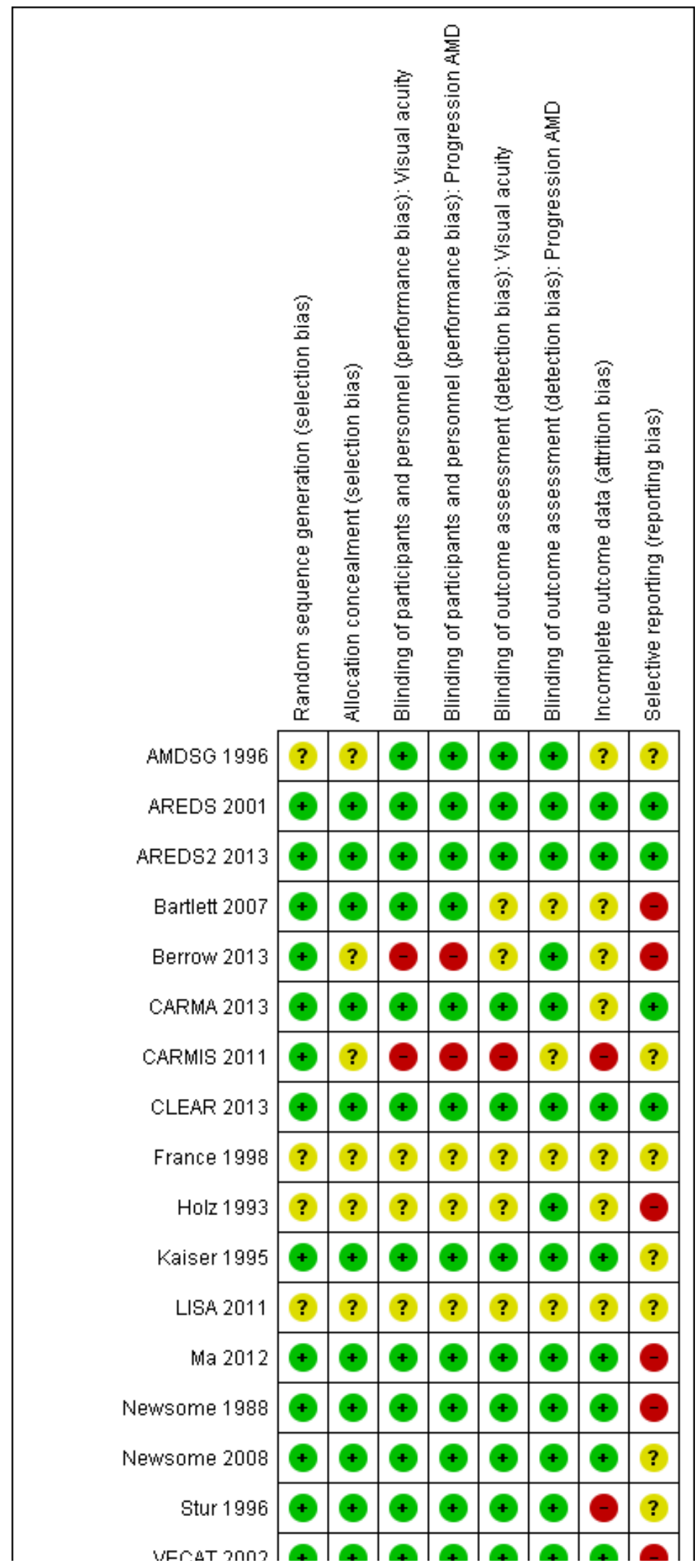


Figure 3. (Continued)

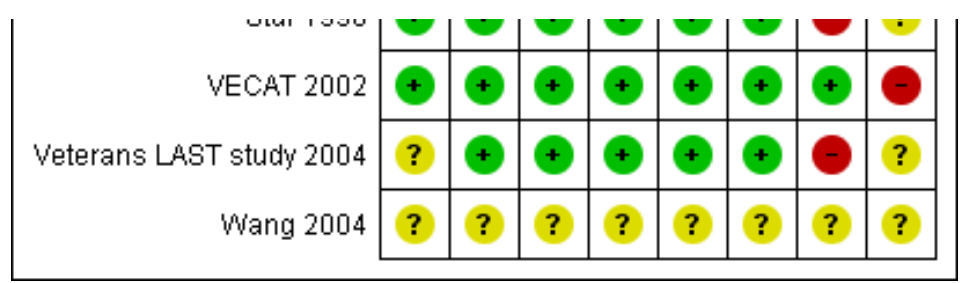

\section{Allocation}

In most trials randomisation appeared to have been executed properly, that is, an unpredictable sequence of treatment allocation was adequately concealed from people recruiting participants into the trial. As Holz 1993 had only been published in abstract form to date, the details of randomisation were not clear.

\section{Blinding}

Two trials had a 'no treatment' control group so were considered to be at high risk for performance and detection bias (Berrow 2013; CARMIS 2011).

In general, there was not a lot of information to judge the success of the masking. In AREDS 2001, four people were documented as being unmasked to study group. More people in the antioxidant group (8.3\%) reported changes in skin colour (yellowing) than in the placebo group $(6.0 \%, \mathrm{P}<0.01)$, and more people in the zinc groups reported difficulty swallowing the study tablets $(17.8 \%$ versus $15.3 \%, P=0.04)$. However, there was little evidence of unmasking when participants were asked to guess their treatment assignment at the end of the study. The percentages of participants who guessed correctly, by treatment assignment, were: placebo $17 \%$, antioxidants alone $16 \%$, zinc alone $18 \%$, and antioxidants plus zinc $16 \%$. In the Veterans LAST study 2004 , the tablets were apparently identical in appearance, but it was not clear whether taste or systemic effects differed between the different groups.

\section{Incomplete outcome data}

Information on attrition bias was not so clearly reported, and it was difficult to assess how likely this bias was. Three studies were considered to be at high risk of attrition bias.

In CARMIS $2011,19 \%$ of the treated group and $38 \%$ of the untreated group were excluded from the final analysis.

In Veterans LAST study 2004, members of the placebo group were removed from analysis, due to the fact that they had taken lutein.

In Stur 1996, analysis of the main outcome measures (visual function and progression of disease) was not done on a strictly intention-to-treat basis, as anyone experiencing the study end point of late-stage AMD (neovascularisation) was withdrawn from the study. Contact with the trial investigator revealed that all of these participants ended up with visual acuity of $20 / 200(6 / 60)$ or less, and that these participants were excluded because the investigators wished to detect functional changes caused by degeneration of the retinal pigment epithelium and the sensory retina, and not vision losses caused by choroidal neovascularisation. Similarly, CARMA 2013 excluded people with CNV from analyses of visual acuity.

\section{Selective reporting}

There was some evidence of selective reporting in six studies, but this was generally difficult to assess, and we could not be confident that selective reporting did not occur in other included studies.

\section{Effects of interventions}

See: Summary of findings for the main comparison Multivitamin versus placebo; Summary of findings 2 Lutein or zeaxanthin versus placebo; Summary of findings 3 Vitamin E versus placebo; Summary of findings 4 Zinc versus placebo

Table 2 provides more information on the outcomes and follow-up times relating to the data included in these analyses.

\section{Multivitamin and mineral supplement versus placebo}

See Summary of findings for the main comparison.

Nine studies investigated multivitamin supplements (Table 1).

Only three trials reported data on our primary outcome of progression to late AMD (AREDS 2001; CARMA 2013; CARMIS 2011), and only one of these trials reported data separately on neovascular AMD and geographic atrophy (AREDS 2001). Mean visual acuity was more commonly reported, but there was considerable variability in the measurement and reporting of this outcome. AMDSG 1996 and Veterans LAST study 2004 measured visual acuity using a Snellen chart and converted the score into logMAR units. AREDS 2001, CARMIS 2011 and Bartlett 2007 used the logMAR visual acuity chart developed as part of the Early Treatment of Diabetic Retinopathy Study (ETDRS 1980). No useable data could be extracted for Berrow 2013, Kaiser 1995 and Wang 2004.

Only one trial reported on quality of life (CARMIS 2011) using the Italian version of the National Eye Institute Visual function questionnaire (NEI-VFQ).

There were several different strategies for dealing with eyes. Some studies reported AMD for the person which means that the unit of analysis was the person and they were counted as having AMD if it was present in one or both eyes (AREDS 2001). Some studies reported findings on right eyes and left eyes separately (AMDSG 1996; Veterans LAST study 2004), selected a trial eye (Bartlett 2007; Kaiser 1995; Wang 2004) or averaged the data for the two eyes in participants where both eyes were included (CARMA 2013).

Data from AREDS 2001 were reported as adjusted odds ratios only. The odds ratios were calculated using repeated-measures logistic regression and were adjusted for baseline co-variates age, sex, race, AMD category and smoking status.

People taking antioxidant vitamins were probably less likely to progress to late AMD (odds ratio (OR) $0.72,95 \%$ confidence interval 
(CI) 0.58 to 0.90 ; 2445 participants; 3 studies; moderate-certainty evidence; Analysis 1.1), neovascular AMD (OR $0.62,95 \% \mathrm{Cl} 0.47$ to 0.82 ; 1206 participants; 1 study; moderate-certainty evidence; Analysis 1.2) and geographic atrophy (OR $0.75,95 \% \mathrm{Cl} 0.51$ to 1.10 ; 1206 participants; 1 study; moderate-certainty evidence; Analysis $1.3)$, and probably less likely to lose 3 or more lines of visual acuity (OR $0.77,95 \% \mathrm{Cl} 0.62$ to 0.96 ; 1791 participants; 1 study; moderatecertainty evidence; Analysis 1.4).

Trials reporting mean visual acuity in continuous format were smaller and had shorter treatment and follow-up durations (AMDSG 1996; Bartlett 2007; CARMA 2013; CARMIS 2011; Veterans LAST study 2004). No effect of treatment on visual acuity was seen from these analyses. The pooled mean difference (MD) was 0.02 $\log M A R, 95 \% \mathrm{Cl}-0.03$ to 0.07 ; participants $=595$; studies $=5 ; \mathrm{I}^{2}=$ 38\%) (Analysis 1.5).

CARMIS 2011 reported higher quality of life (NEI VFQ-25) scores in the treated compared with the non-treated group after 24 months. The mean change in overall score at 24 months follow-up was 3.6 $(95 \% \mathrm{Cl} 0.50$ to 6.81$)$ in the treated group and $-8.7(95 \% \mathrm{Cl}-16.54$ to -0.97 ) in the non-treated group (mean difference (MD) $12.30,95 \%$ $\mathrm{Cl} 4.24$ to 20.36 ; 110 participants; 1 study; low-certainty evidence).

Table 3 summarises information available on adverse effects.

Very low-certainty evidence was available on adverse effects from these Included studies. They were underpowered to look at adverse effects and these were inconsistently reported. Data from AREDS 2001 suggested no important effect on mortality associated with multivitamin use (hazard ratio for mortality $0.87,95 \% \mathrm{Cl} 0.60$ to 1.25). In AREDS 2001 participants in the antioxidant arms more frequently reported yellow skin $(8.3 \%$ versus $6.0 \%, P=0.008)$

None of the trials reported resource use and costs.

\section{Lutein and/or zeaxanthin versus placebo}

\section{See Summary of findings 2.}

Five studies compared lutein supplements (10 or $20 \mathrm{mg}$ ) with placebo and followed up for six months to five years (AREDS2 2013; CLEAR 2013; LISA 2011; Ma 2012; Veterans LAST study 2004). In AREDS2 2013, all participants also took the AREDS formula (Table $1)$.

Only one trial reported data on progression to late AMD, neovascular AMD, and geographic atrophy (AREDS2 2013). CLEAR 2013, LISA 2011, and Ma 2012 reported mean logMAR visual acuity measured on an ETDRS chart. Veterans LAST study 2004 measured visual acuity using a Snellen chart and converted the score into logMAR units. LISA 2011 did not report any data in a form that could be used in this review.

Only one trial reported on quality of life, using the Chinese version of the NEI-VFQ (Ma 2012).

There were several different strategies for dealing with eyes. AREDS2 2013 reported by eye. The study reports hazard ratios adjusted for one or two eyes per person. We have extracted data on eyes only. The confidence intervals for effect estimates from this study, as reported in this review, are therefore narrower than they should be as they do not take into account within-person correlation. As all confidence intervals around effect estimates from this study include 1 (no effect), this lack of adjustment does not make any difference to the conclusions of the review. Some studies reported findings on right eyes and left eyes separately (Veterans LAST study 2004) or selected a trial eye (CLEAR 2013; LISA 2011). In some studies there was not enough information to tell (Ma 2012).

People taking lutein or zeaxanthin may have similar or slightly reduced risk of progression to late AMD (risk ratio (RR) 0.94, $95 \% \mathrm{Cl} 0.87$ to $1.01 ; 6891$ eyes; 1 study; low-certainty evidence; Analysis 2.1), neovascular AMD (RR 0.92, 95\% Cl 0.84 to 1.02; 6891 eyes; 1 study; low-certainty evidence; Analysis 2.2), and geographic atrophy (RR 0.92, 95\% Cl 0.80 to 1.05; 6891 eyes; 1 study; lowcertainty evidence; Analysis 2.3). Similar risk of progression to visual loss of 15 or more letters was seen in lutein and control group (RR $0.98,95 \% \mathrm{Cl} 0.91$ to $1.05 ; 6656$ eyes; 1 study; low-certainty evidence; Analysis 2.4).

Three studies reported mean logMAR visual acuity; there was no evidence of any difference between treatment and control groups (MD 0.00 logMAR, 95\% Cl -0.05 to $0.05 ; 231$ participants; $\left.\right|^{2}=0 \%$ ).

Ma 2012 observed similar changes in quality of life scores between supplement and placebo groups (MD 1.48 score, $95 \% \mathrm{Cl}-5.53$ to 8.49; 108 participants; 1 study; low-certainty evidence).

Table 3 summarises information available on adverse effects.

Very low-certainty evidence was available on adverse effects from these Included studies. They were underpowered to look at adverse effects and these were inconsistently reported. Data from AREDS2 2013 suggested no serious adverse effects associated with lutein and zeaxanthin use. Hazard ratio for mortality comparing lutein/ zeaxanthin to no lutein/zeaxanthin was $1.06(95 \% \mathrm{Cl} 0.87$ to 1.31$)$.

None of the trials reported resource use and costs.

\section{Vitamin E versus placebo}

See Summary of findings 3.

There was only one trial investigating vitamin $\mathrm{E}$ alone (VECAT 2002). This trial randomised 587 participants to vitamin $E$ supplementation and 592 to placebo, and followed them up for an average of four years. Over $80 \%$ of the participants in this trial had no signs of AMD. One eye per person was included in the trial.

The number of late AMD events was low (4/494 in vitamin E and $3 / 504$ in placebo group) and therefore, the estimate of effect was very uncertain (RR $1.36,0.31$ to 6.05 ). We judged this to be very lowcertainty evidence as there were only 7 events (downgraded two levels for imprecision) and only $19 \%$ of the study population had AMD (downgraded one level for indirectness). There were no data on neovascular AMD or geographic atrophy.

There was no evidence of any effect of treatment on visual acuity; 59 people in the vitamin E group and 57 people in the placebo group lost more than nine letters of acuity (equivalent to 2 or more lines) on the Bailey-Lovie chart (RR $1.04,95 \% \mathrm{Cl} 0.74$ to 1.47 ). We downgraded for imprecision and indirectness giving low-certainty evidence.

No serious adverse effects were seen. Similar numbers of people in the vitamin $E$ and placebo groups withdrew due to adverse effects 
(four versus seven), reported any adverse effect (91 versus 83), or ocular adverse effect (105 versus 90).

There were no data on quality of life or resource use and costs.

\section{Zinc versus placebo}

See Summary of findings 4.

Four trials investigated the effect of zinc supplementation (AREDS 2001; Holz 1993 (published in abstract form only); Newsome 1988; Stur 1996). In addition, we are aware of one unpublished study for which we have no data (France 1998). One further trial investigated zinc-monocysteine (Newsome 2008).

Three trials reported data on our primary outcome of progression to late AMD (AREDS 2001; Holz 1993; Stur 1996); only one of these trials reported data separately for neovascular AMD and geographic atrophy (AREDS 2001). Two studies reported mean visual acuity (Newsome 1988; Stur 1996).

There were several different strategies for dealing with eyes. Some studies reported AMD for the person which means that the unit of analysis was the person and they were counted as having AMD if it was present in one or both eyes (AREDS 2001). Some studies reported findings on right eyes and left eyes separately (Newsome 2008), selected a trial eye (Stur 1996) or averaged the data for the two eyes in participants where both eyes were included (CARMA 2013; Newsome 1988). In some studies there was not enough information to tell how eyes had been dealt with (France 1998; Holz 1993).

Data from AREDS 2001 were reported as adjusted odds ratios only. The odds ratios were calculated using repeated-measures logistic regression and were adjusted for baseline co-variates age, sex, race, AMD category and smoking status.

People taking zinc supplements may be less likely to progress to late AMD (OR $0.83,95 \% \mathrm{Cl} 0.70$ to $0.98 ; 3790$ participants; 3 studies; low-certainty evidence; Analysis 4.1), neovascular AMD (OR 0.76 , $95 \% \mathrm{Cl} 0.62$ to 0.93 ; 2442 participants; 1 study; moderate-certainty evidence; Analysis 4.2), geographic atrophy (OR $0.84,95 \% \mathrm{Cl} 0.64$ to 1.10; 2442 participants; 1 study; moderate-certainty evidence; Analysis 4.3), and visual loss (OR $0.87,95 \% \mathrm{Cl} 0.75$ to $1.00 ; 3791$ participants; 2 studies; moderate-certainty evidence; Analysis 4.4).

Only one trial has investigated zinc-monocysteine (Newsome 2008). At six months, people taking zinc-monocysteine read more letters (distance visual acuity). In people treated with zincmonocysteine, the mean (SD) number of letters read correctly on an EDTRS charts with best correction was 39 (0.672) at baseline and 43 $(0.784)$ at six months in their right eyes. In people taking placebo, the values were $40(0.649)$ at baseline and $39(0.921)$ in their right eyes. Differences between the groups were statistically significant. Similar findings were seen for the left eye.

In Stur 1996, the primary outcome was incidence of choroidal neovascularisation (CNV) in all participants. During the treatment period, a CNV developed in the study eye in 14 participants (nine in the treatment group, five in the placebo group). People who experienced a CNV were not included in the analyses of visual acuity.
Very low-certainty evidence was available on adverse effects from these Included studies. They were underpowered to look at adverse effects and these were inconsistently reported.

The main reported adverse effect leading to withdrawal from the studies was gastrointestinal symptoms. Of 286 people randomised into trials of zinc sulfate supplementation compared with placebo (excluding AREDS 2001), 5/146 zinc-treated people withdrew due to gastrointestinal symptoms compared with $2 / 140$ controls. No one developed copper-deficiency anaemia (high zinc intakes can inhibit copper absorption). In AREDS 2001 participants in the zinc arms reported more anaemia ( $13.2 \%$ versus $10.2 \%, P=0.004)$, however, serum haematocrit levels were the same. Later followup of the cohort of people taking part in the AREDS study found that there was a significant increase in hospital admissions due to genitourinary diseases in people taking zinc supplements $(11.1 \%$ versus $7.6 \%, P=0.0003)$. In AREDS2 2013 reported gastrointestinal disorders and hospitalizations for genitourinary diseases were similar comparing high-dose and low-dose zinc.

There were no data reported on quality of life and resource use and costs.

\section{DISCUSSION}

\section{Summary of main results}

The trials contributing to this review fall into two categories. There are three large trials with reasonably long treatment duration and follow-up of four to six years (AREDS 2001; AREDS2 2013; VECAT 2002). The other 16 trials are smaller (ranging from 20 to 400 participants) and have shorter duration of treatment and follow-up (six to 24 months).

The large trials provided reasonably clear answers to different questions. The AREDS 2001 trial provided evidence that long-term supplementation with vitamins $\mathrm{C}$, E, beta-carotene, and zinc, in people with AMD, reduced the risk of progression of the disease and loss of visual acuity. The overall benefit was modest, with a risk reduction in the order of $20 \%$ to $25 \%$. However, given that treatment options for AMD are limited, and vision loss is rarely recovered, this may be of interest to people with AMD. In people with very early signs of AMD, who are at low risk of progression, this would mean that there would be approximately 4 fewer cases of progression to late AMD for every 1000 people taking vitamins ( 1 fewer to 6 fewer cases). In people at high risk of progression (i.e. people with moderate AMD) this would correspond to approximately 8 fewer cases of progression for every 100 people taking vitamins ( 3 fewer to 13 fewer).

AREDS2 2013 compared lutein or zeaxanthin with placebo. There was a modest or no risk reduction in AMD progression that was not statistically significant, but as all participants took the AREDS formula, there was no proper control group. Secondary analyses from the trial suggested that there may be some benefit in replacing beta-carotene with lutein, but these analyses were only exploratory (AREDS 2014). Other trials of lutein or zeaxanthin were small, of short duration, and did not report relevant outcomes. Limited data on mean visual acuity and quality of life did not suggest any important effects of these supplements on outcomes important to patients.

Table 3 summarises information available on adverse effects. 
The VECAT 2002 study suggested that the general population should not take vitamin $\mathrm{E}$ with a view to preventing the incidence or progression of AMD (Evans 2017). However, the study was underpowered to answer the question about whether people with signs of AMD, such as those participating in the AREDS 2001 study, should take vitamin E. Currently, VECAT 2002 is the only published trial on vitamin $E$ supplementation and AMD.

The other trials of multivitamin preparations, Ocuguard (AMDSG 1996), Ocupower (Veterans LAST study 2004), Visaline (Kaiser 1995), and lutein or antioxidant (Bartlett 2007), were either too small to provide evidence either way, or the data were not available in a format suitable to include in this review (CARMIS 2011; LISA 2011). Pooling results, where possible, did not provide evidence of any benefit of supplementation. However, these trials were of relatively short duration.

A total of four published trials investigated zinc supplementation (AREDS 2001; Holz 1993; Newsome 1988; Stur 1996), and one trial examined a novel zinc-monocysteine formulation (Newsome 2008). The AREDS 2001 study indicated that the beneficial effect of zinc supplementation was of a similar order to that of vitamin supplementation. The other trials provided more conflicting evidence. Newsome 1988 found a reduction in the risk of visual acuity loss with supplementation over 12 to 24 months. However, Stur 1996 found no effect of treatment. Stur 1996, which was planned to recruit 500 participants, was terminated early because the results of the first 40 participants at 24 months indicated no benefit of treatment. The other two trials of zinc supplementation are as yet unpublished, although limited results from Holz 1993 were published in abstract form and were included here. Newsome 2008 found that zinc-monocysteine had beneficial effects on visual acuity and contrast sensitivity.

\section{Overall completeness and applicability of evidence}

The main evidence that antioxidant vitamin and mineral supplementation was of benefit came from the AREDS 2001 trial. As AREDS 2001 was a large, well-conducted randomised study, potential biases would have been minimised. The only area where bias may have been introduced was if there were different systemic effects of the antioxidant and zinc supplementation (for example, yellowing of skin or difficulty swallowing tablets), which led the participants to guess which group they were in or alternatively, the retinal fundus photographs might have been different in some way, such that the graders' response was affected by treatment group. However, this is unlikely, and there was little evidence that this was a problem in the study.

It is worth comment that pooling data from trials other than AREDS 2001 revealed little evidence for effectiveness of antioxidant vitamin and mineral supplements on preventing visual loss or progression of the disease. However, the other studies encompassed many different formulations and in general, were rather small and of short duration, which may explain the lack of effect.

AREDS 2001 was the only study to examine in detail the question of safety. They found little evidence of harm, but there was an increased risk of hospital admission due to genitourinary complications in people taking the zinc supplements. The safety of some of the components of the AREDS formulation have been questioned in other studies. Two large randomised controlled trials have indicated that smokers who take beta-carotene may be at increased risk of developing lung cancer (ATBC; Omenn 1996). The Heart Outcomes Prevention Evaluation (HOPE) study found that among people with vascular disease or diabetes, vitamin $E$ supplementation was associated with a higher risk of heart failure (Lonn 2005). A systematic search of the literature for systematic reviews addressing harms of vitamin supplements did not identify any further relevant evidence. Huang 2006 did not identify any consistent adverse effects of mineral and vitamin supplements, but only included nine RCTs in their review. A subsequent Cochrane Review that investigated antioxidant supplements for preventing all cause mortality, included 78 trials with 296,707 participants, and concluded "We found no evidence to support antioxidant supplements for primary or secondary prevention. Beta-carotene and vitamin $E$ seem to increase mortality, and so may higher doses of vitamin A" (Bjelakovic 2012).

\section{Quality of the evidence}

As the majority of the trials were placebo-controlled, we mostly assessed them as being at low risk of bias. In particular, the two trials that contributed most of the data to this review were judged at low risk of bias (AREDS 2001; AREDS2 2013). There was some variable reporting of the smaller trials; the extent to which attrition bias may have played a role was not always clear. There was some evidence of selective outcome reporting with respect to data on visual acuity. We identified three trials that did not report non-significant data. Another problem with visual acuity was the variety of ways in which it could be reported - dichotomous with a variety of potential cut-points, as a continuous variable reporting change or final value. It was possible that investigators had done analyses of visual acuity in a variety of ways and reported the most significant finding. However, in these trials, we did not find evidence of improved visual acuity associated with treatment.

The main reasons for downgrading the evidence were imprecision and indirectness. In particular, as all participants in AREDS2 2013 took multivitamin supplements, the results may not have represented a true reflection of the effect of lutein supplementation.

\section{Potential biases in the review process}

This review follows the guidance for the preparation of Cochrane reviews. We have made various changes to the protocol over the years (see Differences between protocol and review) but these have been guided by improvements in Cochrane methods, the structure of the data, or collaboration with NICE, rather than being data driven.

\section{Agreements and disagreements with other studies or reviews}

There have been a number of reviews published on this topic in the last 3 years (Andreatta 2014; Angelo 2015; Broadhead 2015; Buschini 2015; Carneiro 2017; Chew 2014; Downie 2014; Grover 2014; Hanus 2016; Liu 2015; Manikandan 2016; Prasad 2014; Sacconi 2017; Schmidl 2015; Zampatti 2014). In general, these reviews have been a narrative assessment of observational studies and RCT evidence, focusing mainly on the results of AREDS and AREDS2. On the basis of AREDS, these reviews generally conclude that supplementation may benefit people with AMD. This is the same conclusion as the current review. In general, more emphasis has been placed by these other studies on the secondary analyses 
of the AREDS2 study of lutein and zeaxanthin as a replacement for beta-carotene in the AREDS formula.

There has been one systematic review of lutein and zeaxanthin supplementation published (Liu 2015) which pooled data for 8 studies. All of these studies were identified by the current review but one has been excluded because lutein/zeaxanthin were combined with omega-3 fatty acids (LUTEGA 2013). In the current review, we only included studies that were lutein/zeaxanthin alone i.e. not combined with other antioxidant vitamins (CARMA 2013; CARMIS 2011). The data for the remaining studies were similar, but not identical, comparing Liu 2015 and the current review. The overall estimates of effect for visual acuity were similar with a pooled mean difference of $-0.04 \log \mathrm{MAR}(95 \% \mathrm{Cl}-0.06$ to -0.03$)$ in Liu 2015 and $-0.00 \operatorname{logMAR}(95 \% \mathrm{Cl}-0.05$ to 0.05$)$ in the current review. Liu 2015 used the Jadad scale to assess quality of the included studies but this assessment was ignored in the conclusions. Similarly, no attempt was made to assess the overall certainty of the evidence. Although Liu 2015 concluded that lutein/zeaxanthin improve visual performance, we would probably have concluded, with the same data, that there was low-certainty evidence that lutein/zeaxanthin make little important difference to visual acuity as a mean difference of 2 letters ( $0.04 \log M A R)$ is probably not clinically significant. Liu 2015 also included contrast sensitivity as an outcome and concluded that lutein/zeaxanthin showed "remarkable benefit". We did not consider contrast sensitivity.

The authors of AREDS2 2013 concluded in the main trial report that "Addition of lutein + zeaxanthin [...] to the AREDS formulation in primary analyses did not further reduce risk of progression to advanced AMD." This is similar to the findings of this review, where we conclude that supplements containing lutein and zeaxanthin may have little or no effect on the progression of AMD. The authors of AREDS2 2013 go onto suggest that "...because of potential increased incidence of lung cancer in former smokers, lutein + zeaxanthin could be an appropriate carotenoid substitute in the AREDS formulation." Subsequent exploratory analyses of trial data from AREDS2 2013 suggested a benefit of lutein/zeaxanthin versus beta-carotene in this trial population, all of whom were taking supplements. For this reason, the authors of AREDS2 2013 recommend replacing beta-carotene with lutein. See for example https://nei.nih.gov/areds2/PatientFAQ. We have not considered these secondary analyses of AREDS2 2013 in this review. They were exploratory analyses and the subgroups considered were not preplanned in this review.

\section{AUTHORS' CONCLUSIONS}

\section{Implications for practice}

People with AMD may experience modest delay in progression of the disease with antioxidant vitamin and mineral supplementation. This finding was drawn from one large trial conducted in a relatively well-nourished American population. Until it is replicated by other large-scale trials in other populations, we will not know whether these findings can be applied more generally. Our review shows little effect, if any, of supplements containing lutein and zeaxanthin on the progression of AMD but the evidence was low-certainty.

Antioxidant vitamin and mineral supplements are readily available for purchase without prescription in many countries. The decision to take these supplements is at the discretion of the person with AMD. The following benefits and harms need to be considered.
People with AMD may delay the progression of their condition if they take antioxidant vitamins and zinc at the levels described in this review. Given that there are few other interventions that offer much in the way of disease prevention or cure, this is an important consideration. However, harmful effects associated with long-term vitamin supplementation, particularly in smokers and people with vascular disease, cannot be ruled out. A healthy diet with a variety of fresh fruit and vegetables will have many benefits and is unlikely to be harmful. However, it may be difficult to consume, as part of a normal diet, the levels of antioxidants and zinc described in the trials included in this review.

\section{Implications for research}

Trials in other populations, preferably with a variety of nutritional status, are required. These trials should have a large enough sample size, and long enough duration, to demonstrate effects that are meaningful for people, and should also include outcomes relevant to people affected by AMD, including quality of life assessment. It is likely that AMD develops over many years. Three categories of people may be identified: healthy people at risk because of age or genetic factors; people with early stages of the disease; and people with intermediate or late-stage disease. If antioxidant supplementation is protective, there may be differences in the effect, depending on the stage of the disease.

Trial reporting should include enough information to assess the role of selective outcome reporting bias (ideally by providing online access to the protocol for the study), and clearer information about follow-up of participants in the study, in particular reasons for exclusion.

As antioxidant vitamin and mineral supplements have systemic effects, the literature on this topic would be much improved by a systematic review of the potential harms of such products, including broader sources of evidence than just randomised controlled trials.

\section{ACKNOWLEDGEMENTS}

This work was undertaken in collaboration with the National Institute for Health and Care Excellence (NICE). The views expressed in this publication are those of the authors and not necessarily those of NICE.

We are grateful to:

- Michael Stur and Hedwig J Kaiser for helpful information about the zinc sulfate trial in Austria and the Visaline trial in Switzerland respectively;

- Roy Milton and the AREDS Co-ordinating Center for sending further information and unpublished data;

- Hannah Bartlett for supplying her PhD thesis which included more data on Bartlett 2007;

- Everyone who responded to queries about trials of AMD;

- The Systematic Review Training Centre at the Institute of Child Health, University College London for advice on protocol, and Steve Milan (Cochrane Airways Group) for advice on statistics;

- Ellen Schwartz for reading articles published in German;

- Maoling Wei from the Chinese Cochrane Centre for translating a report written in Chinese; 
- Astrid Fletcher and Argye Hillis for peer review comments on previous versions of this review;

- Guide Dogs for the Blind Association and Moorfields Eye Hospital NHS Foundation Trust for funding previous versions of this review;
- Cochrane Eyes and Vision editorial team: Anupa Shah and Iris Gordon for their assistance throughout the review process, including preparing and executing the electronic searches;

- Catey Bunce for statistical advice; and

- Carol Mccletchie OBE for comments on the plain language summary from a consumer perspective. 


\section{R E F E R E N C E S}

\section{References to studies included in this review \\ AMDSG 1996 \{published data only\}}

Richer S. Multicenter ophthalmic and nutritional age-related macular degeneration study-part 1: design, subjects and procedures. Journal of the American Optometric Association 1996;67(1):12-29.

* Richer S. Multicenter ophthalmic and nutritional age-related macular degeneration study-part 2: antioxidant intervention and conclusions. Journal of the American Optometry Association 1996;67(1):30-49.

\section{AREDS 2001 \{published data only\}}

* Age-Related Eye Disease Study Research Group. A randomized, placebo-controlled clinical trial of high-dose supplementation with vitamins $\mathrm{C}$ and $\mathrm{E}$, beta carotene, and zinc for age-related macular degeneration and vision loss: AREDS report no. 8. Archives of Ophthalmology 2001;119(10):1417-36.

Age-Related Eye Disease Study Research Group. The agerelated eye disease study (AREDS) system for classifying agerelated macular degeneration from stereoscopic color fundus photographs: The age-related eye disease study report no. 6 . American Journal of Ophthalmology 2001;132(5):668-81.

Chew EY, Clemons TE, Agron E, Sperduto RD, Sangiovanni JP, Davis MD, et al. Ten-year follow-up of age-related macular degeneration in the age-related eye disease study: AREDS report no. 36. JAMA Ophthalmology 2014;132(3):272-7.

Chew EY, Clemons TE, Agron E, Sperduto RD, Sangiovanni JP, Kurinij N, et al. Long-term effects of vitamins $\mathrm{C}$ and $\mathrm{E}$, betacarotene, and zinc on age-related macular degeneration: AREDS report no. 35. Ophthalmology 2013;120(8):1604-11.

Chew EY, Klein ML, Clemons TE, Agron E, Ratnapriya R, Edwards AO, et al. No clinically significant association between $\mathrm{CFH}$ and ARMS2 genotypes and response to nutritional supplements: AREDS report number 38. Ophthalmology 2014;121(11):2173-80.

Clemons TE, Kurinji N, Sperduto RD, AREDS Research Group. Associations of mortality with ocular disorders and an intervention of high-dose antioxidants and zinc in the agerelated eye disease study: AREDS report no. 13. Archives of Ophthalmology 2004;122(5):716-26.

Johnson AR, Munoz A, Gottlieb JL, Jarrard DF. High dose zinc increases hospital admissions due to genitourinary complications. Journal of Urology 2007;177(2):639-43.

Moriarty-Craige SE, Ha KN, Sternberg P, Lynn M, Bressler S, Gensler $\mathrm{G}$, et al. Effects of long-term zinc supplementation on plasma thiol metabolites and redox status in patients with age-related macular degeneration. American Journal of Ophthalmology 2007;143(2):206-11.

The Age-Related Eye Disease Study Research Group. The agerelated eye disease study (AREDS): design implications AREDS report no. 1. Controlled Clinical Trials 1999;20(6):573-600.
AREDS2 2013 \{published data only\}

Age-Related Eye Disease Study 2 (AREDS2) Research Group, Chew EY, Clemons TE, Sangiovanni JP, Danis RP, Ferris FL 3rd, et al. Secondary analyses of the effects of lutein/zeaxanthin on age-related macular degeneration progression: AREDS2 report No. 3. JAMA Ophthalmology 2014;132(2):142-9.

Age-Related Eye Disease Study 2 Research Group. Lutein + zeaxanthin and omega-3 fatty acids for age-related macular degeneration: the age-related eye disease study 2 (AREDS2) randomized clinical trial. JAMA 2013;309(19):2005-15.

Chew EY, Clemons T, SanGiovanni JP, Danis R, Domalpally A, McBee W, AREDS2 Research Group. The age-related eye disease study 2 (AREDS2): study design and baseline characteristics (AREDS2 report number 1). Ophthalmology 2012;119(11):2282-9.

Hubbard LD, Danis RP, Neider MW, Thayer DW, Wabers HD, White JK, et al. Brightness, contrast, and color balance of digital versus film retinal images in the age-related eye disease study 2. Investigative Ophthalmology and Visual Science 2008;49(8):3269-82.

McBee WL, Clemons TE, Chew EY, SanGiovanni JP. An examination of site visit data audit results compiled during the initial four years of a long-term clinical trial. Clinical Trials Conference: 32nd Meeting of the Society of Clinical Trials. 2011 May 15-18; Vancouver (BC). 2011.

Writing Group for the AREDS2 Research Group, Bonds DE, Harrington M, Worrall BB, Bertoni AG, Eaton CB, Hsia J, et al. Effect of long-chain omega-3 fatty acids and lutein + zeaxanthin supplements on cardiovascular outcomes: results of the agerelated eye disease study 2 (AREDS2) randomized clinical trial. JAMA Internal Medicine 2014;174(5):763-71.

\section{Bartlett 2007 \{published data only\}}

Bartlett $\mathrm{H}$, Eperjesi F. A randomised controlled trial investigating the effect of nutritional supplementation on visual function in normal, and age-related macular disease affected eyes: design and methodology. Nutrition Journal 2003;2:12. [DOI: 10.1186/1475-2891-2-12; ISRCTN registry: ISRCTN78467674]

* Bartlett HE, Eperjesi F. Effect of lutein and antioxidant dietary supplementation on contrast sensitivity in age-related macular disease: a randomized controlled trial. European Journal of Clinical Nutrition 2007;61(9):1121-7.

\section{Berrow 2013 \{published data only\}}

Berrow EJ, Bartlett HE, Eperjesi F, Gibson JM. The effects of a lutein-based supplement on objective and subjective measures of retinal and visual function in eyes with age-related maculopathy - a randomised controlled trial. British Journal of Nutrition 2013;109(11):2008-14.

\section{CARMA 2013 \{published data only\}}

Beatty S, Chakravarthy U, Nolan JM, Muldrew KA, Woodside JV, Denny $F$, et al. Secondary outcomes in a clinical trial of carotenoids with coantioxidants versus placebo in 
early age-related macular degeneration. Ophthalmology 2013;120(3):600-6.

Beatty S, Nolan JM, Muldrew KA, Woodside J, Stevenson MR, Chakravarthy U. Visual outcome after antioxidant supplementation. Ophthalmology 2013;120(3):645.

Lai Y, Grattan J, Shi Y, Young G, Muldrew A, Chakravarthy U. Functional and morphologic benefits in early detection of neovascular age-related macular degeneration using the preferential hyperacuity perimeter. Retina 2011;31(8):1620-6.

Neelam K, Hogg RE, Stevenson MR, Johnston E, Anderson R, Beatty S, et al. Carotenoids and co-antioxidants in age-related maculopathy: design and methods. Ophthalmic Epidemiology 2008;15(6):389-401.

\section{CARMIS 2011 \{published data only\}}

Piermarocchi S, Saviano S, Parisi V, Tedeschi M, Panozzo G, Scarpa G, et al. Carotenoids in age-related maculopathy Italian study (CARMIS): two-year results of a randomized study. European Journal of Ophthalmology 2011;22(2):216-25.

\section{CLEAR 2013 \{published data only\}}

Murray IJ, Makridaki M, Van der Veen RL, Carden D, Parry NR, Berendschot TT. Lutein supplementation over a one-year period in early AMD might have a mild beneficial effect on visual acuity: the CLEAR study. Investigative Ophthalmology and Visual Science 2013;54(3):1781-8.

Tian Y, Kijlstra A, Van der Veen RL, Makridaki M, Murray IJ, Berendschot TT. The effect of lutein supplementation on blood plasma levels of complement factor D, C5a and C3d. PLoS One 2013;8:e73387.

\section{France 1998 \{unpublished data only\}}

Professor Soubrane. Zinc supplementation. Universitaire de Creteil, France.

\section{Holz 1993 \{published data only\}}

Holz FG, Wolfensberger TJ, Piguet B, Gross-Jendroska M, Arden GB, Bird AC. Oral zinc-therapy in age-related macular degeneration: a double-blind study. German Journal of Ophthalmology 1993;2:391.

\section{Kaiser 1995 \{published and unpublished data\}}

Kaiser HJ, Flammer J, Stumpfig D, Hendrickson P. Visaline in the treatment of age-related macular degeneration: a pilot study. Ophthalmologica 1995;209(6):302-5.

\section{LISA 2011 \{published data only\}}

Schmetterer L, Weigert G, Kaya S, Werkmeister R, Gahofer G. Effects of lutein supplementation on macular pigment optical density and visual acuity in patients with age-related macular degeneration.. European Journal of Ophthalmology 2013;23(4):605.

Schmidl D, Weigert G, Kaya S, Pemp B, Sacu S, Lasta M, et al. How lutein supplementation affects macular pigment optical density and visual acuity in patients with age related macular degeneration. Joint Annual Meeting of the German, Swiss, and Austrian Societies for Clinical Pharmacology and Toxicology;
2011 Oct 20-22; Zurich. British Journal of Clinical Pharmacology, 2011.

Weigert G, Kaya S, Pemp B, Sacu S, Lasta M, Werkmeister RM, et al. Effects of lutein supplementation on macular pigment optical density and visual acuity in patients with age-related macular degeneration. Investigative Ophthalmology and Visual Science 2011;52(11):8174-8.

\section{Ma 2012 \{published data only\}}

Huang YM, Dou HL, Huang FF, Xu XR, Zou ZY, Lin XM. Effect of supplemental lutein and zeaxanthin on serum, macular pigmentation, and visual performance in patients with early age-related macular degeneration. Biomed Research International 2015;2015:564738.

Huang YM, Dou HL, Huang FF, Xu XR, Zou ZY, Lu XR, et al. Changes following supplementation with lutein and zeaxanthin in retinal function in eyes with early age-related macular degeneration: a randomised, double-blind, placebo-controlled trial. British Journal of Ophthalmology 2015;99(3):371-5.

Huang YM, Yan SF, Ma L, Zou ZY, Xu XR, Dou HL, et al. Serum and macular responses to multiple xanthophyll supplements in patients with early age-related macular degeneration. Nutrition 2013;29(2):387-92.

Ma L, Dou HL, Huang YM, Lu XR, Xu XR, Qian F, et al. Improvement of retinal function in early age-related macular degeneration after lutein and zeaxanthin supplementation: a randomized, double-masked, placebo-controlled trial. American Journal of Ophthalmology 2012;154(4):625-34.

Ma L, Yan SF, Huang YM, Lu XR, Qian F, Pang HL, et al. Effect of lutein and zeaxanthin on macular pigment and visual function in patients with early age-related macular degeneration. Ophthalmology 2012;119(11):2290-7.

NCT01048476. Effects of lutein and zeaxanthin supplementation on age-related macular degeneration. clinicaltrials.gov/ct2/ show/NCT01048476 (first received 12 January 2010).

\section{Newsome 1988 \{published data only\}}

Newsome DA, Swartz M, Leone NC, Elston RC, Miller E. Oral zinc in macular degeneration. Archives of Ophthalmology 1988;106(2):192-8.

\section{Newsome 2008 \{published data only\}}

Newsome DA. A randomized, prospective, placebo-controlled clinical trial of a novel zinc-monocysteine compound in age-related macular degeneration. Current Eye Research 2008;33(7):591-8.

\section{Stur 1996 \{published data only\}}

Stur M, Tittl M, Reitner A, Meisinger V. Oral zinc and the second eye in age-related macular degeneration. Investigative Ophthalmology and Visual Science 1996;37(7):1225-35.

\section{VECAT 2002 \{published data only\}}

${ }^{*}$ Garrett SK, McNeil JJ, Silagy C, Sinclair M, Thomas AP, Robman LD, et al. Methodology of the VECAT study: vitamin E intervention in cataract and age-related maculopathy. Ophthalmic Epidemiology 1999;6(3):195-208. 
Garrett SK, Thomas AP, Cicuttini F, Silagy C, Taylor HR, McNeil JJ. Community-based recruitment strategies for a longitudinal interventional study: the VECAT experience. Journal of Clinical Epidemiology 2000;53(5):541-8.

Robman LD, Tikellis G, Garrett SK, Harper CA, McNeil JJ, Taylor HR, et al. Baseline ophthalmic findings in the vitamin E, cataract and age-related maculopathy (VECAT) study. Australian and New Zealand Journal of Ophthalmology 1999;27(6):410-6.

Taylor HR, Tikellis G, Robman LD, McCarty CA, McNeil JJ. Vitamin E supplementation and age-related maculopathy. Investigative Ophthalmology and Visual Science 2001;42:S311.

Tikellis G, Robman LD, Harper CA, Garrett SK, McNeil JJ, Taylor HR, et al. The VECAT study: methodology and statistical power for measurement of age-related macular features. Vitamin E, cataract, and age-related maculopathy study. Ophthalmic Epidemiology 1999;6(3):181-94.

\section{Veterans LAST study 2004 \{published data only\}}

Richer S, Devenport J, Lang JC. LAST II: Differential temporal responses of macular pigment optical density in patients with atrophic age-related macular degeneration to dietary supplementation with xanthophylls. Optometry 2007;78(5):213-9.

* Richer S, Stiles W, Statkute L, Pulido J, Frankowski J, Rudy D, et al. Double-masked, placebo-controlled, randomized trial of lutein and antioxidant supplementation in the intervention of atrophic age-related macular degeneration: the Veterans LAST study (lutein antioxidant supplementation trial). Optometry 2004;75(4):216-30.

\section{Wang 2004 \{published data only\}}

Wang H, Li RX, Wang MF. Effects of zinc and antioxidant on visual function of patients with age-related macular degeneration. Zhongguo Linchuant Kangfu 2004;8:1290-1.

\section{References to studies excluded from this review}

\section{Akuffo 2015 \{published data only\}}

Akuffo KO, Nolan JM, Howard AN, Moran R, Stack J, Klein R, et al. Sustained supplementation and monitored response with differing carotenoid formulations in early age-related macular degeneration. Eye 2015;29(7):902-12.

\section{Anonymous 2015 \{published data only\}}

Anonymous. Eye health: The role of nutritional supplements in reducing the risk and progression of age-related macular degeneration. Australian Journal of Pharmacy 2015;96(1139):60-2.

\section{Bahrami 2006 \{published data only\}}

Bahrami H, Melia M, Dagnelie G. Lutein supplementation in retinitis pigmentosa: $P C$-based vision assessment in a randomized double-masked placebo-controlled clinical trial. BMC Ophthalmology 2006;6:23.

\section{Barakat 2006 \{published data only\}}

Barakat MR, Metelitsina TI, DuPont JC, Grunwald JE. Effect of niacin on retinal vascular diameter in patients with age-related macular degeneration. Current Eye Research 2006;31(7-8):629-34.

Benzie 2006 \{published data only\}

Benzie IF, Chung WY, Wang J, Richelle M, Bucheli P. Enhanced bioavailability of zeaxanthin in a milk-based formulation of wolfberry (Gou Qi Zi; Fructus barbarum L). British Journal of Nutrition 2006;96(1):154-60.

Bone 2007 \{published data only\}

Bone RA, Landrum JT, Cao Y, Howard AN, Alvarez-Calderon F. Macular pigment response to a supplement containing mesozeaxanthin, lutein and zeaxanthin. Nutrition and Metabolism 2007;4:12.

\section{Cangemi 2007 \{published data only\}}

Cangemi FE. TOZAL Study: an open case control study of an oral antioxidant and omega-3 supplement for dry AMD. BMC Ophthalmology 2007;7:3.

\section{Christen 2007 \{published data only\}}

Christen WG, Manson JE, Glynn RJ, Gaziano JM, Chew EY, Buring JE, et al. Beta carotene supplementation and age-related maculopathy in a randomized trial of US physicians. Archives of Ophthalmology 2007;125(3):333-9.

\section{Connolly 2011 \{published data only\}}

Connolly EE, Beatty S, Loughman J, Howard AN, Louw MS, Nolan JM. Supplementation with all three macular carotenoids: response, stability, and safety. Investigative Ophthalmology and Visual Science 2011;52(12):9207-17.

\section{CREST 2014 \{published data only\}}

Akuffo KO, Beatty S, Stack J, Dennison J, O'Regan S, Meagher KA, et al. Central retinal enrichment supplementation trials (CREST): design and methodology of the CREST randomized controlled trials. Ophthalmic Epidemiology 2014;21(2):111-23.

\section{Cumurcu 2006 \{published data only\}}

Cumurcu T, Mendil D, Etikan I. Serum zinc and copper level in age-related macular degeneration. Trace Elements and Electrolytes 2006;23(2):103-7.

\section{Falsini 2010 \{published data only\}}

Falsini B, Piccardi M, Minnella A, Savastano C, Capoluonga E, Fadda A, et al. Influence of saffron supplementation on retinal flicker sensitivity in early age-related macular degeneration. Investigative Ophthalmology and Visual Science 2010;51(12):6118-24.

\section{Franciose 2006 \{published data only\}}

Franciose JL, Askew EW, Lang JC, Bernstein PS. Serum and macular responses to antioxidant supplementation versus a carotenoid-rich dietary intervention in the elderly. Current Topics in Nutraceuticals Research 2006;4(1):69-78.

\section{Goodrow 2006 \{published data only\}}

Goodrow EF, Wilson TA, Houde SC, Vishwanathan R, Scollin PA, Handelman G, et al. Consumption of one egg per day increases serum lutein and zeaxanthin concentrations in older adults 
without altering serum lipid and lipoprotein cholesterol concentrations. Journal of Nutrition 2006;136(10):2519-24.

ISRCTN35481392 \{published data only\}

ISRCTN35481392. Macular pigment and its contribution to visual performance and comfort. www.controlled-trials.com/ ISRCTN35481392 (first received 24 July 2008).

ISRCTN57556290 \{published data only\}

ISRCTN57556290. A multi-site trial of a novel nutritional supplement (taurine, omega-3 fatty acids, zinc, antioxidants, and lutein) and micro-current stimulation in the treatment of atrophic (dry) age-related macular degeneration. www.controlled-trials.com/ISRCTN57556290 (first received 28 December 2006).

\section{ISRCTN81595685 \{published data only\}}

ISRCTN81595685. Comparison of macular and serum responses after supplementation with two different macular carotenoid formulations. www.controlled-trials.com/ISRCTN81595685 (first received 27 August 2009).

\section{Kamburoglu 2006 \{published data only\}}

Kamburoglu G, Gumus K, Kadayifcilar S, Eldem B. Plasma homocysteine, vitamin B12 and folate levels in age-related macular degeneration. Graefe's Archive for Clinical and Experimental Ophthalmology 2006;244(5):565-9.

\section{Khachik 2006 \{published data only\}}

Khachik F, de Moura FF, Chew EY, Douglass LW, Ferris FL, Kim J, et al. The effect of lutein and zeaxanthin supplementation on metabolites of these carotenoids in the serum of persons aged 60 or older. Investigative Ophthalmology and Visual Science 2006;47(12):5234-42.

\section{Kolber 2013 \{published data only\}}

Kolber MR, Tennant M, Nickonchuk T. Vitamins for age-related macular degeneration demonstrate minimal differences. Canadian Family Physician 2013;59(5):503.

\section{Kopsell 2006 \{published data only\}}

Kopsell DA, Lefsrud MG, Kopsell DE, Wenzel AJ, Gerweck C, Curran-Celentano J. Spinach cultigen variation for tissue carotenoid concentrations influences human serum carotenoid levels and macular pigment optical density following a 12-week dietary intervention. Journal of Agricultural and Food Chemistry 2006;54(21):7998-8005.

\section{Landrum 2012 \{published data only\}}

Landrum J, Bone R, Mendez V, Valenciaga A, Babino D. Comparison of dietary supplementation with lutein diacetate and lutein: a pilot study of the effects on serum and macular pigment. Acta Biochimica Polonica 2012;59(1):167-9.

\section{Lim 2006 \{published data only\}}

Lim JI, Walonker AF, Levin L, Mahmoud M, Sadda S, Flaxel CJ, et al. One-year results of a pilot study using oral 13-cis retinoic acid as a treatment for subfoveal predominantly occult choroidal neovascularization in patients with age-related macular degeneration. Retina 2006;26(3):314-21.

\section{LUNA 2007 \{published data only\}}

* Trieschmann M, Beatty S, Nolan JM, Hense HW, Heimes B, Austermann $\mathrm{U}$, et al. Changes in macular pigment optical density and serum concentrations of its constituent carotenoids following supplemental lutein and zeaxanthin: the LUNA study. Experimental Eye Research 2007;84(4):718-28.

Zeimer M, Dietzel M, Hense HW, Heimes B, Austermann U, Pauleikhoff $D$. Profiles of macular pigment optical density and their changes following supplemental lutein and zeaxanthin: new results from the LUNA study. Investigative Ophthalmology and Visual Science 2012;53(8):4852-9.

\section{LUTEGA 2013 \{published data only\}}

Arnold C, Winter L, Frohlich K, Jentsch S, Dawczynski J, Jahreis $\mathrm{G}$, et al. Macular xanthophylls and omega-3 longchain polyunsaturated fatty acids in age-related macular degeneration: a randomized trial. JAMA Ophthalmology 2013;131(5):564-72.

Dawczynski J, Jentsch S, Schweitzer D, Hammer M, Lang GE, Strobel J. Long term effects of lutein, zeaxanthin and omega-3LCPUFAs supplementation on optical density of macular pigment in AMD patients: the LUTEGA study. Graefes Archive for Clinical and Experimental Ophthalmology 2013;251(12):2711-23.

Dawczynski J, Jentsch S, Schweitzer D, Hammer M, Strobel J. [Changes of macular pigment and drusen morphology in patients with lutein supplementation] [Anderung von makulapigment und drusenmorphologie unter luteinsupplementation]. Klinische Monatsblatter fur Augenheilkunde 2012;229(1):69-71.

\section{LUXEA 2006 \{published data only\}}

Kvansakul J, Rodriguez-Carmona M, Edgar DF, Barker FM, Kopcke W, Schalch W, et al. Supplementation with the carotenoids lutein or zeaxanthin improves human visual performance. Ophthalmic and Physiological Optics 2006;26(4):362-71.

Rodriguez-Carmona M, Kvansakul J, Harlow JA, Köpcke W, Schalch W, Barbur JL. The effects of supplementation with lutein and/or zeaxanthin on human macular pigment density and colour vision. Ophthalmic and Physiological Optics 2006;26(2):137-47.

* Schalch W, Cohn W, Barker FM, Köpcke W, Mellerio J, Bird AC, et al. Xanthophyll accumulation in the human retina during supplementation with lutein or zeaxanthin - the LUXEA (lutein xanthophyll eye accumulation) study. Archives of Biochemistry and Biophysics 2007;458(2):128-35.

\section{Meagher 2013 \{published data only\}}

Meagher K, Nolan JM, Thurnham DI, Howard AN, Beatty S. Macular response to supplementation with differing carotenoid formulations in subjects with and without age-related macular degeneration. European Journal of Ophthalmology 2013;612:23.

\section{Moeller 2006 \{published data only\}}

Moeller SM, Parekh N, Tinker L, Ritenbaugh C, Blodi B, Wallace RB, et al. Associations between intermediate agerelated macular degeneration and lutein and zeaxanthin in 
the carotenoids in age-related eye disease study (CAREDS): ancillary study of the women's health initiative. Archives of Ophthalmology 2006;124(8):1151-62.

\section{NCT00006202 \{published data only\}}

NCT00006202. Lutein for age-related macular degeneration [Dose ranging study of lutein supplementation in persons over age 60]. clinicaltrials.gov/ct2/show/NCT00006202 (first received 9 September 2000).

\section{NCT00121589 \{published data only\}}

NCT00121589. Lutein/zeaxanthin and omega-3 supplementation in persons over age 60. clinicaltrials.gov/ct2/ show/NCT00121589 (first received 20 July 2005).

\section{NCT00563979 \{published data only\}}

NCT00563979. Enhancement of macular pigment density by oral lutein supplementation (EMPOLS). clinicaltrials.gov/ct2/ show/NCT00563979 (first received 20 July 2005).

\section{NCT00564902 \{published data only\}}

NCT00564902. The zeaxanthin and visual function study (ZVF) [Randomized, double blind, lutein controlled study of zeaxanthin and visual function in atrophic age related macular degeneration patients]. clinicaltrials.gov/ct2/show/ NCT00564902 (first received 27 November 2007).

\section{NCT00718653 \{published data only\}}

NCT00718653. Effects of antioxidants on human macular pigments. clinicaltrials.gov/ct2/show/NCT00718653 (first received 17 July 2008).

\section{NCT00800995 \{published data only\}}

NCT00800995. Superoxide Dismutase (SOD) as antioxidant treatment of age related macular degeneration (ARMD) [SOD as antioxidant treatment of ARMD]. clinicaltrials.gov/ct2/show/ NCT00800995 (first received 2 December 2008).

\section{NCT00893724 \{published data only\}}

NCT00893724. Supplemental adjuvants for intracellular nutrition and treatment (SAINTS) [The effect of supplemental adjuvants for intracellular nutrition and treatment on diabetic macular edema and neovascular age-related macular degeneration]. clinicaltrials.gov/ct2/show/NCT00893724 (first received 4 May 2009).

\section{NCT02264938 \{published data only\}}

NCT02264938. Drusen morphology changes in nonexudative age-related degeneration after oral antioxidants supplementation [Drusen morphology changes in nonexudative age-related degeneration using spectral domain optical coherence tomography after oral antioxidants supplementation: one-year results]. clinicaltrials.gov/ct2/show/ NCT02264938 (first received 9 October 2014).

\section{Nolan 2006 \{published data only\}}

Nolan J, Stack J, Mellerio J, Godhinio M, O'Donovan O, Neelam K, et al. Monthly consistency of macular pigment optical density and serum concentrations of lutein and zeaxanthin. Current Eye Research 2006;31(2):199-213.
Nolan 2007 \{published data only\}

Nolan JM, Stack J, O'Donovan O, Loane E, Beatty S. Risk factors for age-related maculopathy are associated with a relative lack of macular pigment. Experimental Eye Research 2007;84(1):61-74.

Nolan 2012 \{published data only\}

Nolan JM, Akkali MC, Loughman J, Howard AN, Beatty S. Macular carotenoid supplementation in subjects with atypical spatial profiles of macular pigment. Experimental Eye Research 2012;101:9-15.

\section{Nussenblatt 2006 \{published data only\}}

Nussenblatt RB, Kim J, Thompson DJ, Davis MD, Chew E, Ferris $\mathrm{FL}$, et al. Vitamin $\mathrm{E}$ in the treatment of uveitis-associated macular edema. American Journal of Ophthalmology 2006;141(1):193-4.

\section{Owsley 2006 \{published data only\}}

Owsley C, McGwin G, Jackson GR, Heimburger DC, Piyathilake CJ, Klein R, et al. Effect of short-term, high-dose retinol on dark adaptation in aging and early age-related maculopathy. Investigative Ophthalmology and Visual Science 2006;47(4):1310-8

PHS II 2012 \{published data only\}

Christen WG, Glynn RJ, Manson JE, MacFadyen J, Bubes V, Schvartz M, et al. Effects of multivitamin supplement on cataract and age-related macular degeneration in a randomized trial of male physicians. Ophthalmology 2014;121(2):525-34.

Christen WG, Glynn RJ, Sesso HD, Kurth T, Macfadyen J, Bubes V, et al. Vitamins $E$ and $C$ and medical record-confirmed agerelated macular degeneration in a randomized trial of male physicians. Ophthalmology 2012;119(8):1642-9.

\section{Rosenthal 2006 \{published data only\}}

Rosenthal JM, Kim J, de Monasterio F, de Monastario F, Thompson DJ, Bone RA, et al. Dose-ranging study of lutein supplementation in persons aged 60 years or older. Investigative Ophthalmology and Visual Science 2006;47(12):5227-33.

\section{Sabour-Pickett 2014 \{published data only\}}

Sabour-Pickett S, Beatty S, Connolly E, Loughman J, Stack J, Howard A, et al. Supplementation with three different macular carotenoid formulations in patients with early age-related macular degeneration. Retina 2014;34(9):1757-66.

\section{Sasamoto 2011 \{published data only\}}

Sasamoto Y, Gomi F, Sawa M, Tsujikawa M, Nishida K. Effect of 1-year lutein supplementation on macular pigment optical density and visual function. Graefe's Archive for Clinical and Experimental Ophthalmology 2011;249(12):1847-54.

Scalinci 2002 \{published data only\}

Scalinci SZ, Limoli PG, Morara M, Vismara S, Scorolli L, Corazza D, et al. Dynamic phototherapy of age-related macular degeneration with or without antioxidant therapy. Canadian Journal of Ophthalmology 2002;37(7):399-404. 
Scorolli 2002 \{published data only\}

Scorolli L, Scalinci SZ, Limoli PG, Morara M, Vismara S, Scorolli L, et al. Photodynamic therapy for age related macular degeneration with and without antioxidants. Canadian Journal of Ophthalmology 2002;37(7):399-404.

\section{Souied 2013 \{published data only\}}

Souied EH, Delcourt C, Querques G, Bassols A, Merle B, Zourdani $A$, et al. Oral docosahexaenoic acid in the prevention of exudative age-related macular degeneration: the nutritional AMD treatment 2 study. Ophthalmology 2013;120(8):1619-31.

Told 2014 \{published data only\}

Told R, Palkovits S, Schmidl D, Boltz A, Gouya G, Wolzt M, et al. Retinal hemodynamic effects of antioxidant supplementation in an endotoxin-induced model of oxidative stress in humans. Investigative Ophthalmology and Vision Science 2014;55(4):2220-7.

\section{Told 2015 \{published data only\}}

Told R, Schmidl D, Palkovits S, Boltz A, Gouya G, Wolzt M, et al. Antioxidative capacity of a dietary supplement on retinal hemodynamic function in a human lipopolysaccharide (LPS) model. Investigative Ophthalmology and Visual Science 2015;56(1):403-11.

Vannas 1958 \{published data only\}

Vannas S, Orma H. On the treatment of arteriosclerotic chorioretinopathy. Acta Ophthalmologica 1958;36:601-12.

\section{Vidal 2011 \{published data only\}}

Vidal K, Bucheli P, Gao QT, Moulin J, Shen LS, Blum S, et al. Effect of a milk-based wolfberry preparation on immune function and physical status of elderly. Clinical Nutrition. Gothenurg Sweden: ESPEN, 2011.

\section{Wang 2007 \{published data only\}}

Wang W, Connor SL, Johnson EJ, Klein ML, Hughes S, Connor WE. Effect of dietary lutein and zeaxanthin on plasma carotenoids and their transport in lipoproteins in age-related macular degeneration. American Journal of Clinical Nutrition 2007;85(3):762-9.

\section{Wenzel 2006 \{published data only\}}

Wenzel AJ, Gerweck C, Barbato D, Nicolosi RJ, Handelman GJ, Curran-Celentano J. A 12-wk egg intervention increases serum zeaxanthin and macular pigment optical density in women. Journal of Nutrition 2006;136(10):2568-73.

\section{Wolf-Schnurrbusch 2015 \{published data only\}}

Wolf-Schnurrbusch UE, Zinkernagel MS, Munk MR, Ebneter A, Wolf $S$. Oral lutein supplementation enhances macular pigment density and contrast sensitivity but not in combination with polyunsaturated fatty acids. Investigative Ophthalmology and Visual Science 2015;56(13):8069-74.

Wong 2010 \{published data only\}

Wong WT, Kam W, Cunningham D, Harrington M, Hammel K, Meyerle CB, et al. Treatment of geographic atrophy by the topical administration of OT-551: results of a phase II clinical trial. Investigative Ophthalmology and Visual Science 2010;51(12):6131-9.

Zhao 2006 \{published data only\}

Zhao DY, Bhosale P, Bernstein PS. Carotenoids and ocular health. Current Topics in Nutraceuticals Research 2006;4(1):53-68.

\section{References to ongoing studies}

NCT01694680 \{published data only\}

NCT01694680. Intervention trial in early age-related macular degeneration (I-TEAM) [Intervention study to assess the effect of daily consumption of a lutein-enriched-egg beverage on maintenance of visual function in subjects with early signs of age-related macular degeneration]. clinicaltrials.gov/ct2/show/ NCT01694680 (first received 25 September 2012).

\section{NCT02625376 \{published data only\}}

NCT02625376. Resveratrol for exudative age-related macular degeneration (AGED) [Influence of resveratrol and resvega versus placebo on incidence of bilateralisation of exudative AMD: a double masked prospective study]. clinicaltrials.gov/ct2/ show/NCT02625376 (first received 6 August 2015).

\section{Additional references}

\section{Andreatta 2014}

Andreatta W, El-Sherbiny S. Evidence-based nutritional advice for patients affected by age-related macular degeneration. Ophthalmologica 2014;231(4):185-90.

\section{Angelo 2015}

Angelo G, Drake VJ, Frei B. Efficacy of multivitamin/mineral spplementation to reduce chronic disease risk: a critical review of the evidence from observational studies and randomized controlled trials. Critical Reviews in Food Science and Nutrition 2015;55(14):1968-91.

\section{AREDS 2014}

The Age-Related Eye Disease Study 2 (AREDS2) Research Group. Secondary analyses of the effects of lutein/zeaxanthinon agerelated macular degeneration progression AREDS2 Report No. 3. JAMA Ophthalmology 2014;132(2):142-9.

\section{ATBC}

The Alpha-Tocopherol, Beta Carotene Cancer Prevention Study Group. The effect of vitamin E and beta carotene on the incidence of lung cancer and other cancers in male smokers. New England Journal of Medicine 1994;330(15):1029-35.

\section{Bjelakovic 2012}

Bjelakovic G, Nikolova D, Gluud LL, Simonetti RG, Gluud C. Antioxidant supplements for prevention of mortality in healthy participants and patients with various diseases. Cochrane Database of Systematic Reviews 2012, Issue 3. [DOI: 10.1002/14651858.CD007176.pub2] 


\section{Broadhead 2015}

Broadhead GK, Grigg JR, Chang AA, McCluskey P. Dietary modification and supplementation for the treatment of age-related macular degeneration. Nutrition Reviews 2015;73(7):448-62.

\section{Bunce 2010}

Bunce C, Xing W, Wormald R. Causes of blind and partial sight certifications in England and Wales: April 2007-March 2008. Eye 2010;24(11):1692-9.

\section{Buschini 2015}

Buschini E, Fea AM, Lavia CA, Nassisi M, Pignata G, Zola M, et al. Recent developments in the management of dry age-related macular degeneration. Clinical Ophthalmology 2015;9:563-74.

\section{Carneiro 2017}

Carneiro A, Andrade JP. Nutritional and lifestyle interventions for age-related macular degeneration: a review. Oxidative Medicine and Cellular Longevity 2017;2017:Article ID 6469138. [DOI: 10.1155/2017/6469138]

\section{Chew 2014}

Chew EY. Vitamins and minerals, for eyes only?. JAMA Ophthalmology 2014;132(6):665-6.

\section{Christen 1996}

Christen WG, Glynn RJ, Hennekens CH. Antioxidants and agerelated eye disease. Current and future perspectives. Annals of Epidemiology 1996;6(1):60-6.

\section{Covidence [Computer program]}

Veritas Health Innovation. Covidence systematic review software. Version accessed prior to 27 October 2016. Melbourne: Veritas Health Innovation, 2016.

\section{Deeks 2011}

Deeks JJ, Higgins JP, Altman DG, editor(s). Chapter 9: Analysing data and undertaking meta-analyses. In: Higgins JP, Green S editor(s). Cochrane Handbook for Systematic Reviews of Interventions Version 5.1.0 (updated March 2011). The Cochrane Collaboration 2011. Available from handbook.cochrane.org.

\section{Downie 2014}

Downie LE, Keller PR. Nutrition and age-related macular degeneration: research evidence in practice. Optometry and Vision Science 2014;91(8):821-31.

\section{ETDRS 1980}

Early Treatment Diabetic Retinopathy Study Research Group. Early Treatment Diabetic Retinopathy Study Manual of Operations. Baltimore: ETDRS Co-ordinating Center, 1980.

\section{Evans 2017}

Evans JR, Lawrenson JG. Antioxidant vitamin and mineral supplements for preventing age-related macular degeneration. Cochrane Database of Systematic Reviews 2017, Issue 7. [DOI: 10.1002/14651858.CD000253.pub4]

\section{Glanville 2006}

Glanville JM, Lefebvre C, Miles JN, Camosso-Stefinovic J. How to identify randomized controlled trials in MEDLINE: ten years on. Journal of the Medical Library Association 2006;94(2):130-6.

\section{GRADEpro 2014 [Computer program]}

GRADE Working Group, McMaster University. GRADEpro. Version accessed 4 August 2016. Hamilton (ON): GRADE Working Group, McMaster University, 2014.

\section{Grover 2014}

Grover AK, Samson SE. Antioxidants and vision health: facts and fiction. Molecular and Cellular Biochemistry 2014;388(1-2):173-83.

\section{Hanus 2016}

Hanus J, Zhao F, Wang S. Current therapeutic developments in atrophic age-related macular degeneration. British Journal of Ophthalmology 2016;100(1):122-7.

\section{Higgins 2011}

Higgins JP, Altman DG, Sterne JAC, editor(s). Chapter 8: Assessing risk of bias in included studies. In: Higgins JP, Green S editor(s). Cochrane Handbook for Systematic Reviews of Interventions Version 5.1.0 (updated March 2011). The Cochrane Collaboration, 2011. Available from handbook.cochrane.org.

\section{Huang 2006}

Huang HY, Caballero B, Chang S, Alberg AJ, Semba RD, Schneyer CR, et al. The efficacy and safety of multivitamin and mineral supplement use to prevent cancer and chronic disease in adults: a systematic review for a National Institutes of Health state-of-the-science conference. Annals of Internal Medicine 2006;145(5):372-85.

\section{Klein 1992}

Klein R, Klein BE, Linton KL. Prevalence of age-related maculopathy. The beaver dam eye study. Ophthalmology 1992;99(6):933-43.

\section{Liu 2015}

Liu R, Wang T, Zhang B, Qin L, Wu C, Li Q, et al. Lutein and zeaxanthin supplementation and association with visual function in age-related macular degeneration. Investigative Ophthalmology and Visual Science 2016;56(1):252-8.

\section{Lonn 2005}

Lonn E, Bosch J, Yusuf S, Sheridan P, Pogue J, Arnold JM. Effects of long term vitamin E supplementation on cardiovascular events and cancer: a randomized controlled trial. JAMA 2005;293(11):1338-47.

\section{Manikandan 2016}

Manikandan R, Thiagarajan R, Goutham G, Arumugam M, Beulaja M, Rastrelli L, et al. Zeaxanthin and ocular health, from bench to bedside. Fitoterapia 2016;109:58-66.

\section{NICE 2016}

NICE. Macular degeneration - NICE guidelines. www.nice.org.uk/ guidance/indevelopment/gid-cgwave0658/ (accessed 28 March 2016). 


\section{Omenn 1996}

Omenn GS, Goodman GE, Thornquist MD, Balmes J, Cullen MR, Glass A, et al. Effects of a combination of beta carotene and vitamin A on lung cancer and cardiovascular disease. New England Journal of Medicine 1996;334(18):1189-90.

\section{Prasad 2014}

Prasad AS. Zinc: an antioxidant and anti-inflammatory agent: role of zinc in degenerative disorders of aging. Journal of Trace Elements in Medicine and Biology 2014;28(4):364-71.

\section{Review Manager 52014 [Computer program]}

Nordic Cochrane Centre, The Cochrane Collaboration. Review Manager 5 (RevMan 5). Version 5.3. Copenhagen: Nordic Cochrane Centre, The Cochrane Collaboration, 2014.

\section{Rudnicka 2012}

Rudnicka AR, Jarrar Z, Wormald R, Cook DG, Fletcher A, Owen CG. Age and gender variations in age-related macular degeneration prevalence in populations of European ancestry: a meta-analysis. Ophthalmology 2012;119(3):571-80.

\section{Sacconi 2017}

Sacconi R, Corbelli E, Querques L, Bandello F, Querques G. A review of current and future management of geographic atrophy. Ophthalmology and Therapy 2017 Apr 8 [Epub ahead of print]. [DOI: 10.1007/s40123-017-0086-6]

\section{Schmidl 2015}

Schmidl D, Garhofer G, Schmetterer L. Nutritional supplements in age-related macular degeneration. Acta Ophthalmologica 2015;93(2):105-21.

\section{CHARACTERISTICS OF STUDIES}

Characteristics of included studies [ordered by study ID]

\section{Schünemann 2011}

Schünemann HJ, Oxman AD, Vist GE, Higgins JP, Deeks JJ, Glasziou P, et al. Chapter 12: Interpreting results and drawing conclusions. In: Higgins JP, Green S editor(s), Cochrane Handbook for Systematic Reviews of Interventions Version 5.1.0 (updated March 2011). The Cochrane Collaboration, 2011. Available from handbook.cochrane.org.

\section{Zampatti 2014}

Zampatti S, Ricci F, Cusumano A, Marsella LT, Novelli G, Giardina E. Review of nutrient actions on age-related macular degeneration. Nutrition Research 2014;34(2):95-105.

\section{References to other published versions of this review \\ Evans 2006}

Evans JR. Antioxidant vitamin and mineral supplements for slowing the progression of age-related macular degeneration. Cochrane Database of Systematic Reviews 2006, Issue 2. [DOI: 10.1002/14651858.CD000254.pub2]

\section{Evans 2012}

Evans JR, Lawrenson JG. Antioxidant vitamin and mineral supplements for slowing the progression of age-related macular degeneration. Cochrane Database of Systematic Reviews 2012, Issue 11. [DOI: 10.1002/14651858.CD000254.pub3]

* Indicates the major publication for the study

\section{AMDSG 1996}

$\begin{array}{ll}\text { Methods } & \text { Parallel group RCT } \\ & \text { Method of allocation: sponsor prepared coded tablets } \\ & \text { Masking: participant - not clear; provider - yes; outcome - yes } \\ \text { Losses to follow-up: } 4 \text { died (2 treatment, } 2 \text { control); } 1 \text { adverse effect withdrawn (treatment); } 7 \text { lost to } \\ \text { follow-up (1 treatment, } 6 \text { control) }\end{array}$


AMDSG 1996 (Continued)

Inclusion criteria:

- people with a monocular 1 line drop in Snellen visual acuity not attributable to cataract, amblyopia, systemic, or ophthalmic disease AND clinically observable drusen, RPE disruption and loss of macular reflex

Exclusion criteria:

- longer than 1 year use of vitamins

- ex-prisoners of war

- chronic alcoholics with tobacco or nutritional amblyopia

- gastrointestinal absorption disorders

- Ocuguard (Twin Lab Inc, Ronkonkoma, NY) broad-spectrum antioxidant: beta-carotene 20,000 IU, vitamin E $200 \mathrm{IU}$, vitamin C $750 \mathrm{mg}$, citrus bioflavonoid complex $125 \mathrm{mg}$, quercitin (bioflavonoid) $50 \mathrm{mg}$, bilberry extract (bioflavonoid) $5 \mathrm{mg}$, rutin (bioflavonoid) $50 \mathrm{mg}$, zinc picolinate $12.5 \mathrm{mg}$, selenium 50 $\mu \mathrm{g}$, taurine $100 \mathrm{mg}$, n-acetyl cysteine $100 \mathrm{mg}$, l-glutathione $5 \mathrm{mg}$, vitamin B2 $25 \mathrm{mg}$, chromium 100 $\mu \mathrm{g}$ (daily)

○ unknown number people randomised (eyes unknown )

- 39 (unknown \%) people followed up (eyes unknown )

Comparator:

- placebo, starch

- unknown number people randomised (eyes unknown)

- 32 (unknown \%) people followed up (eyes unknown)

Duration: 18 months

Similarity between intervention and comparator: treatment and placebo may not have been identical

\section{Outcomes}

Primary: not specified

Secondary: not specified

Outcomes reported in the paper:

- Snellen acuity with best refraction converted to logMAR units for analysis

- near vision M units with dual sided Bailey-Lovie chart

- contrast sensitivity

- retinal grading score (adapted from Chesapeake Bay Study)

- subjective perception of vision; adverse gastrointestinal reactions

Follow-up: 18 months

Eyes: Reported right and left eyes separately

Notes

Source of funding: Twin Laboratories Inc, Ronkokoma NY; Stereo Optical Inc, Chicago, IL; Eye Communications Inc, Upland, CA; Illinois College of Optometry, Chicago, IL; Pacific University College of Optometry, Forest Grove, OR; Ezell Foundation, American Academy of Optometry, Rockville, MD

Declaration of interest: unknown

Date study conducted: unknown

Trial registration number: unknown

\section{Risk of bias}


AMDSG 1996 (Continued)

\section{Bias Authors' judgement Support for judgement}

Random sequence genera- Unclear risk tion (selection bias)

Quote: "Both the capsule for the placebo group (starch) and the capsule for the antioxidant group (Ocuguard) were formulated by Twin Laboratores Inc., Ronkonkoma, NY. An intermediary company, Eye Communications, Inc., Upland, CA. was responsible for assigning and maintaining the identity of codes, labelling and distribution of masked bottles of capsules to each DVA Medical Centre pharmacy service"

Quote: "Group one and group two patients were randomised between capsule number 1601 (starch placebo) and capsule number 1602 (Ocuguard) at each center by the optometrist co-investigator. Neither the optometrist nor the registered dietitian co-investigators nor the veteran subject knew the identify of the capsules."

\section{Allocation concealment Unclear risk} (selection bias)

Cen

Quote: "Both the capsule for the placebo group (starch) and the capsule for the antioxidant group (Ocuguard) were formulated by Twin Laboratores Inc., Ronkonkoma, NY. An intermediary company, Eye Communications, Inc., Upland, CA. was responsible for assigning and maintaining the identity of codes, labelling and distribution of masked bottles of capsules to each DVA Medical Centre pharmacy service"

Quote: "Group one and group two patients were randomised between capsule number 1601 (starch placebo) and capsule number 1602 (Ocuguard) at each center by the optometrist co-investigator. Neither the optometrist nor the registered dietitian co-investigators nor the veteran subject knew the identify of the capsules."

$\begin{array}{ll}\begin{array}{l}\text { Blinding of participants } \\ \text { and personnel (perfor- }\end{array} & \text { Quote: "Both the capsule for the placebo group (starch) and the capsule for } \\ \text { mance bias) } & \text { the antioxidant group (Ocuguard) were formulated by Twin Laboratores Inc., } \\ \text { Visual acuity } & \begin{array}{l}\text { Ronkonkoma, NY. An intermediary company, Eye Communications, Inc., Up- } \\ \text { land, CA. was responsible for assigning and maintaining the identity of codes, } \\ \text { labelling and distribution of masked bottles of capsules to each DVA Medical } \\ \text { Centre pharmacy service" }\end{array}\end{array}$

Quote: "Group one and group two patients were randomised between capsule number 1601 (starch placebo) and capsule number 1602 (Ocuguard) at each center by the optometrist co-investigator. Neither the optometrist nor the registered dietitian co-investigators nor the veteran subject knew the identify of the capsules."

Blinding of participants Low risk and personnel (performance bias)

Progression AMD
Quote: "Both the capsule for the placebo group (starch) and the capsule for the antioxidant group (Ocuguard) were formulated by Twin Laboratores Inc., Ronkonkoma, NY. An intermediary company, Eye Communications, Inc., Upland, CA. was responsible for assigning and maintaining the identity of codes, labelling and distribution of masked bottles of capsules to each DVA Medical Centre pharmacy service"

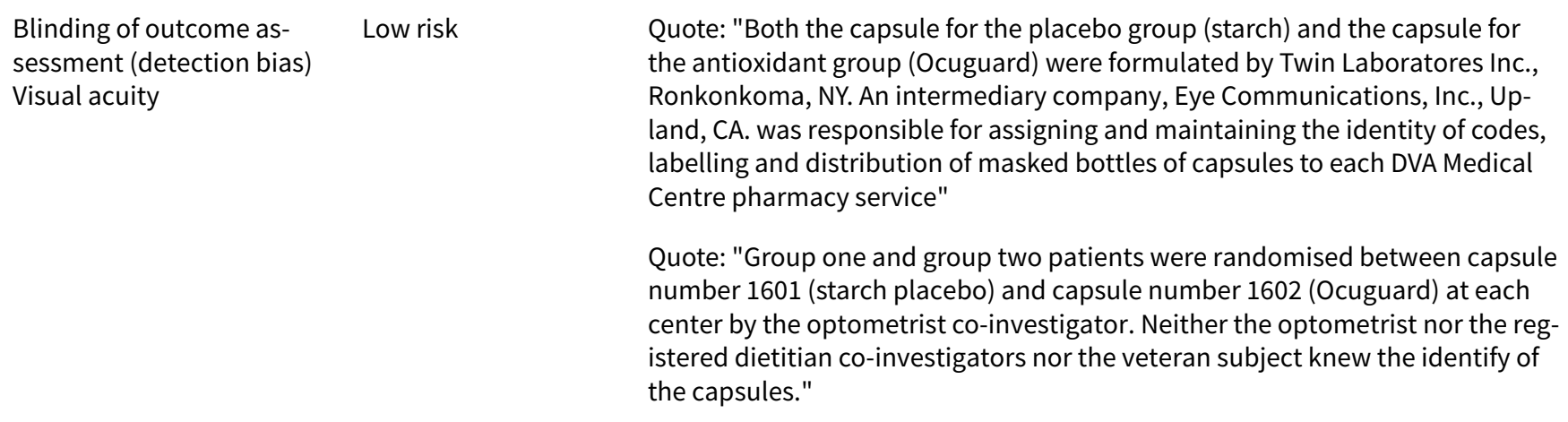


AMDSG 1996 (Continued)

Blinding of outcome as- Low risk sessment (detection bias)

Progression AMD
Quote: "Both the capsule for the placebo group (starch) and the capsule for the antioxidant group (Ocuguard) were formulated by Twin Laboratores Inc., Ronkonkoma, NY. An intermediary company, Eye Communications, Inc., Upland, CA. was responsible for assigning and maintaining the identity of codes, labelling and distribution of masked bottles of capsules to each DVA Medical Centre pharmacy service"

Quote: "Group one and group two patients were randomised between capsule number 1601 (starch placebo) and capsule number 1602 (Ocuguard) at each center by the optometrist co-investigator. Neither the optometrist nor the registered dietitian co-investigators nor the veteran subject knew the identify of the capsules."
Incomplete outcome data Unclear risk (attrition bias)

All outcomes
17 participants withdrew from the study over 18 months. 4 participants died. 1 participant experienced an idiosyncratic reaction and was dropped. Attrition data were as follows: "71 patients at baseline, 67 patients at $6 \mathrm{~m}, 59$ patients at $12 \mathrm{~m}, 59$ patients at $18 \mathrm{~m}$." Similar numbers of dropouts from groups 1 and 2 but the numbers were not clearly described.
Selective reporting (re- Unclear risk porting bias)
Difficult to assess with the information given - no access to study protocol and trial was not registered.

AREDS 2001

$\begin{array}{ll}\text { Methods } & \text { Parallel group RCT } \\ & 2 \times 2 \text { factorial design. } 67 \% \text { participants took additional supplements to RDA levels (Centrum). In } 1996 \\ & \text { current smokers offered option of discontinuing supplementation; } 2 \% \text { of participants and } 18 \% \text { of } \\ \text { smokers did so. A further } 2.3 \% \text { reassigned to no beta-carotene group. Intention-to-treat analysis main- } \\ \text { tained. } \\ \text { Method of allocation: coded bottles } \\ \text { Masking: participant - yes; provider - yes; outcome - yes } \\ \text { Losses to follow-up: } 2.4 \% \text { balanced across study groups }\end{array}$

Participants

\author{
Country: USA \\ Number of people randomised: 3640 (eyes unknown) \\ Number (\%) of people followed up: $2.4 \%$ lost to follow up \\ Average age (range): 69 years (55 to 80 ) \\ Percentage women: $56 \%$ \\ Ethnic group: 96\% white \\ Baseline visual acuity: unknown \\ Comorbidities affecting the eye: unknown \\ Percentage current smokers: $8 \%$ \\ Inclusion criteria:
}

- $20 / 32$ or better in at least 1 eye

- ocular media clear and therefore able to obtain adequate stereoscopic fundus photographs

- at least 1 eye free from eye disease that could complicate assessment of AMD

Exclusion criteria: 
AREDS 2001 (Continued)

- illness or disorders that would make long-term follow-up or compliance with study protocol unlikely or difficult

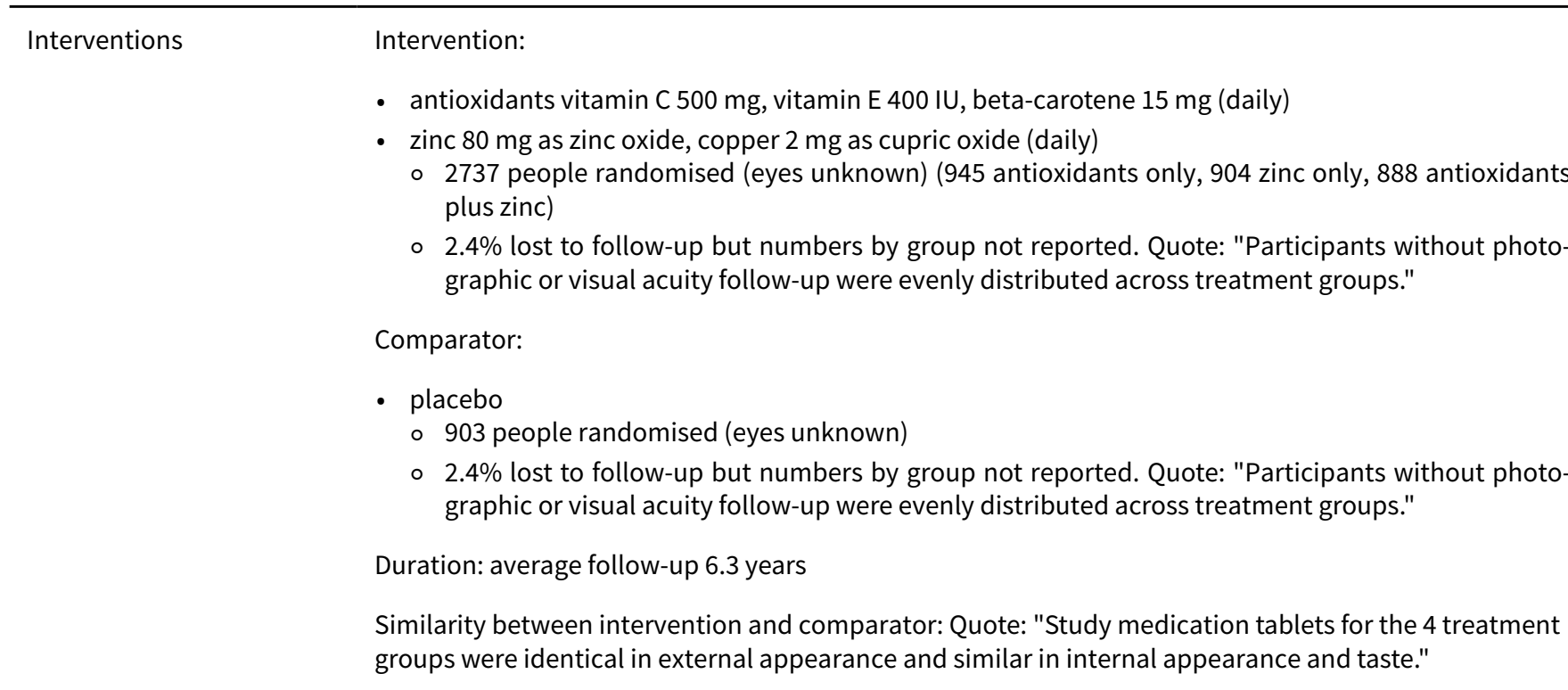

Outcomes Primary:

- progression to advanced AMD (assessed using stereoscopic fundus colour photograph)

- 15 letter or more decrease in visual acuity score (EDTRS logMAR chart)

Secondary:

- safety outcomes included: reported adverse events; serum levels of haemoglobin; hospitalisations and mortality.

Follow-up: annual follow-up for at least 5 years

Eyes: outcome was "in at least one eye" i.e. reported by person

Notes

Source of funding: Quote: "Supported by contracts from the National Eye Institute, National Institutes of Health, with additional support from Bausch and Lomb Pharmaceuticals."

Declaration of interest: Quote: "The AREDS investigators have no commercial or proprietary interest in the supplements used in this study."

Date study conducted: 1992 to 2001

Trial registration number: unknown

\section{Risk of bias}

\begin{tabular}{lll}
\hline Bias & Authors' judgement & Support for judgement \\
\hline $\begin{array}{l}\text { Random sequence genera- } \\
\text { tion (selection bias) }\end{array}$ & Low risk & $\begin{array}{l}\text { Quote: "Simple randomization, stratified by clinical center and AMD catego- } \\
\text { ry, was used to assign treatment. Participants in Categories 2, 3, and 4 were as- } \\
\text { signed with probability one quarter to each treatment group" }\end{array}$ \\
& $\begin{array}{l}\text { Quote: "Multiple unique bottle codes were randomly assigned to each of the } 4 \\
\text { treatments for Categories 2, 3, and 4, and also to each of the } 2 \text { treatments for } \\
\text { participants in Category 1. A bottle code corresponding to the assigned treat- } \\
\text { ment was randomly selected for each participant". }\end{array}$ \\
&
\end{tabular}


AREDS 2001 (Continued)

Allocation concealment Low risk (selection bias)
Quote: "Multiple unique bottle codes were randomly assigned to each of the 4 treatments for Categories 2, 3, and 4, and also to each of the 2 treatments for participants in Category 1 . A bottle code corresponding to the assigned treatment was randomly selected for each participant".
Blinding of participants Low risk and personnel (performance bias)

Visual acuity
Quote: "The 4 treatment interventions were double-masked..."

"Study medication tablets for the 4 treatment groups were identical in external appearance and similar in internal appearance and taste. The coordinating center was custodian of the treatment code"

Quote: "Four participants $(0.1 \%)$ were reported to have been unmasked during the trial"
Blinding of participants Low risk and personnel (perfor-

mance bias)

Progression AMD
Quote: "The 4 treatment interventions were double-masked..."

Quote: "Study medication tablets for the 4 treatment groups were identical in external appearance and similar in internal appearance and taste. The coordinating center was custodian of the treatment code"

Quote: "Four participants $(0.1 \%)$ were reported to have been unmasked during the trial"

\begin{tabular}{lll}
\hline $\begin{array}{l}\text { Blinding of outcome as- } \\
\begin{array}{l}\text { sessment (detection bias) } \\
\text { Visual acuity }\end{array}\end{array}$ & Low risk & $\begin{array}{l}\text { Quote: "Visual acuity was assessed by certified examiners using the ETDRS log- } \\
\text { MAR chart and a standardized refraction and visual acuity protocol (AREDS } \\
\text { Manual of Operations; The EMMES Corporation, Rockville, Md)" }\end{array}$ \\
\hline $\begin{array}{l}\text { Blinding of outcome as- } \\
\begin{array}{l}\text { sessment (detection bias) } \\
\text { Progression AMD }\end{array}\end{array}$ & Low risk & $\begin{array}{l}\text { Quote: "Stereoscopic fundus photographs of the macula were taken at base- } \\
\text { line and annually, beginning } 2 \text { years after randomization, and graded centrally } \\
\text { using standardized grading procedures." }\end{array}$
\end{tabular}

Incomplete outcome data Low risk (attrition bias)

All outcomes
Quote: "Participants without photographic or visual acuity follow-up were evenly distributed across treatment groups."

Quote: "Only 2.4\% of AREDS participants were lost to follow-up (missed at least their last 2 consecutive visits). Losses to follow-up were balanced across treatment groups"

Quote: "Of almost 50,000 possible follow-up visits, $10 \%$ were missed. The frequency of missed visits and mean follow-up time ( 6.3 years) did not differ by treatment group. Most participants (90\%) had at least 5 years of follow-up."

treatment group. Most participants ( $90 \%)$ had at least 5 years of follow-up."

Selective reporting (re- Low risk porting bias)
Quote: "At the start of the study, 2 primary outcomes were defined for study eyes in the AMD trial: (1) progression to advanced AMD and (2) at least a 15-letter decrease in visual acuity score."

\section{AREDS2 2013}

Methods
Marallel group RCT
Method of allocation: coded tablets
Masking: participant - yes; provider - yes; outcome - yes
Loss to follow-up: Quote: "Of the 4203 randomised participants, 141 (3\%) were lost to follow-up and
368 (9\%) died during the course of the study. Distributions were similar across the 4 treatment groups."
Quote: "Participants lost to follow-up or who died during the course of the study were censored at the
time of last contact." See follow-up data below - $99 \%$ of participants were included in the analysis.


AREDS2 2013 (Continued)

Participants
Country: USA

Number of people randomised: 4203 (6916 eyes)

Number (\%) of people followed up: 4176 (99\%) using LOCF (6891 eyes)

Average age (range): 74 years (68 to 79 )

Percentage women: $56 \%$

Ethnic group: $97 \%$ white

Baseline visual acuity: average 78 letters on EDTRS chart

Comorbidities affecting the eye: $25 \%$ bilateral pseudophakic, $13 \%$ with diabetes

Percentage current smokers: $7 \%$

Inclusion criteria:

- high risk of progression to advanced AMD with either bilateral large drusen or non-foveal geographic atrophy (no advanced AMD) or large drusen or non-foveal geographic atrophy in one eye and advanced AMD in the fellow eye (AREDS Simple Scale Score of 2, 3 or 4)

- age 50 to 85 years

- took at least $75 \%$ of study medication during the run-in phase

- able and willing to consent to both the qualification and the randomisation/follow-up phases of the study

- likely, willing, and able to undergo yearly examinations for at least five years

- agreed to stop current use of supplements containing lutein, zeaxanthin, omega-3 LCPUFAs (specifically DHA+EPA), vitamin C, vitamin E, beta-carotene, zinc or copper, other than those supplied by AREDS2

- fundus photographs of adequate quality as assessed with a standardized protocol by the Reading Center (University of Wisconsin Fundus Photograph Reading Center)

- randomised within three months following the qualification visit

Exclusion criteria:

- the presence of ocular disease in either eye that may have confounded evaluation of the retina

- previous retinal or other ocular surgical procedures (other than cataract extraction) that may have complicated assessment of the progression of AMD

- a chronic requirement for any systemic or ocular medication administered for other diseases and known to be toxic to the retina or optic nerve

- previous daily supplementation with $2 \mathrm{mg}$ or more of lutein, or $500 \mathrm{mg}$ or more of omega-3 LCPUFAs, or both, for a period of 1 year or more prior to the date of randomization. (A participant was eligible for the study if he or she agreed to stop taking these supplements during the study run-in period)

- intraocular pressure of $26 \mathrm{~mm} \mathrm{Hg}$ or higher, or some reason to believe that the participant might have glaucoma

- cataract surgery within 3 months or capsulotomy within 6 weeks prior to the qualification visit

- history of lung cancer

- any systemic disease with a poor five-year survival prognosis

- haemochromatosis

- Wilson's disease

- recent diagnosis of oxalate kidney stones

- any condition that would make adherence or follow-up difficult or unlikely

- current participation in other studies that might affect adherence to the AREDS2 follow-up schedule

- use of systemic anti-angiogenic therapy for treatment of choroidal neovascularization or cancer 
- lutein $10 \mathrm{mg}$ and zeaxanthin $2 \mathrm{mg}$ (1 tablet/day)

- 2123 people randomised (3468 eyes)

- 2107 (99\%) people followed up (3451 eyes)

Comparator:

- placebo (1 tablet/day)

- 2080 people randomised (3448 eyes)

- 2069 (99\%) people followed up (3440 eyes)

Almost all participants in both intervention and comparator groups took AREDS supplement and multivitamin with the study medication.

Duration: 5 years (median)

Similarity between intervention and comparator: The placebo was composed from free flowing corn starch-coated matrix of beadlets formed into a tablet of identical shape, size, and coating/internal colour (using the same quantity of colorings agents) as that containing lutein + zeaxanthin.

Other study arm: There was another study arm looking at docosahexaenoic acid (DHA) $350 \mathrm{mg}$ and eicosapentaenoic acid (EPA) $650 \mathrm{mg}$ (2 soft-gel capsules/day); it was not included in this review

\section{Outcomes}

Primary:

- progression to advanced AMD in people at moderate to high risk for progression

Secondary:

- progression to moderate vision loss

- adverse events

- progression of lens opacity or incidence of cataract surgery

- effect of study supplements on cognitive function

- effect of DHA/EPA on cardiovascular morbidity and mortality

Follow-up: annual follow-up for 5 years

Eyes: Quote: "The unit of analysis for ophthalmic outcomes was by eye. The primary efficacy outcome, time to progression to advanced AMD, was assessed using a Cox proportional hazards model incorporating the method of Wei et al for obtaining robust variance estimates that allows for dependence among multiple event times (1 or 2 study eyes)." from the National Eye Institute/National Institutes of Health (NEI/NIH), Department of Health and Human Services, Bethesda, MD. Contract No. HHS-N-260-2005-00007-C. ADB Contract No. N01-EY-5-0007. Funds were generously contributed to these contracts by the following NIH institutes: Office of Dietary Supplements (ODS), National Center for Complementary and Alternative Medicine (NCCAM), National Institute on Aging (NIA), National Heart, Lung and Blood Institute (NHLBI), and National Institute of Neurological Disorders and Stroke (NINDS)"

Declaration of interest: Quote: "A complete list of all AREDS2 investigator financial disclosures, which were collected for regulatory purposes, pursuant to US FDA regulations in 21 CFR Part 54, can be found at www.areds2.org. The member(s) of the writing committee have made the following disclosure(s): Frederick L. Ferris III; Bausch \& Lomb (P) and the remainder had no conflicts of interest."

Date study conducted: September 2006 to October 2012 (from clinicaltrials.gov entry)

Trial registration number: NCT00345176

\section{Risk of bias}

Bias Authors' judgement Support for judgement

Random sequence genera- Low risk tion (selection bias)
Quote: "A random block design was implemented using the AREDS2 Advantage Electronic Data Capture system (AdvantageEDC SM ) by the AREDS2 Co- 
ordinating Center (The EMMES Corporation, Rockville, Maryland) and stratified by clinical center and AMD status (large drusen both eyes or large drusen in one eye and advanced AMD in the fellow eye) to assure approximate balance across centers over time."

\begin{tabular}{ll}
\hline $\begin{array}{l}\text { Allocation concealment } \\
\text { (selection bias) }\end{array}$ & Low risk
\end{tabular}

\begin{tabular}{ll}
\hline $\begin{array}{l}\text { Blinding of participants } \\
\text { and personnel (perfor- }\end{array}$ & Low risk
\end{tabular}

mance bias)

Visual acuity

Quote: "All 4 formulations are balanced on excipients and packaged in capsules of identical size, shape and color."

\begin{tabular}{|c|c|c|}
\hline $\begin{array}{l}\text { Blinding of participants } \\
\text { and personnel (perfor- } \\
\text { mance bias) }\end{array}$ & Low risk & $\begin{array}{l}\text { Judgement comment: Placebo controlled trial. Fundus images graded by } \\
\text { masked graders. }\end{array}$ \\
\hline Progression AMD & & $\begin{array}{l}\text { Quote: "All } 4 \text { formulations are balanced on excipients and packaged in cap- } \\
\text { sules of identical size, shape and color." }\end{array}$ \\
\hline
\end{tabular}

\begin{tabular}{|c|c|c|}
\hline $\begin{array}{l}\text { Blinding of outcome as- } \\
\text { sessment (detection bias) } \\
\text { Visual acuity }\end{array}$ & Low risk & $\begin{array}{l}\text { Judgement comment: Placebo controlled trial. Personnel measuring visual } \\
\text { acuity unaware of allocation. } \\
\text { Quote: "All } 4 \text { formulations are balanced on excipients and packaged in cap- } \\
\text { sules of identical size, shape and color." }\end{array}$ \\
\hline $\begin{array}{l}\text { Blinding of outcome as- } \\
\text { sessment (detection bias) } \\
\text { Progression AMD }\end{array}$ & Low risk & $\begin{array}{l}\text { Judgement comment: Placebo controlled trial. Fundus images graded by } \\
\text { masked graders. } \\
\text { Quote: "All } 4 \text { formulations are balanced on excipients and packaged in cap- } \\
\text { sules of identical size, shape and color." }\end{array}$ \\
\hline $\begin{array}{l}\text { Incomplete outcome data } \\
\text { (attrition bias) } \\
\text { All outcomes }\end{array}$ & Low risk & $\begin{array}{l}\text { Quote: "Of the } 4203 \text { randomised participants, } 141(3 \%) \text { were lost to follow-up } \\
\text { and } 368(9 \%) \text { died during the course of the study. Distributions were similar } \\
\text { across the } 4 \text { treatment groups." }\end{array}$ \\
\hline $\begin{array}{l}\text { Selective reporting (re- } \\
\text { porting bias) }\end{array}$ & Low risk & $\begin{array}{l}\text { Judgement comment: AMD outcomes pre-specified in clinical trials registry } \\
\text { and in published protocol paper were reported. }\end{array}$ \\
\hline
\end{tabular}

\section{Bartlett 2007}

\begin{tabular}{|c|c|}
\hline Methods & $\begin{array}{l}\text { Parallel group RCT } \\
\text { Method of allocation: sponsor prepared coded tablets } \\
\text { Masking: participant - yes; provider - yes; outcome - ye } \\
\text { Losses to follow-up: } 5 \text { ( } 2 \text { treatment, } 3 \text { control) }\end{array}$ \\
\hline \multirow[t]{6}{*}{ Participants } & Country: UK \\
\hline & Number of people randomised: 30 (30 eyes) \\
\hline & Number (\%) of people followed up: 25 (83\%) (25 eyes) \\
\hline & Average age (range): 69 years ( 55 to 82 ) \\
\hline & Percentage women: $53 \%$ \\
\hline & Ethnic group: $100 \%$ white \\
\hline
\end{tabular}


Baseline visual acuity: average visual acuity in intervention group was $0.20 \log M A R$ and in control group was 0.08 logMAR

Comorbidities affecting the eye: unknown

Percentage current smokers: unknown

Inclusion criteria:

- provide written informed consent

- be available to attend one of the research centres

- present with no ocular pathology in at least 1 eye, or no ocular pathology other than soft or hard drusen, and areas of increased or decreased pigment associated with drusen. Fundus examination was used to determine the presence of AMD.

Exclusion criteria:

- type I and II diabetes

- prescribed antiplatelet or anticoagulant medication

- concurrent use of nutritional supplements

- advanced AMD in 1 or both eyes

Interventions

Intervention:

- lutein esters $6 \mathrm{mg}$, retinol $750 \mathrm{mg}$, vitamin C $250 \mathrm{mg}$, vitamin E $34 \mathrm{mg}$, zinc $10 \mathrm{mg}$, copper $0.5 \mathrm{mg}$ (daily)

- 17 people randomised (17 eyes)

- $15(88 \%)$ people followed up (15 eyes)

Comparator:

- placebo tablets containing cellulose (daily)

- 13 people randomised (13 eyes)

- $10(77 \%)$ people followed up (10 eyes)

Duration: 9 months

Similarity between intervention and comparator: Quote: "The study formulation and placebo tablets were produced by Quest Vitamins Ltd, and were identical in external and internal appearance, and taste."

Secondary: unknown

Outcome measures specified on trial registration entry:

- Distance and near visual acuity (VA) measured using Bailey-Lovie logMAR charts

- Contrast sensitivity (CS) measured using a Pelli-Robson chart (Clement Clarke International, Harlow Essex, UK)

- Colour vision measured using the PV-16 quantitative colour vision test

- Macular Mapping (MM) test

- Eger Macular Stressometer (EMS) used to assess glare recovery

- Fundus photographs of the macular will be assessed using colour and edge analysis software

Trial publication provided data on contrast sensitivity at 9-month follow-up.

Protocol listed more outcomes (see below under selective reporting) and specified 9 and 18 months follow-up.

Follow-up: 9 months (reported) and 18 months (not reported) 

provide $80 \%$ power at the $5 \%$ significance level for CS based on an effect size of 0.3 log units, and mean and standard deviation (SD) values taken from a sample of 50 ARM and atrophic AMD patients of the University optometry clinic (1.3970.22 log CS)."

Sample size calculations reported in protocol paper: "From initial data collection we have calculated the treatment group sizes required in order to have $80 \%$ power at the $5 \%$ significance level for VA, CS, MM test, and the EMS. These values suggest that a total of 63 normal, and 96 age-related macular disease participants are required."

Source of funding: Quote: "The project was sponsored by the UK College of Optometrists. Intervention and placebo tablets were provided by Quest Vitamins Ltd UK."

Declaration of interest: unknown

Date study conducted: March 2003 and December 2004

Trial registration number: ISRCTN78467674 (registered retrospectively)

\section{Risk of bias}

\section{Bias \\ Authors' judgement Support for judgement}

Random sequence genera- Low risk tion (selection bias)
"The random number generator function in Microsoft Excel is being used to allocate participants to $\mu$ and $\lambda$ groups. Odd numbers allocate to the $\mu$ group."

"Only one investigator (HB) was involved in the randomization process, which employed the random number generator in Microsoft Excel for Windows XP. Odd and even numbers were used to identify group."

$\begin{array}{ll}\begin{array}{l}\text { Allocation concealment } \\ \text { (selection bias) }\end{array} & \text { Low risk } \\ \text { assignment." }\end{array}$

"Only one investigator (HB) was involved in the randomization process, which employed the random number generator in Microsoft Excel for Windows XP. Odd and even numbers were used to identify group."

"Investigators and participants do not know which symbol represents the placebo tablets, and which represents the active formulation."

$\begin{array}{ll}\begin{array}{l}\text { Blinding of participants } \\ \text { and personnel (perfor- }\end{array} & \text { "The study formulation and placebo tablets have been produced by Quest Vit- } \\ \text { mance bias) } & \text { amins Ltd, Aston Science Park, Birmingham, B7 4AP, and are identical in exter- } \\ \text { Visual acuity } & \text { nal and internal appearance, and taste. The manufacturer has allocated distin- } \\ & \text { guishing symbols, } \mu \text { and } \lambda \text {. The tablets are packaged in identical, sealed, white } \\ & \text { containers; the only difference being the symbol on the label. Investigators } \\ & \text { and participants do not know which symbol represents the placebo tablets, } \\ \text { and which represents the active formulation." }\end{array}$


Bartlett 2007 (Continued)

and participants do not know which symbol represents the placebo tablets, and which represents the active formulation."

"End of trial assessment using questionnaires indicated ' masking success. Out of those participants taking the placebo tablet, $10 \%$ correctly guessed which tablet they were taking, and $10 \%$ incorrectly guessed. Out of those taking nutritional supplement, $13 \%$ guessed correctly which tablet they were taking, and $7 \%$ incorrectly guessed. The remaining participants did not know which group they were randomised to."

\begin{tabular}{ll}
\hline Blinding of outcome as- & Unclear risk $\quad$ Not reported \\
sessment (detection bias) & \\
Progression AMD &
\end{tabular}

Incomplete outcome data Unclear risk

"Statistical analysis was carried out on a per protocol basis."

(attrition bias)

All outcomes

Selective reporting (re- High risk

porting bias)

Protocol report: following outcomes listed: visual acuity, contrast sensitivity, colour vision, macular mapping test, glare recovery, fundus photographs analysed by colour and edge analysis software.

Trial report only reported contrast sensitivity (CS): Quote: "Outcome measure CS was measured using a Pelli-Robson chart (Clement Clarke International, Edinburgh Way, Harlow, Essex, CM20 2TT, UK) and scored per letter."

\section{Berrow 2013}

\section{Methods}

Parallel group RCT

Method of allocation: unclear

Masking: participant - no; provider - no; outcome - yes

Loss to follow-up: unclear, either no loss to follow-up or 2/16 (12.5\%) loss to follow-up

\section{Participants}

\section{Country: UK}

Number of people randomised: 14 (14 eyes)

Number (\%) of people followed up: 14 (100\%) (14 eyes)

Average age (range): 68 years ( 56 to 83 )

Percentage women: unknown

Ethnic group: Caucasian

Baseline visual acuity: unknown

Comorbidities affecting the eye: unknown

Percentage current smokers: unknown but average 7 pack-years in antioxidant group and 13.5 packyears in the placebo group

Inclusion criteria:

- best-corrected distance VA of 0.2 LogMAR or better (for good mfERG central fixation)

- clear optical media, as determined by a clear view of the fundus 
- no signs of other retinal or optic nerve disease other than ARM (as determined by fundal photography and questionnaire) in the study eye

- good general health (as determined by health questionnaire)

- no prescribed medication that could affect the retina (as determined by health questionnaire)

Exclusion criteria:

- moderate-to-dense lens opacities

- intraocular lens

- corneal opacities

- glaucoma or ocular hypertension

- previous history of intraocular inflammation

- previous history of retinal detachment

- retinal disease (other than ARM)

- previous retinal laser

- diabetes

- systemic hypertension

- history of ocular trauma

- neurological disease

- age-related macular degeneration (AMD) in the study eye

- drugs causing retinal toxicity

- previous ocular surgery

- epilepsy

- Ocuvite Duo (Bausch and Lomb) vitamin C $150 \mathrm{mg}$, cupric oxide $400 \mu \mathrm{g}$, vitamin E $15 \mathrm{mg}$, zinc oxide 20 $\mathrm{mg}$, lutein $12 \mathrm{mg}$, zeaxanthin $0.6 \mathrm{mg}$, EPA $240 \mathrm{mg}$, DHA $840 \mathrm{mg}$

- 8 people randomised (8 eyes)

- $8(100 \%)$ people followed up (8 eyes)

Comparator:

- no treatment

- 6 people randomised ( 6 eyes)

- $6(100 \%)$ people followed up (6 eyes)

Duration: 40 weeks

Similarity between intervention and comparator: different because no placebo group

Outcomes

from clinical trial registry entry

Primary:

- multifocal electroretinogram amplitudes and latencies, assessed every 20 weeks for a period of 80 weeks

Secondary:

- macular pigment optical density, assessed every 20 weeks for a period of 80 weeks

No numeric data on outcomes reported. Quote: "All participants undertook VA and CS assessment at all three visits. There were no significant changes between the treated and non-treated groups over 40 weeks for these measures."

Follow-up: 40 weeks and 60 weeks

Eyes: Quote: "Only one eye from each participant was studied.[...] The eye with the best-corrected distance VA was determined at the participant's first visit and this eye was assessed for subsequent visits. 
If one eye had ARM, this eye was used. If both eyes had ARM, the eye with the best-corrected distance VA was used to ensure good mfERG fixation."

Notes

Source of funding: Quote: "The authors would like to thank Bausch and Lomb, Kingston-Upon-Thames, Surrey, UK for funding the research position and supplying the Ocuvite Duo nutritional supplement."

Declaration of interest: Quote: "The authors declare no competing financial interests"

Date study conducted: January 2009 to December 2011

Trial registration number: ISRCTN17842302 (retrospectively registered)

\section{Risk of bias}

\begin{tabular}{lll}
\hline Bias & Authors' judgement & Support for judgement \\
\hline $\begin{array}{ll}\text { Random sequence genera- } \\
\text { tion (selection bias) }\end{array}$ & Low risk & $\begin{array}{l}\text { Quote: "A total of fourteen participants with ARM were randomly allocated, us- } \\
\text { ing Microsoft Excel random number generator, to either receive a lutein-based } \\
\text { oral supplement (treated group) or no supplement (non-treated group) at visit } \\
\text { one." }\end{array}$ \\
\hline
\end{tabular}

Allocation concealment Unclear risk Judgement comment: Not clearly reported.

(selection bias)

\begin{tabular}{|c|c|c|}
\hline $\begin{array}{l}\text { Blinding of participants } \\
\text { and personnel (perfor- } \\
\text { mance bias) } \\
\text { Visual acuity }\end{array}$ & High risk & $\begin{array}{l}\text { Judgement comment: No placebo - control group did not receive any interven- } \\
\text { tion. }\end{array}$ \\
\hline
\end{tabular}

Blinding of participants High risk and personnel (performance bias)

Progression AMD
Judgement comment: No placebo - control group did not receive any intervention.

\begin{tabular}{|c|c|c|}
\hline $\begin{array}{l}\text { Blinding of outcome as- } \\
\text { sessment (detection bias) } \\
\text { Visual acuity }\end{array}$ & Unclear risk & $\begin{array}{l}\text { Judgement comment: No placebo - control group did not receive any interven- } \\
\text { tion but study was described as "single masked", so outcome assessors were } \\
\text { not aware of group assignment up to } 40 \text { weeks, when unmasking occurred. } \\
\text { However, measurement of visual acuity may be influenced by participants } \\
\text { knowledge of intervention. }\end{array}$ \\
\hline
\end{tabular}

\begin{tabular}{|c|c|c|}
\hline $\begin{array}{l}\text { Blinding of outcome as- } \\
\text { sessment (detection bias) } \\
\text { Progression AMD }\end{array}$ & Low risk & $\begin{array}{l}\text { Judgement comment: No placebo - control group did not receive any interven- } \\
\text { tion but study was described as "single masked", so outcome assessors were } \\
\text { not aware of group assignment up to } 40 \text { weeks, when unmasking occurred. }\end{array}$ \\
\hline
\end{tabular}

Incomplete outcome data Unclear risk (attrition bias)

Quote: "A total of fourteen participants with ARM were randomly allocated, usAll outcomes ing Microsoft Excel random number generator, to either receive a lutein-based oral supplement (treated group) or no supplement (non-treated group) at visit one. These were from an original cohort of sixteen participants, two of which withdrew without giving reason. Only one eye from each"

Judgement comment: Unclear to which group the 2 participants who withdrew had been randomly allocated.

Selective reporting (re- High risk
porting bias)

Judgement comment: Trial was registered retrospectively, so not possible to check this. Follow-up at 80 weeks was not reported. 
CARMA 2013

Methods

Parallel group RCT

Method of allocation: labelled containers

Masking: participant - yes; provider - yes; outcome - yes

Loss to follow-up: high attrition after 12 months - $9 \%$ follow-up at 3 years
Country: Ireland

Number of people randomised: 433 (614 eyes)

Number (\%) of people followed up: at 12 months, 493 eyes (80\%); at 24 months, 260 eyes (42\%); and at 36 months, 58 eyes ( $9 \%)$

Average age (range): 74 years (unknown)

Percentage women: $57 \%$

Ethnic group: unknown

Baseline visual acuity: average 80 letters on logMAR chart

Comorbidities affecting the eye: unknown

Percentage current smokers: $14 \%$

Inclusion criteria:

- 50 years and older

- any severity of early AMD in one eye and late AMD (neovascular AMD or central geographic atrophy) in the fellow eye. The study eye was the eye free of late-stage AMD.

- features of early AMD in at least 1 eye when both eyes were free of late-stage AMD.The minimum severity level was 20 soft distinct or indistinct drusen in the central macular field; if there were fewer than 20 drusen, focal hyperpigmentation was required to be present. Both eyes could be study eyes.

- visual acuity of $0.3 \operatorname{logMAR}$ units or better (70 letters or better on the ETDRS chart equivalent to Snellen $20 / 40$ ) in the eye selected to be study eye

Exclusion criteria:

- not explicitly stated

- Ocuvite (Bausch and Lomb, Berlin, Germany) lutein $12 \mathrm{mg}$, zeaxanthin $0.6 \mathrm{mg}$, vitamin E $15 \mathrm{mg}$, vitamin C $150 \mathrm{mg}$, zinc oxide $20 \mathrm{mg}$, copper $0.4 \mathrm{mg}$ (daily dose) one tablet twice daily

- 216 people randomised (304 eyes)

○ unknown number (unknown \%) people followed up (243 eyes) at 12 months

Comparator:

- Placebo (cellulose microcrystalline, lactose and magnesium stearate) (twice daily) - 217 people randomised (310 eyes)

○ unknown number (unknown \%) people followed up (250 eyes) at 12 months

Duration: Total study duration 3 years but high attrition after 12 months

Similarity between intervention and comparator: Quote: "The placebo consisted of cellulose, lactose, and magnesium stearate and was manufactured to be indistinguishable from the active preparation in size, color, smell, and taste."

Outcomes Primary:


CARMA 2013 (Continued)

- distance visual acuity

Secondary:

- retinal visual acuity

- morphological progression of AMD (grading of stereoscopic colour fundus photographs)

- macular pigment levels and serum levels of antioxidants

Follow-up: every 6 months for 3 years, but high attrition after 12 months

Eyes: mixture of one or two eyes per person (see above for details). Quote "Data will be aggregated to one result per participant-the sole result will stand for group 1 participants, and the mean of the two results will be applied to group 2 participants. " Analysis were then weighted by number of eyes.

Source of funding: Quote: "Supported by a grant from Bausch and Lomb, Dr. Mann Pharma, Berlin, Germany. The data set was managed and analyzed by the independent statistician (MRS) and his team. The senior corresponding author (UC) had full access to the data outputs. The funders had no access to the data, were not involved in the data analysis, and had no role in the construction of the manuscript, except in the approval of the final draft."

Declaration of interest: Quote: "The author(s) have no proprietary or commercial interest in any materials discussed in this article."

Date study conducted: June 2004 to April 2008

Trial registration number: ISRCTN94557601 (retrospectively registered)

\section{Risk of bias}

Bias Authors' judgement Support for judgement

Random sequence genera- Low risk tion (selection bias)

Quote: "Each participant enrolled in the CARMA Study is allocated a unique number, which determines treatment allocation according to the computerized randomization database."

Quote: "A block randomization design was used with stratification by center and by group status, and separate block randomised lists were provided to each site."

Allocation concealment Low risk
(selection bias)

Quote: "Each participant enrolled in the CARMA Study is allocated a unique number, which determines treatment allocation according to the computerized randomization database." and "This unique number exists on the identification label of each study preparation box. The masked study-preparation boxes are kept in the hospital pharmacy, and released in a sequential manner by the pharmacist on randomization of each participant, beginning with the first in the numerical series assigned to each clinical center. The participants are advised to take 1 tablet twice daily with a meal.The CARMA Study is strictly a double-masked clinical trial in that neither the CARMA participants nor the study staff, including the study investigator, are aware of the nature of study preparation allocated to the participants. To ensure masking, the study-preparation boxes are labelled with pre-assigned numbers at the site of manufacturing, and then shipped to both clinical centers for distribution. A single pharmacist involved with manufacturing of the study preparation holds the key to randomization of the CARMA supplements."

\begin{tabular}{|c|c|c|}
\hline $\begin{array}{l}\text { Blinding of participants } \\
\text { and personnel (perfor- } \\
\text { mance bias) } \\
\text { Visual acuity }\end{array}$ & Low risk & $\begin{array}{l}\text { Quote: "The study preparations (active and placebo) were packaged in identi- } \\
\text { cal containers that bore only the participant information and study label and } \\
\text { were indistinguishable in all respects from each other." and "Participants and } \\
\text { study staff were masked to treatment assignments" }\end{array}$ \\
\hline
\end{tabular}


CARMA 2013 (Continued)

Blinding of participants and personnel (perfor-

Low risk mance bias)

Progression AMD
Quote: "The study preparations (active and placebo) were packaged in identical containers that bore only the participant information and study label and were indistinguishable in all respects from each other." and "Participants and study staff were masked to treatment assignments"

\begin{tabular}{lll}
\hline $\begin{array}{l}\text { Blinding of outcome as- } \\
\text { sessment (detection bias) }\end{array}$ & Low risk & $\begin{array}{l}\text { Quote: "The study preparations (active and placebo) were packaged in identi- } \\
\text { Cal containers that bore only the participant information and study label and } \\
\text { Visual acuity }\end{array}$ \\
& $\begin{array}{l}\text { were indistinguishable in all respects from each other." and "Participants and } \\
\text { study staff were masked to treatment assignments" }\end{array}$
\end{tabular}

\begin{tabular}{lll}
\hline $\begin{array}{l}\text { Blinding of outcome as- } \\
\text { sessment (detection bias) } \\
\text { Progression AMD }\end{array}$ & Low risk & $\begin{array}{l}\text { Judgement comment: Fundus images graded by masked graders and all study } \\
\text { personnel masked to intervention allocation. }\end{array}$ \\
\hline $\begin{array}{l}\text { Incomplete outcome data } \\
\text { (attrition bias) } \\
\text { All outcomes }\end{array}$ & Unclear risk & $\begin{array}{l}\text { Judgement comment: High attrition and people with CNV and geographic at- } \\
\text { rophy excluded from analyses of visual acuity. }\end{array}$ \\
\hline $\begin{array}{l}\text { Selective reporting (re- } \\
\text { porting bias) }\end{array}$ & Low risk & $\begin{array}{l}\text { Judgement comment: Negative primary outcome eventually published (in } \\
\text { Ophthalmology) as letter, separately from the publication of the positive re- } \\
\text { sults in the secondary analysis, which appeared as a full paper in the same } \\
\text { journal. }\end{array}$ \\
\hline
\end{tabular}

\section{CARMIS 2011}

$\begin{array}{ll}\text { Methods } & \text { Parallel group RCT } \\ & \text { Method of allocation: random list, unclear how delivered } \\ & \text { Masking: participant - no; provider - no; outcome - unclear } \\ & \text { Losses to follow-up: } 18 \% \text { in supplement group, } 38 \% \text { in no supplement group }\end{array}$

Country: Italy
Number of people randomised: 145 (145 eyes)
Number (\%) of people followed up: 84 (58\%) (84 eyes)
Average age (range): 73 years (unknown)
Percentage women: $59 \%$
Ethnic group: unknown
Baseline visual acuity: average 82 letters (ETDRS chart)
Comorbidities affecting the eye: $30 \%$ of intervention group had had cataract surgery but none of the
control group

Percentage current smokers: $17 \%$

Inclusion criteria:

- age 55 to 80

- diagnosis of nonexudative (dry) age-related macular degeneration (AMD) in at least one eye having extensive (as measured by drusen area) intermediate $(\geq 63 \mathrm{~mm},<125 \mathrm{~mm}$ ) drusen; and at least one large ( $\geq 125 \mathrm{~mm}$ ) drusen or geographic atrophy not involving the center of the macula

- best-corrected visual acuity in the trial eye $\geq 20 / 32$ ( 0.2 logarithm of the minimum angle of resolution [logMAR]), 74 letters of Early Treatment Diabetic Retinopathy Study [ETDRS] chart)

- able to understand and comply with the requirements of the trial 
- no condition limiting view of the fundus (e.g. vitreous haemorrhage, cataracts, epiretinal membrane)

- available for a minimum trial duration of approximately 6 months

- agree to take only the nutritional supplement that is provided during this study

Exclusion criteria:

- ocular disease that causes irreversible reduction of visual acuity (amblyopia, uncontrolled glaucoma, anterior ischaemic optic neuropathy, clinically significant macular edema)

- lens opacity and score 4+ (Lens Opacity Classification System II)

- insufficient pupil dilation

- previous laser treatment of the posterior pole for any other reason

- macular changes not attributable to AMD

- carotenoids intolerance

- major chronic disease

- life expectation lower than 6 months

- withdrawal of informed consent

- enrolment in another clinical study with experimental product within the last 4 weeks or during the current study

Interventions

Intervention:

- vitamin C $180 \mathrm{mg}$, vitamin E $30 \mathrm{mg}$, zinc $22.5 \mathrm{mg}$, copper $1 \mathrm{mg}$, lutein $10 \mathrm{mg}$, zeaxanthin $1 \mathrm{mg}$ and astaxanthin $4 \mathrm{mg}$ (AZYR SIFI, Catania, Italy) (daily)

- 103 people randomised (103 eyes)

- $84(82 \%)$ people followed up (84 eyes)

Comparator:

- no dietary supplementation

- 42 people randomised (42 eyes)

- 26 (62\%) people followed up (26 eyes)

Duration: 24 months

Similarity between intervention and comparator: different, no placebo group

Outcomes

Reported in methods section of paper:

Primary:

- change in BCVA (the number of letters read on the logMAR chart)

Secondary:

- changes in macular function by CS using a Pelli-Robson chart (Clement Clarke International, Harlow Essex, UK) scored per lines

- changes in visual function via the Italian-validated version of the 25 -item NEI VFQ

Reported in results section:

- multi-focal electroretinograms (ERG) at 6 and 12 months

Follow-up: 6, 12, and 24 months

Eyes: One eye per person. Quote: "When patients fulfilled the inclusion criteria (Tab. I), the eye with the best VA was selected. When both eyes had the same VA, the right eye was chosen for final analysis."

\section{Notes}

\section{Source of funding: unknown}

Declaration of interest: Quote: "The authors report no proprietary interest or financial support." 
Trial registration number: unknown

\section{Risk of bias}

Bias Authors' judgement Support for judgement

Random sequence genera- Low risk tion (selection bias)

Allocation concealment Unclear risk
(selection bias)

Quote: "A permuted blocks allocation scheme was used to perform this random allocation"

Quote: "A 24-month prospective open-label randomised study... "

Quote: "The study coordinator allocated study numbers sequentially, as participants were enrolled. Participants were then randomly allocated to the treatment or no treatment group. A permuted blocks allocation scheme was used to perform this random allocation. The allocation list was stored at a remote site."

Quote: "Study drug was administered by an unmasked physician who had no other role in the study."

No mention was made of allocation ratios, but 103 people were recruited to treatment group and 42 to no treatment group

Blinding of participants High risk Quote: "A 24-month prospective open-label randomised study... "
and personnel (performance bias)

Visual acuity

Blinding of participants $\quad$ High risk Quote: "A 24-month prospective open-label randomised study... "
and personnel (perfor-
mance bias)
Progression AMD

\begin{tabular}{|c|c|c|}
\hline $\begin{array}{l}\text { Blinding of outcome as- } \\
\text { sessment (detection bias) } \\
\text { Visual acuity }\end{array}$ & High risk & $\begin{array}{l}\text { Quote: "A 24-month prospective open-label randomised study... " } \\
\text { Quote: "In order to allow for an unbiased assessment of VA and ancillary stud } \\
\text { measures, an independent physician was assigned the role of masked evalua- } \\
\text { tor." }\end{array}$ \\
\hline & & $\begin{array}{l}\text { However, as participants were not masked, this could have affected the mea- } \\
\text { surement of visual acuity. }\end{array}$ \\
\hline
\end{tabular}

\begin{tabular}{|c|c|c|}
\hline $\begin{array}{l}\text { Blinding of outcome as- } \\
\text { sessment (detection bias) } \\
\text { Progression AMD }\end{array}$ & Unclear risk & $\begin{array}{l}\text { Quote: "A 24-month prospective open-label randomised study... " } \\
\text { Quote: "In order to allow for an unbiased assessment of VA and ancillary study } \\
\text { measures, an independent physician was assigned the role of masked evalua- } \\
\text { tor." }\end{array}$ \\
\hline $\begin{array}{l}\text { Incomplete outcome data } \\
\text { (attrition bias) } \\
\text { All outcomes }\end{array}$ & High risk & $\begin{array}{l}\text { Quote: "Nineteen people in the group T-AMD, and } 16 \text { subjects from the group } \\
\text { NT-AMD, were excluded from final data analysis." This exclusion was uneven } \\
\text { between the } 2 \text { groups: } 19 / 103(18.4 \%) \text { and } 16 / 42 \text { ( } 38.1 \%) \text {, and also inconsis- } \\
\text { tent with the data in table III, page } 6 \text {. In table III, } 14 \text { people withdrew from the } \\
\text { carotenoids group and } 3 \text { from the control group; } 20 \text { people discontinued the } \\
\text { intervention in the carotenoids group and } 17 \text { in the control group. }\end{array}$ \\
\hline
\end{tabular}

Selective reporting (re- Unclear risk Unclear. Fundus examination but progression of AMD was not reported.
porting bias)


Method of allocation: coded tablets prepared by manufacturer

Masking: participant - yes; provider - yes; outcome - yes

Loss to follow-up: $13 \%$

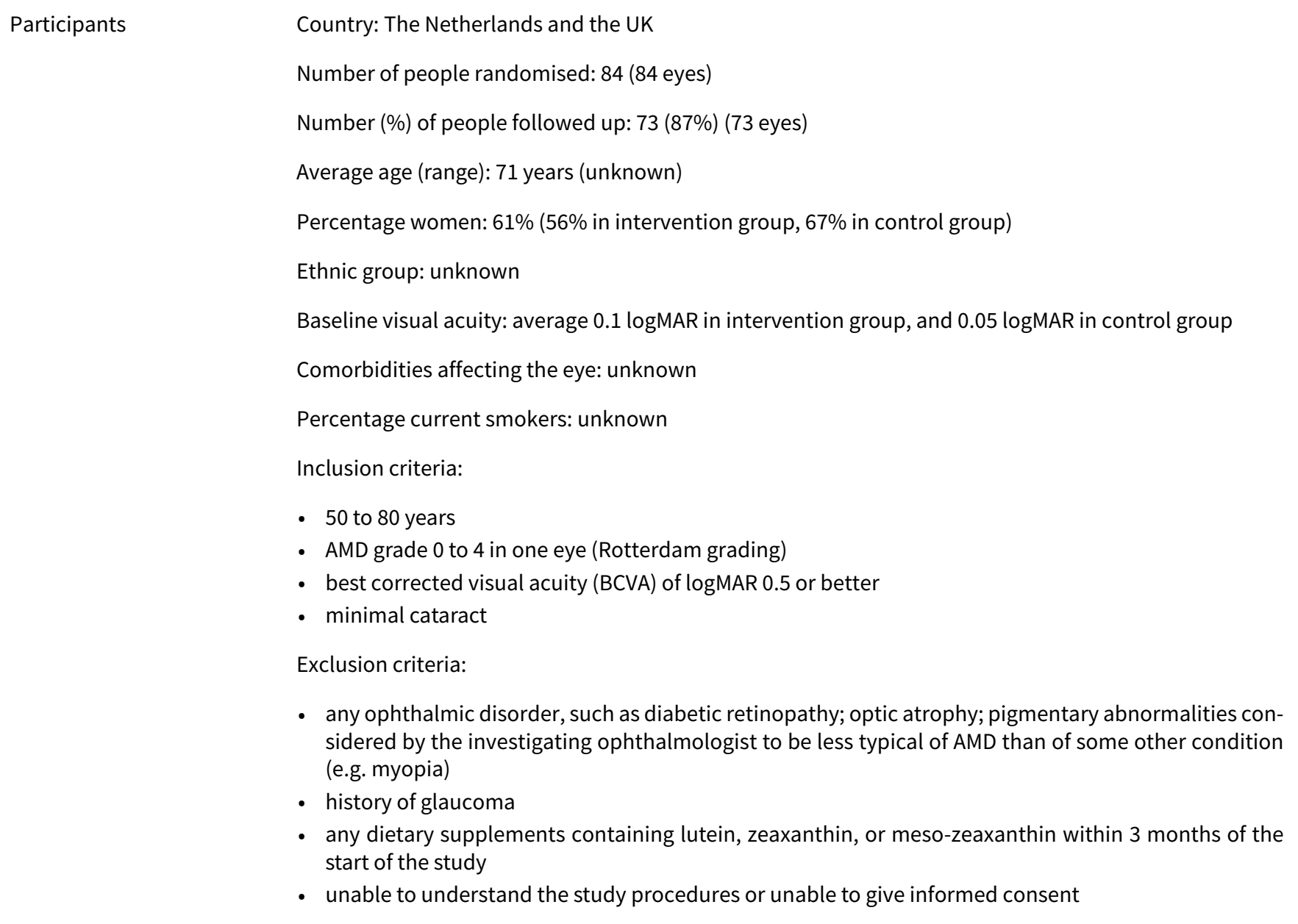

Interventions

Intervention:

- lutein $10 \mathrm{mg}$ (daily)

- 42 people randomised (42 eyes)

- $36(86 \%)$ people followed up (36 eyes)

Comparator:

- placebo soya bean oil (daily)

- 42 people randomised (42 eyes)

- 37 (88\%) people followed up (37 eyes)

Duration: 12 months

Similarity between intervention and comparator: Quote: "The [..] capsules and their packaging were completely indistinguishable" 
CLEAR 2013 (Continued)

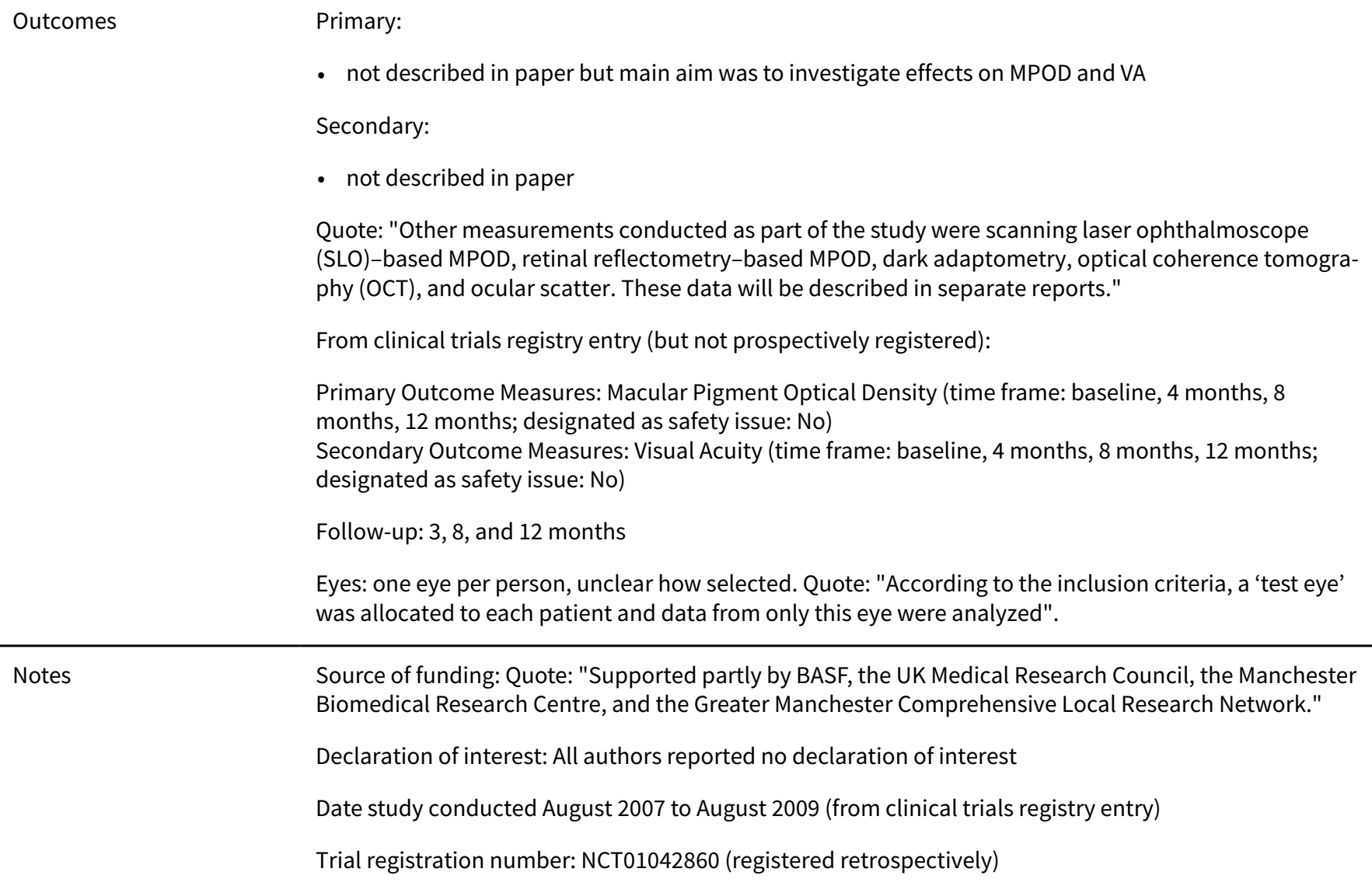

\section{Risk of bias}

\section{Bias}

\section{Authors' judgement Support for judgement}

Random sequence genera- Low risk tion (selection bias)

Quote: "A randomization code was generated by the sample manufacturer. Treatment numbers were allocated in ascending order using the next available consecutive number and capsules distributed accordingly."

Judgement comment: Unclear how code was generated, but we have assumed it was unpredictable.

\begin{tabular}{ll}
\hline $\begin{array}{l}\text { Allocation concealment } \quad \text { Low risk } \\
\text { (selection bias) }\end{array}$ & $\begin{array}{l}\text { Quote: "The P and L capsules and their packaging were completely indistin- } \\
\text { guishable. The code remained with the manufacturer until the end of the in- } \\
\text { tervention trial. The experimenters were unaware of which patients were as- } \\
\text { signed to which groups." }\end{array}$
\end{tabular}

$\begin{array}{ll}\begin{array}{l}\text { Blinding of participants } \\ \text { and personnel (perfor- }\end{array} & \text { Quote: "The P and L capsules and their packaging were completely indistin- } \\ \text { mance bias) } & \text { guishable. The code remained with the manufacturer until the end of the in- } \\ \text { Visual acuity } & \text { tervention trial. The experimenters were unaware of which patients were as- } \\ \text { signed to which groups" }\end{array}$

\begin{tabular}{ll}
\hline $\begin{array}{l}\text { Blinding of participants } \\
\text { and personnel (perfor- }\end{array}$ & Low risk \\
$\begin{array}{l}\text { mance bias) } \\
\text { Progression AMD }\end{array}$ & $\begin{array}{l}\text { guishable. The code remained with the manufacturer until the end of the in- } \\
\text { tervention trial. The experimenters were unaware of which patients were as- } \\
\text { signed to which groups" }\end{array}$
\end{tabular}

\begin{tabular}{|c|c|c|}
\hline $\begin{array}{l}\text { Blinding of outcome as- } \\
\text { sessment (detection bias) } \\
\text { Visual acuity }\end{array}$ & Low risk & $\begin{array}{l}\text { Quote: "The P and L capsules and their packaging were completely indistin- } \\
\text { guishable. The code remained with the manufacturer until the end of the in- }\end{array}$ \\
\hline
\end{tabular}


CLEAR 2013 (Continued)

tervention trial. The experimenters were unaware of which patients were assigned to which groups"

\begin{tabular}{|c|c|c|}
\hline $\begin{array}{l}\text { Blinding of outcome as- } \\
\text { sessment (detection bias) } \\
\text { Progression AMD }\end{array}$ & Low risk & $\begin{array}{l}\text { Quote: "The } P \text { and } L \text { capsules and their packaging were completely indistin- } \\
\text { guishable. The code remained with the manufacturer until the end of the in- } \\
\text { tervention trial. The experimenters were unaware of which patients were as- } \\
\text { signed to which groups" }\end{array}$ \\
\hline
\end{tabular}

$\begin{array}{ll}\begin{array}{l}\text { Incomplete outcome data } \\ \text { (attrition bias) }\end{array} & \text { Low risk }\end{array}$

All outcomes

Judgement comment: Follow-up high and similar between lutein (86\%) and

Selective reporting (re- Low risk Judgement comment: Outcomes in trials registry entry were reported.
porting bias)

France 1998

\begin{tabular}{ll}
\hline Methods & Parallel group RCT \\
Method of allocation: unknown \\
Masking: participant - unknown; provider - unknown; outcome - unknown \\
Loss to follow-up: unknown \\
\hline Country: France \\
Number of people randomised: 170 (170 eyes) \\
Number (\%) of people followed up: unknown \\
Average age (range): unknown \\
Percengage female: unknown \\
Ethnic group: unknown \\
Baseline visual acuity: unknown \\
Comorbidities affecting the eye: unknown \\
Percentage current smokers: unknown \\
Inclusion criteria: \\
- neovascular AMD in one eye and drusen in the other
\end{tabular}

Interventions Intervention:

- zinc supplementation (30 mg/day)

- unknown number people randomised (eyes unknown)

- unknown number people followed up (eyes unknown)

Comparator:

- not known, but study described as "double blind"

- unknown number people randomised (eyes unknown)

- unknown number people followed up (eyes unknown)

Duration: unknown 
France 1998 (Continued)

Similarity between intervention and comparator: unknown

\begin{tabular}{ll} 
Outcomes & Primary: unknown \\
Secondary: unknown \\
Follow-up: unknown \\
Eyes: one eye per person \\
\hline Trial is unpublished. \\
"Following an initial analysis, the study was terminated due to lack of effect, combined with high rate \\
of intolerance to study medication." [Personal communication from investigator.] \\
Source of funding: unknown \\
Declaration of interest: unknown \\
Date study conducted: unknown \\
Trial registration number: unknown
\end{tabular}

\section{Risk of bias}

\begin{tabular}{lll} 
Bias & Authors' judgement & Support for judgement \\
\hline $\begin{array}{l}\text { Random sequence genera- } \\
\text { tion (selection bias) }\end{array}$ & Unclear risk & No information available \\
\hline $\begin{array}{l}\text { Allocation concealment } \\
\text { (selection bias) }\end{array}$ & Unclear risk & No information available \\
\hline $\begin{array}{l}\text { Blinding of participants } \\
\text { and personnel (perfor- } \\
\text { mance bias) } \\
\text { Visual acuity }\end{array}$ & Unclear risk & No information available \\
\hline
\end{tabular}

Blinding of participants $\quad$ Unclear risk $\quad$ No information available
and personnel (perfor-
mance bias)
Progression AMD

\begin{tabular}{lll}
\hline Blinding of outcome as- & Unclear risk & No information available \\
sessment (detection bias) & \\
Visual acuity & \\
\hline
\end{tabular}

\begin{tabular}{lll}
\hline Blinding of outcome as- & Unclear risk & No information available \\
sessment (detection bias)
\end{tabular}

Progression AMD

\begin{tabular}{ll}
\hline Incomplete outcome data & Unclear risk \\
(attrition bias)
\end{tabular}

All outcomes

\begin{tabular}{lll}
\hline $\begin{array}{l}\text { Selective reporting (re- } \\
\text { porting bias) }\end{array}$ & Unclear risk & No information available
\end{tabular}


Holz 1993

\begin{tabular}{ll}
\hline Methods & Parallel group RCT \\
Method of allocation: not known \\
Masking: participant - yes; provider - yes; outcome - yes \\
Losses to follow-up: not known \\
\hline Country: UK \\
Number of people randomised: 58 (eyes not known) \\
Number (\%) of people followed up: not known \\
Average age (range): 68 years (55 to 82) \\
Percentage women: not known \\
Ethnic group: not known \\
Baseline visual acuity: not known \\
Comorbidities affecting the eye: not known \\
Percentage current smokers: not known
\end{tabular}

Interventions

Intervention:

- zinc sulfate $200 \mathrm{mg}$ (daily) 2 x $100 \mathrm{mg}$ tablet

- 28 people randomised (eyes not known)

- unknown number people followed up (eyes not known)

Comparator:

- placebo (lactose capsule) $2 \times 1$ tablet daily

- 30 people randomised (eyes not known)

- unknown number people followed up (eyes not known)

Duration: 12 to 24 months

Similarity between intervention and comparator: not known

Primary: not known
Secondary: not known
Quote: "Parameters tested included visual acuity, peripheral and macular colour-contrast-sensitivity;
pattern ERG and dark adaptation. Stereo fundus photographs and fluorescein angiograms were ana-
lyzed by investigators in a masked fashion using a standardized grading scheme"
Follow-up: 12 to 24 months
Eyes: unclear
Data available from abstract only:
Source of funding: Gertrud-Kusen-Stiftung, Hamburg, grant \# Ho92/93-01-2
Declaration of interest: not known
Date study conducted: not known
Trial registration number: not known


Holz 1993 (Continued)

Risk of bias

\begin{tabular}{|c|c|c|}
\hline Bias & Authors' judgement & Support for judgement \\
\hline $\begin{array}{l}\text { Random sequence genera- } \\
\text { tion (selection bias) }\end{array}$ & Unclear risk & "randomised double-blind study" \\
\hline $\begin{array}{l}\text { Allocation concealment } \\
\text { (selection bias) }\end{array}$ & Unclear risk & Not reported \\
\hline $\begin{array}{l}\text { Blinding of participants } \\
\text { and personnel (perfor- } \\
\text { mance bias) } \\
\text { Visual acuity }\end{array}$ & Unclear risk & "randomised double-blind study" \\
\hline $\begin{array}{l}\text { Blinding of participants } \\
\text { and personnel (perfor- } \\
\text { mance bias) } \\
\text { Progression AMD }\end{array}$ & Unclear risk & "randomised double-blind study" \\
\hline $\begin{array}{l}\text { Blinding of outcome as- } \\
\text { sessment (detection bias) } \\
\text { Visual acuity }\end{array}$ & Unclear risk & "randomised double-blind study" \\
\hline $\begin{array}{l}\text { Blinding of outcome as- } \\
\text { sessment (detection bias) } \\
\text { Progression AMD }\end{array}$ & Low risk & $\begin{array}{l}\text { "randomised double-blind study" } \\
\text { "Stereo fundus photographs and fluorescein angiograms were analyzed by in- } \\
\text { vestigators in a masked fashion using a standardized grading scheme" }\end{array}$ \\
\hline $\begin{array}{l}\text { Incomplete outcome data } \\
\text { (attrition bias) } \\
\text { All outcomes }\end{array}$ & Unclear risk & Not reported \\
\hline $\begin{array}{l}\text { Selective reporting (re- } \\
\text { porting bias) }\end{array}$ & High risk & $\begin{array}{l}\text { For visual acuity, trial report states that outcome was analysed but only re- } \\
\text { ports that result was not significant }\end{array}$ \\
\hline
\end{tabular}

\section{Kaiser 1995}

Methods

Parallel group RCT

Method of allocation: sponsor prepared coded tablets

Masking: participant - yes; provider - yes; outcome - yes

Losses to follow-up: none

Country: Switzerland
Number of people randomised: 20 (20 eyes)
Number (\%) of people followed up: 20 (20 eyes)
Average age (range): 73 years (50 to unknown)
Percentage women: $74 \%$
Ethnic group: not known
Baseline visual acuity: not known


Percentage current smokers: not known

Inclusion criteria:

- people with non serous AMD. All participants had regional atrophy of the pigment epithelium. Corrected visual acuity was between $20 / 100$ and 20/25 with distance correction of less than 4 dioptres.

Exclusion criteria:

- people with diabetes mellitus, endocrine problems, cardiac dysrhythmia, cardial infarction or hypotension, other ocular disorders

- Visaline (Novopharma Cham, Switzerland). Each tablet contains $1.5 \mathrm{mg}$ buphenine $\mathrm{HCl}, 10 \mathrm{mg}$ beta-carotene, $10 \mathrm{mg}$ tocopherol acetate and $50 \mathrm{mg}$ ascorbic acid. Participants took 2 tablets in the morning and at night, daily, except for Saturdays and Sundays.

- 9 people randomised (9 eyes)

- $9(100 \%)$ people followed up (9 eyes)

Comparator:

- placebo resembling active treatment prepared by sponsor

- 11 people randomised (11 eyes)

- $11(100 \%)$ people followed up (11 eyes)

Duration: 6 months

Similarity between intervention and comparator: not known

Outcomes

Primary: not specified

Secondary: not specified

Outcomes reported:

- distance and near visual acuity

- intraocular pressure

- visual fields

- lens opacity

- retinal visual acuity

- colour vision

- contrast sensitivity

Follow-up: 3 and 6 months

Eyes: Only 1 eye per person was evaluated. In cases of bilateral AMD, the eye with better visual acuity was selected

$\begin{array}{ll}\text { Notes } & \text { Source of funding:not known } \\ & \text { Declaration of interest: not known } \\ & \text { Date study conducted: not known } \\ & \text { Trial registration number: not known }\end{array}$

\section{Risk of bias}


Kaiser 1995 (Continued)

Random sequence genera- Low risk Sequence generation not described in the report but through contact with intion (selection bias) vestigator
Quote: "The allocation schedule was generated by the company and treatment schedule was concealed from people enrolling patients."

Allocation concealment not described in the report but through contact with investigator

Quote: "The allocation schedule was generated by the company and treatment schedule was concealed from people enrolling patients."

\begin{tabular}{ll}
\hline $\begin{array}{l}\text { Blinding of participants } \\
\text { and personnel (perfor- }\end{array}$ & Low risk \\
$\begin{array}{l}\text { mance bias) } \\
\text { Visual acuity }\end{array}$ & $\begin{array}{l}\text { Study was placebo-controlled. Placebo not described in the report but inves- } \\
\text { tigator reported that: "The placebo was also prepared by the company and } \\
\text { tablets resembled the active treatment." }\end{array}$ \\
\end{tabular}

$\begin{array}{ll}\begin{array}{l}\text { Blinding of participants } \\ \text { and personnel (perfor- }\end{array} & \text { Low risk } \\ \begin{array}{l}\text { mance bias) } \\ \text { Progression AMD }\end{array} & \begin{array}{l}\text { Study was placebo-controlled. Placebo not described in the report but inves- } \\ \text { tigator reported that: "The placebo was also prepared by the company and } \\ \text { tablets resembled the active treatment." }\end{array}\end{array}$

\begin{tabular}{|c|c|c|}
\hline $\begin{array}{l}\text { Blinding of outcome as- } \\
\text { sessment (detection bias) } \\
\text { Visual acuity }\end{array}$ & Low risk & $\begin{array}{l}\text { Study was placebo-controlled. Placebo not described in the report but inves- } \\
\text { tigator reported that: "The placebo was also prepared by the company and } \\
\text { tablets resembled the active treatment." }\end{array}$ \\
\hline $\begin{array}{l}\text { Blinding of outcome as- } \\
\text { sessment (detection bias) } \\
\text { Progression AMD }\end{array}$ & Low risk & $\begin{array}{l}\text { Study was placebo-controlled. Placebo not described in the report but inves- } \\
\text { tigator reported that: "The placebo was also prepared by the company and } \\
\text { tablets resembled the active treatment." }\end{array}$ \\
\hline $\begin{array}{l}\text { Incomplete outcome data } \\
\text { (attrition bias) } \\
\text { All outcomes }\end{array}$ & Low risk & 20 participants enrolled and 20 followed up \\
\hline
\end{tabular}

Selective reporting (re- Unclear risk Difficult to assess with the information available
porting bias)

\section{LISA 2011}

\begin{tabular}{ll}
\hline Methods & Parallel group RCT \\
& Method of allocation: 2:1 intervention:control \\
& Masking: participant - yes; provider - yes; outcome - yes \\
Losses to follow-up: unclear
\end{tabular}

Country: Austria
Number of people randomised: 126 (126 eyes)
Number (\%) of people followed up: $116(92 \%)$ using LOCF (116 eyes)
Average age (range): 72 years (50 to 90)
Percentage women: $57 \%$
Ethnic group: not known
Baseline visual acuity: $83.9 \%$ (visual acuity reported as a percentage)


LISA 2011 (Continued)

Comorbidities affecting the eye: not known

Percentage current smokers: not known

Inclusion criteria:

- people in categories 2, 3, or 4, according to the AREDS grading scheme

- aged 50 to 90 years

- clear nonlenticular ocular media

- visual acuity $>0.4$

Exclusion criteria:

- primary retinal pigment epithelium atrophy $>125 \mu \mathrm{m}$

- moderate or severe nonproliferative diabetic retinopathy, proliferative diabetic retinopathy

- participation in a clinical trial in the 3 weeks preceding the study

- ocular surgery within the last 6 months

- history of treatment with photosensitising drugs

Interventions

Intervention:

- lutein (Lutamax DUO; Pharmaselect, Vienna, Austria). The dosage in months 1 to 3 was $20 \mathrm{mg}$ once daily, and in months 4 to 6 was $10 \mathrm{mg}$ once daily

- 84 people randomised (84 eyes)

- unknown number people followed up (eyes unknown)

Comparator:

- placebo

- 42 people randomised (42 eyes)

○ unknown number people followed up (eyes unknown)

Duration: 6 months

Similarity between intervention and comparator: unclear

Outcomes

Primary: not known

Secondary: not known

Outcomes reported in paper:

- macular pigment optical density

- mean differential light threshold

- distance visual acuity (ETDRS chart)

- mean arterial pressure

- pulse rate

- intraocular pressure

From clinical trials.gov, but retrospectively registered

Primary Outcome Measures: Macular pigment optical density (MPOD) as measured with optical reflectometry (time frame: 5 minutes; designated as safety issue: No)

Secondary Outcome Measures: visual acuity using ETDRS charts (time frame: 15 minutes; designated as safety issue: No)

Central visual field defects assessed with scanning laser scotometry (time frame: 30 minutes; designated as safety issue: No)

Changes in fundus appearance as documented with fundus photos (time Frame: 5 minutes; designated as safety issue: No)

Determination of an increased systemic antioxidative state in plasma and low density lipoprotein and Ppasma lutein concentrations (time frame: 5 minutes; designated as safety issue: No) 
Eyes: Quote: "In each subject only one eye was chosen for inclusion. If both eyes were eligible, one eye was selected randomly."

Notes

Source of funding: Quote: "Supported by Pharmaselect, Vienna, Austria"

Declaration of interest: All authors reported none

Date study conducted: November 2006 to May 2011 (from clinicaltrials.gov)

Trial registration number: NCT00879671 (registered retrospectively)

\section{Risk of bias}

\begin{tabular}{lll}
\hline Bias & Authors' judgement & Support for judgement \\
\hline $\begin{array}{ll}\text { Random sequence genera- } \\
\text { tion (selection bias) }\end{array}$ & Unclear risk & $\begin{array}{l}\text { "The randomization of lutein (Lutamax DUO; Pharmaselect, Vienna, Austria) } \\
\text { versus placebo was 2:1, resulting in a total of 84 patients in the lutein group } \\
\text { and 42 patients in the placebo group." } \\
\text { Allocation sequence generation not described }\end{array}$ \\
\end{tabular}

Allocation concealment $\quad$ Unclear risk No description of allocation concealment. However, states 'double masked'
(selection bias)
(selection bias)

\begin{tabular}{|c|c|c|}
\hline $\begin{array}{l}\text { Blinding of participants } \\
\text { and personnel (perfor- }\end{array}$ & Unclear risk & $\begin{array}{l}\text { "All subjects were asked to bring their study medication to all visits, to allov } \\
\text { compliance testing by tablet counting." }\end{array}$ \\
\hline Visual acuity & & $\begin{array}{l}\text { No description of placebo. Potential for unmasking as to intervention re- } \\
\text { ceived. }\end{array}$ \\
\hline & & $\begin{array}{l}\text { No specific information provided as to the blinding of outcome assessors } \\
\text { (grading of fundus images, assessment of MPOD or visual function). }\end{array}$ \\
\hline
\end{tabular}

\begin{tabular}{|c|c|c|}
\hline Progression AMD & & $\begin{array}{l}\text { No description of placebo. Potential for unmasking as to intervention re- } \\
\text { ceived. }\end{array}$ \\
\hline & & $\begin{array}{l}\text { No specific information provided as to the blinding of outcome assessors } \\
\text { (grading of fundus images, assessment of MPOD or visual function) }\end{array}$ \\
\hline
\end{tabular}

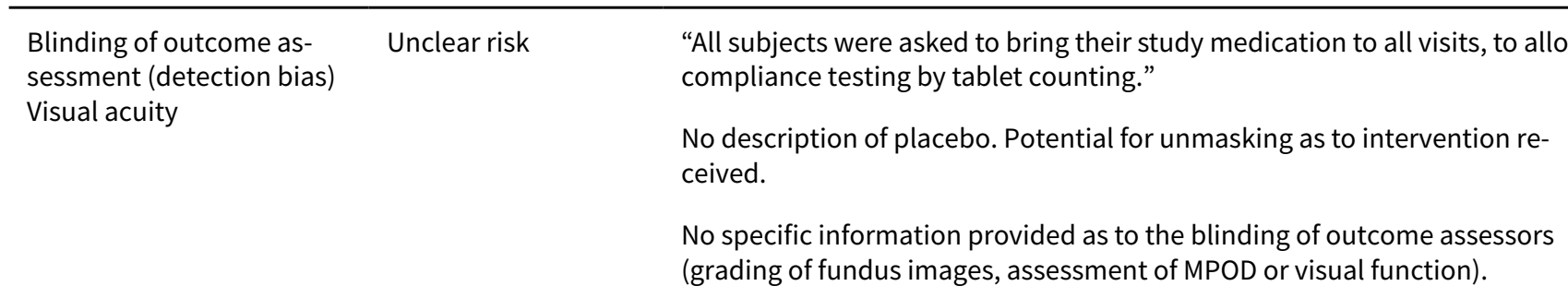

Blinding of outcome as- Unclear risk sessment (detection bias) Progression AMD

\begin{abstract}
"All subjects were asked to bring their study medication to all visits, to allow compliance testing by tablet counting."

No description of placebo. Potential for unmasking as to intervention received.

No specific information provided as to the blinding of outcome assessors (grading of fundus images, assessment of MPOD or visual function)
\end{abstract}


LISA 2011 (Continued)

Incomplete outcome data Unclear risk (attrition bias)

All outcomes
10 people were not included in the analysis, but not clear to which group these people were randomised.

In addition, 10/84 (11.9\%) people in the lutein group were lost to follow-up. In two people, the withdrawal was due to serious adverse events. One participant had a myocardial infarction, and the other participant developed CNV in the study eye. 6/42 (14.3\%) people in the placebo group were lost to follow-up. One person developed CNV, which was again classified as a serious adverse event. In participants who were lost to follow-up, the last observation was carried forward.

Selective reporting (re- Unclear risk Difficult to assess with the information available.

porting bias)

\section{Ma 2012}

\section{Methods}

Parallel group RCT

Method of allocation: not described

Masking: participant - yes; provider - yes; outcome - yes

Loss to follow-up: unclearly reported but could be $1 / 108$

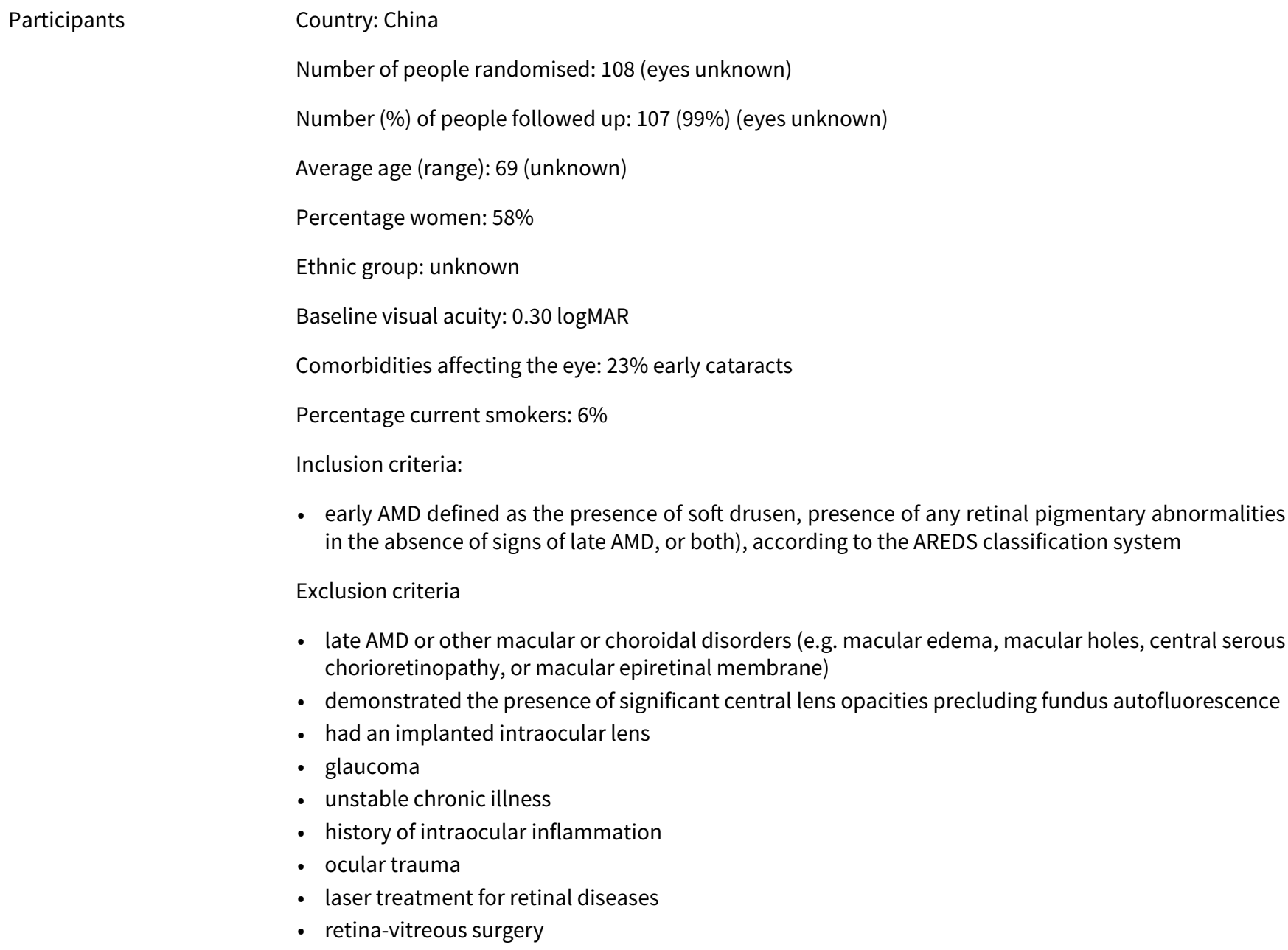

- early AMD defined as the presence of soft drusen, presence of any retinal pigmentary abnormalities in the absence of signs of late AMD, or both), according to the AREDS classification system

Exclusion criteria

- late AMD or other macular or choroidal disorders (e.g. macular edema, macular holes, central serous chorioretinopathy, or macular epiretinal membrane)

- demonstrated the presence of significant central lens opacities precluding fundus autofluorescence

- had an implanted intraocular lens

- glaucoma

- unstable chronic illness

- history of intraocular inflammation

- ocular trauma

- laser treatment for retinal diseases

- retina-vitreous surgery 
Ma 2012 (Continued)

- photodynamic therapy

- currently taking medications affecting macular function (e.g., chloroquine or oxazepam)

- consumed dietary supplements containing vitamins or carotenoids within the 6 months before enrolment

Interventions

Intervention:

- lutein $10 \mathrm{mg}$ or lutein $20 \mathrm{mg}$ or lutein $10 \mathrm{mg}$ and zeaxanthin $10 \mathrm{mg}$ (3 groups) (daily)

- 80 people randomised (eyes unknown)

- 79 (99\%) people followed up (eyes unknown)

Comparator:

- placebo (daily)

- 27 people randomised (eyes unknown)

- $27(100 \%)$ people followed up (eyes unknown)

Duration: 12 months

Similarity between intervention and comparator: unclear, placebo was not described

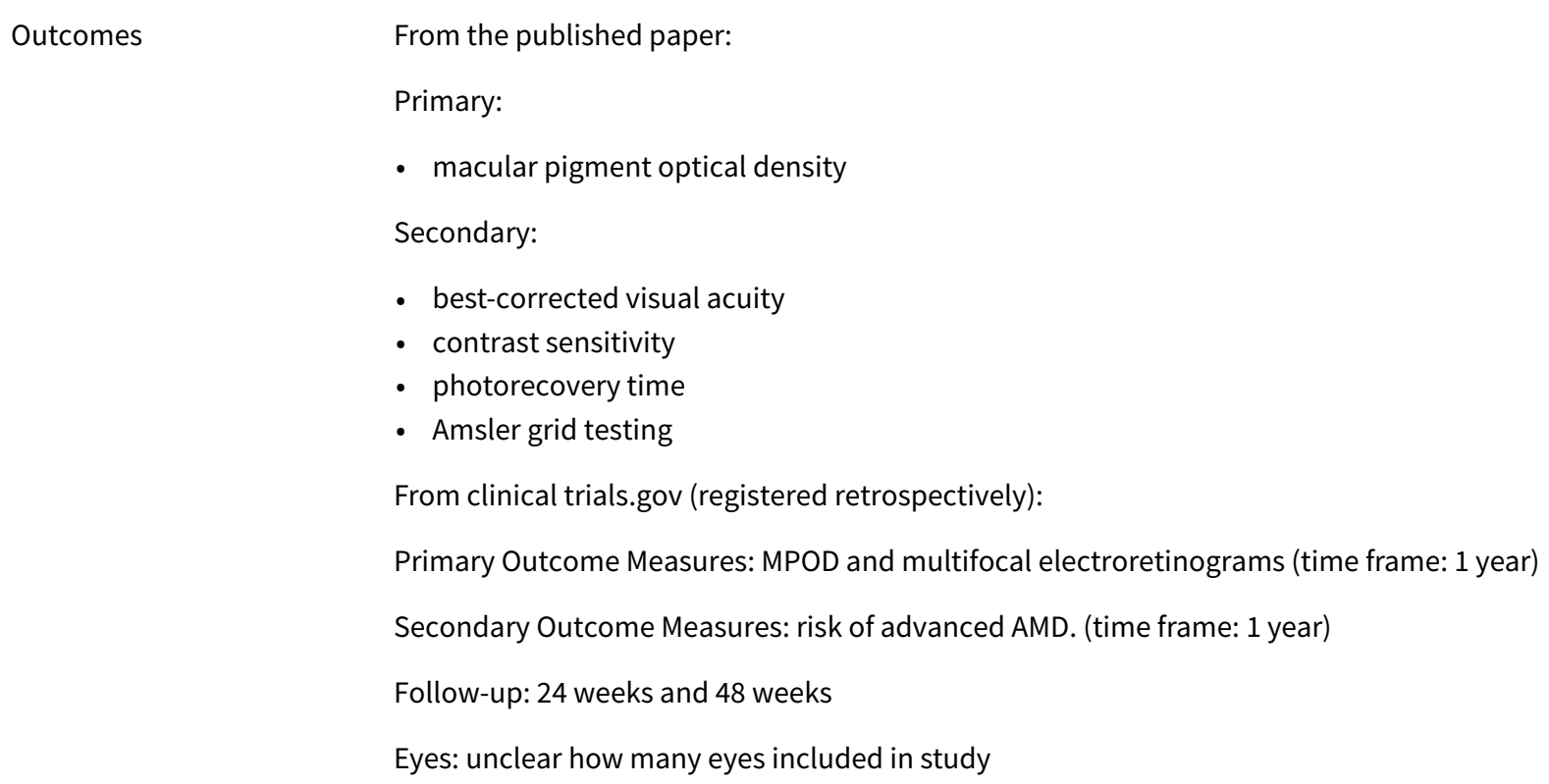

From clinical trials.gov (registered retrospectively):

Primary Outcome Measures: MPOD and multifocal electroretinograms (time frame: 1 year)

Secondary Outcome Measures: risk of advanced AMD. (time frame: 1 year)

Follow-up: 24 weeks and 48 weeks

Eyes: unclear how many eyes included in study

Notes

Source of funding: Quote: "Supported by the National Natural Science Foundation of China (grant no.: NSFC-30872113), Beijing, China."

Declaration of interest: Quote: "The author(s) have no proprietary or commercial interest in any materials discussed in this article."

Date study conducted: September 2009 to April 2012

Trial registration number: NCT01048476 (registered retrospectively) and NCT10528605 (registered retrospectively)

\section{Risk of bias}

\begin{tabular}{lll}
\hline Bias & Authors' judgement & Support for judgement \\
\hline $\begin{array}{l}\text { Random sequence genera- } \\
\text { tion (selection bias) }\end{array}$ & Low risk & $\begin{array}{l}\text { Quote: "The randomization sequence with stratification by baseline macular } \\
\text { pigment optical density (MPOD) was computer generated, using a permuted } \\
\text { block design with block size of 8." }\end{array}$ \\
\hline
\end{tabular}


Ma 2012 (Continued)

$\begin{array}{ll}\begin{array}{l}\text { Allocation concealment } \\ \text { (selection bias) }\end{array} & \text { Quote: "All participants, the study investigators, and data analysts were } \\ \text { masked to treatment assignment." }\end{array}$
(selection bias)

Blinding of participants Low risk and personnel (performance bias)

Visual acuity

Quote: "All participants, the study investigators, and data analysts were masked to treatment assignment."

Quote: "To protect the blinding, the different capsules were indistinguishable by size, weight, or color." and personnel (perfor- masked to treatment assignment."

mance bias)

Progression AMD
Quote: "To protect the blinding, the different capsules were indistinguishable by size, weight, or color."

\begin{tabular}{|c|c|c|}
\hline $\begin{array}{l}\text { Blinding of outcome as- } \\
\text { sessment (detection bias) }\end{array}$ & Low risk & $\begin{array}{l}\text { Quote: "All participants, the study investigators, and data analysts were } \\
\text { masked to treatment assignment." }\end{array}$ \\
\hline
\end{tabular}

visual acuity

Quote: "To protect the blinding, the different capsules were indistinguishable by size, weight, or color."

Blinding of outcome as- $\quad$ Low risk
sessment (detection bias)

Progression AMD Quote: "All participants, the study investigators, and data analysts were
masked to treatment assignment."

Quote: "To protect the blinding, the different capsules were indistinguishable by size, weight, or color."

\begin{tabular}{ll}
\hline $\begin{array}{l}\text { Incomplete outcome data } \\
\text { (attrition bias) }\end{array}$ & Low risk \\
All outcomes & $\begin{array}{l}\text { Judgement comment: Only 1/108 participants apparently discontinued treat- } \\
\text { ment and was excluded from the analysis. All other participants were followed } \\
\text { up. }\end{array}$ \\
\hline
\end{tabular}

Selective reporting (re- High risk
porting bias)

Methods
Parallel group RCT
Method of allocation: computer-generated table of random numbers
Masking: participant - yes; provider - yes; outcome - yes
Losses to follow-up: 23 (10 treatment, 13 placebo)

Country: USA
Number of people randomised: 174 (eyes unknown)
Number (\%) of people followed up: 151 (87\%) (258 eyes)
Average age (range): unknown (42 to 89 years)
Percentage women: $65 \%$
Ethnic group: unknown
Baseline visual acuity: unknown


Percentage current smokers: unknown

Inclusion criteria:

- macular degeneration: clinically visible drusen with varying degrees of pigmentary change with visual acuity in 1 eye of 20/80 or better

Exclusion criteria:

- cataract reducing vision more than 1 line

- other known serious eye disease; diabetes mellitus

- other known systemic or metabolic disease or congenital condition, which might interfere with results

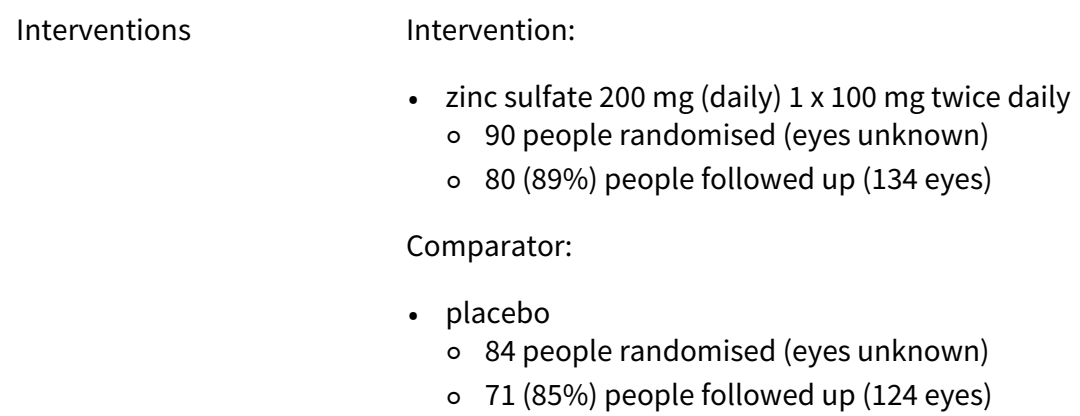

Duration: 1 to 2 years

Similarity between intervention and comparator: Quote: "Identical appearing tablets containing lactose and fructose served as the placebo." Analyses were also stratified according to number of eyes per person.

Secondary: not specified

Outcomes reported in paper:

- Pinhole corrected visual acuity using ETDRS charts

- changes in visible pigment, drusen or atrophy from grading of macular photographs

- adverse effects of zinc including copper deficiency anaemia

Follow-up: 6, 12, 18, and 24 months

Eyes: Some people had one eye enrolled in the study and some had two eyes: "To analyze the results of two eyes of the same participant, the individual eye data were averaged and that value was used."

Declaration of interest: unknown

Date study conducted: unknown

Trial registration number: unknown

\section{Risk of bias}

Bias Authors' judgement Support for judgement


Newsome 1988 (Continued)

Random sequence genera- Low risk Quote: "Subjects were randomly assigned [...] using a computer-generated tation (selection bias)

ble of random numbers."

Allocation concealment Low risk

(selection bias)

Quote: "Subjects were randomly assigned to receive either zinc or placebo [...]. The individual who recorded the zinc-treated or placebo group assignment maintained personal control over the randomization sheet and participated in no other phases of the study. This individual also handed the study tablets to subjects. All other personnel were masked to the study."

Blinding of participants Low risk and personnel (performance bias)

Visual acuity
Quote: "All other personnel were masked to the study."

Quote: "Zinc sulfate was prepared as white tablets containing $100 \mathrm{mg}$ of United States Pharmacopeia-graded material. Identical-appearing tablets containing lactose and fructose served as the placebo. All tablets were bottled in identical containers."

\begin{tabular}{|c|c|c|}
\hline $\begin{array}{l}\text { Blinding of participants } \\
\text { and personnel (perfor- } \\
\text { mance bias) } \\
\text { Progression AMD }\end{array}$ & Low risk & $\begin{array}{l}\text { Quote: "All other personnel were masked to the study." } \\
\text { Quote: "Zinc sulfate was prepared as white tablets containing } 100 \text { mg of Unit- } \\
\text { ed States Pharmacopeia-graded material. Identical-appearing tablets contain- } \\
\text { ing lactose and fructose served as the placebo. All tablets were bottled in iden- } \\
\text { tical containers." }\end{array}$ \\
\hline
\end{tabular}

\begin{tabular}{|c|c|c|}
\hline $\begin{array}{l}\text { Blinding of outcome as- } \\
\text { sessment (detection bias) }\end{array}$ & Low risk & $\begin{array}{l}\text { Quote: "All visual acuities were determined by one of two masked observers } \\
\text { throughout the study" }\end{array}$ \\
\hline
\end{tabular}
Visual acuity

Blinding of outcome as-
sessment (detection bias) $\quad$ Low risk Quote: "Two independent observers masked as to patient identity,..."

Progression AMD

Incomplete outcome data Low risk
(attrition bias)

(attrition bias)

"A total of 90 subjects [...] were randomised to zinc and 84 subjects [...] to placebo. [....... . A total of ten subjects were lost to follow-up from the zincAll outcomes treated group and 13 subjects from the placebo group. [...] This figure represents dropout rates of $11.1 \%$ and $15.4 \%$ from the zinc-treated and placebo groups, respectively."

Reasons for loss to follow-up zinc/placebo

- Stopped taking pills $5 / 6$

- Started taking zinc $1 / 2$

- Gastrointestinal symptoms $1 / 0$

- Died 2/1

- Poor compliance 0/1

- Developed diabetes mellitus 0/1

- Unavailable $1 / 2$

Selective reporting (re- High risk porting bias)

"Other ocular functions assessed included ocular vision and photostress recover tests (These observations are being analysed and will be reported later)"

Methods
Parallel group RCT
Method of allocation: random allocation using a 50\% likelihood scheme
Masking: participant - yes; provider - yes; outcome - yes




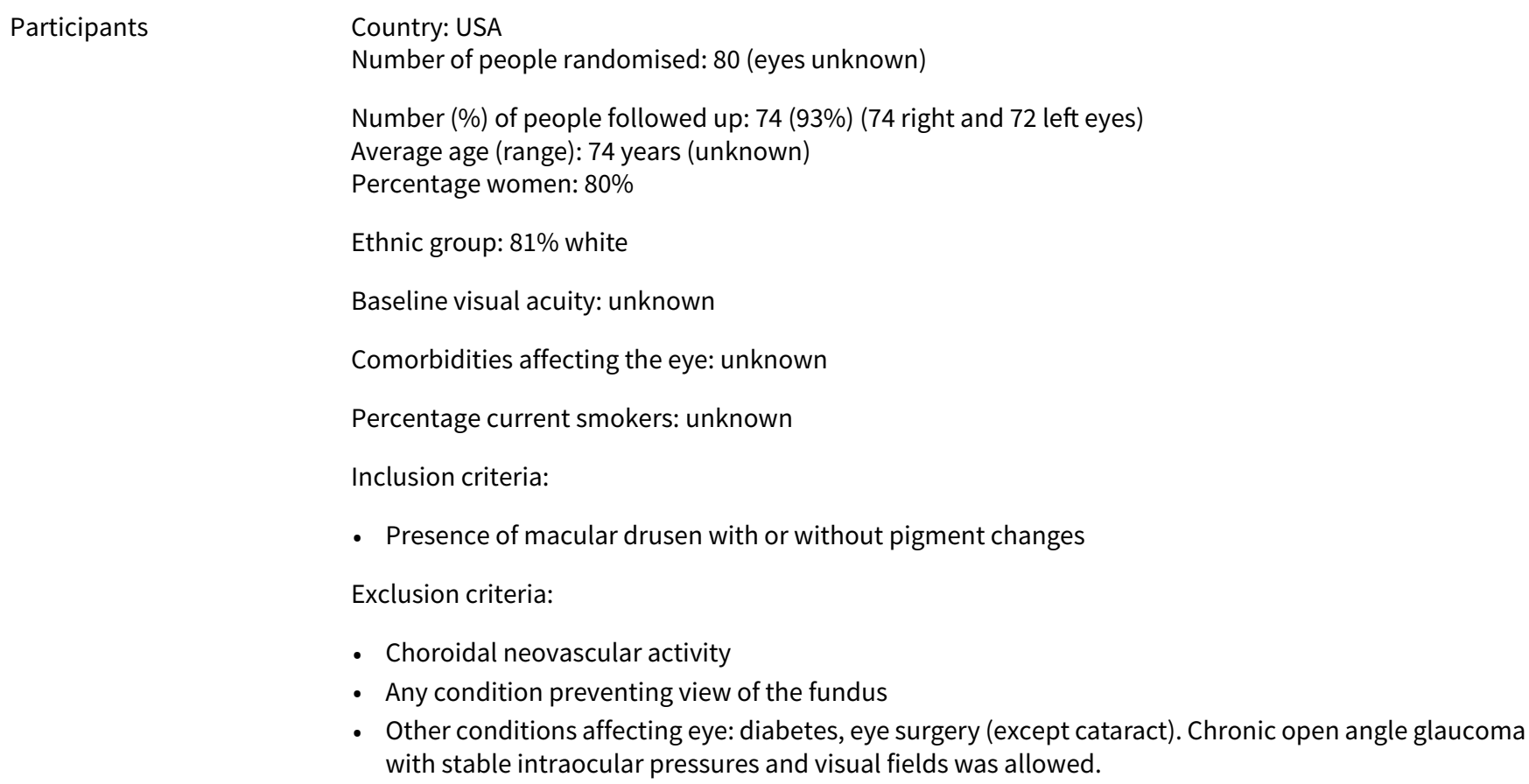

- Presence of macular drusen with or without pigment changes

Exclusion criteria:

- Choroidal neovascular activity

- Any condition preventing view of the fundus

- Other conditions affecting eye: diabetes, eye surgery (except cataract). Chronic open angle glaucoma with stable intraocular pressures and visual fields was allowed.

Both ZMC and placebo groups enrolled 40 participants, with best-corrected visual acuity $20 / 25$ to 20/70, macular drusen, and pigment changes

- zinc-monocysteine $50 \mathrm{mg}$ (daily $1 \times 25 \mathrm{mg}$ twice daily

- 40 people randomised (eyes unknown)

- 37 (100\%) people followed up (37 right and 25 left eyes)

Comparator:

- placebo
- 40 people randomised (eyes unknown)
- 37 (100\%) people followed up (37 right and 37 left eyes)

Duration: 6 months

Similarity between intervention and comparator: unknown

\begin{tabular}{ll}
\hline Outcomes & Primary: \\
- change in acuity \\
- change in contrast sensitivity \\
Secondary: not specified \\
Follow-up: 6 months \\
Eyes: analysed right and left eyes separately \\
Source of funding: "This study was supported in part by the Retinal Disease Research Foundation, Inc. \\
DN co-owns the U.S. patents on ZMC, licensed to Pipex Pharmaceuticals." \\
Declaration of interest: unknown
\end{tabular}


Newsome 2008 (Continued)

Date study conducted: unknown

Trial registration number: unknown

\section{Risk of bias}

\begin{tabular}{|c|c|c|}
\hline Bias & Authors' judgement & Support for judgement \\
\hline $\begin{array}{l}\text { Random sequence genera- } \\
\text { tion (selection bias) }\end{array}$ & Low risk & $\begin{array}{l}\text { Quote: "A total of } 80 \text { subjects ( } 40 \text { per group) volunteered for the study and } \\
\text { were randomised using a } 50 \% \text { likelihood scheme." }\end{array}$ \\
\hline $\begin{array}{l}\text { Allocation concealment } \\
\text { (selection bias) }\end{array}$ & Low risk & $\begin{array}{l}\text { Quote: "An unmasked co-ordinator gave subjects, upon enrolment, study ma- } \\
\text { terials in numbered containers using the randomization scheme. This individ- } \\
\text { ual performed no data collection." }\end{array}$ \\
\hline $\begin{array}{l}\text { Blinding of participants } \\
\text { and personnel (perfor- } \\
\text { mance bias) } \\
\text { Visual acuity }\end{array}$ & Low risk & $\begin{array}{l}\text { Quote: "Study materials were in tinted pharmaceutical capsules that provided } \\
\text { an indistinguishable appearance between ZMC and the plant cellulose place- } \\
\text { bo." }\end{array}$ \\
\hline
\end{tabular}

$\begin{array}{ll}\begin{array}{l}\text { Blinding of participants } \\ \text { and personnel (perfor- }\end{array} & \text { Low risk } \\ \begin{array}{l}\text { mance bias) } \\ \text { Progression AMD }\end{array} & \begin{array}{l}\text { Quote: "Study materials were in tinted pharmaceutical capsules that provided } \\ \text { an indistinguishable appearance between ZMC and the plant cellulose place- } \\ \text { bo." }\end{array}\end{array}$

\begin{tabular}{|c|c|c|}
\hline $\begin{array}{l}\text { Blinding of outcome as- } \\
\text { sessment (detection bias) } \\
\text { Visual acuity }\end{array}$ & Low risk & $\begin{array}{l}\text { Quote: "Functional assessment....by masked trained examiners..." } \\
\text { Quote: "Masked examiners determined contrast sensitivity...." }\end{array}$ \\
\hline $\begin{array}{l}\text { Blinding of outcome as- } \\
\text { sessment (detection bias) } \\
\text { Progression AMD }\end{array}$ & Low risk & $\begin{array}{l}\text { Quote: "Functional assessment....by masked trained examiners..." } \\
\text { Quote: "Masked examiners determined contrast sensitivity...." }\end{array}$ \\
\hline $\begin{array}{l}\text { Incomplete outcome data } \\
\text { (attrition bias) } \\
\text { All outcomes }\end{array}$ & Low risk & $\begin{array}{l}\text { Quote: "Thirty-seven [out of } 40 \text { ] in each group competed all visits..." } \\
\text { Reasons for drop-out: } 2 \text { of placebo group died from pre-existing medical con- } \\
\text { ditions; the rest of the dropouts }(\mathrm{N}=4) \text { were due to gastrointestinal-related } \\
\text { complaints }\end{array}$ \\
\hline
\end{tabular}

Selective reporting (re- Unclear risk Judgement comment: Difficult to assess with the information available.
porting bias)

\begin{tabular}{|c|c|}
\hline \multirow[t]{4}{*}{ Methods } & Parallel group RCT \\
\hline & Method of allocation: sponsor-prepared coded bottles \\
\hline & Masking: participant - yes; provider - yes; outcome - yes \\
\hline & $\begin{array}{l}\text { Losses to follow-up: } 6 \text { withdrawn due to adverse gastrointestinal effects ( } 4 \text { treatment, } 2 \text { control); } 14 \\
\text { withdrawn when developed neovascularisation ( } 9 \text { treatment, } 5 \text { control); } 14 \text { lost to follow-up ( } 6 \text { treat } \\
\text { ment, } 8 \text { control) }\end{array}$ \\
\hline \multirow[t]{3}{*}{ Participants } & Country: Austria \\
\hline & Number of people randomised: 112 (112 eyes) \\
\hline & $\begin{array}{l}\text { Number (\%) of people followed up: } 92(82 \%) \text { ( } 92 \text { eyes); } 78 \text { (70\%) (78 eyes) included the analyses be- } \\
\text { cause eyes that developed CNV were excluded }\end{array}$ \\
\hline
\end{tabular}


Stur 1996 (Continued)

\author{
Average age (range): 71 years ( 50 to unknown) \\ Percentage women: $57 \%$ \\ Ethnic group: unknown \\ Baseline visual acuity: average $0.075 \log M A R$ \\ Comorbidities affecting the eye: unknown \\ Percentage current smokers: $21 \%$ \\ Inclusion criteria:
}

- exudative AMD in 1 eye (defined as angiographic evidence of classic or occult choroidal neovascularisation or RPE detachment) and early ARM with visual acuity 20/40 or better in other eye (early ARM: macular drusen with no angiographic evidence of exudative lesion)

Exclusion criteria:

- dense senile cataract

- any other eye disease that could produce significant and permanent loss of visual acuity during follow-up

- physical status that could prevent follow-up; history of serious systemic or metabolic disease

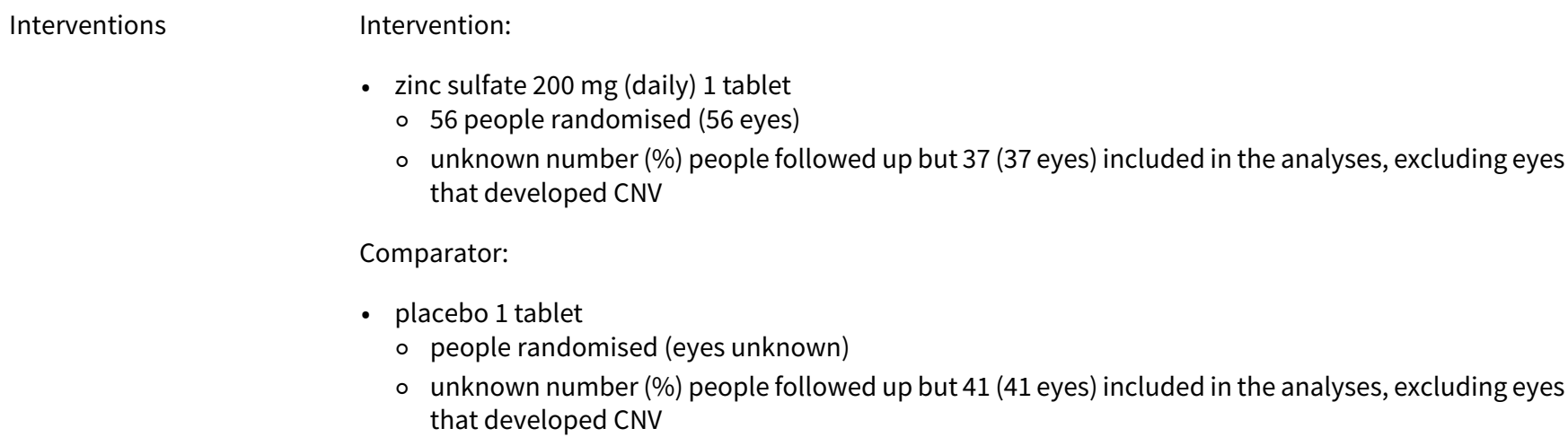

Similarity between intervention and comparator: Intervention was lemon flavoured effervescent tablet made of citric acid containing saccharine and sorbitol and placebo was as treatment, but without the zinc sulfate

Outcomes

Primary: not specified

Secondary: not specified

Outcomes reported in paper:

- Best-corrected logMAR visual acuity measured using Bailey-Lovie chart

- contrast sensitivity

- incidence of choroidal neovascularisation

- progression of disease (Wisconsin Age-related Maculopathy Grading System)

- copper deficiency anaemia

Follow-up: 6, 12, 18, and 24 months

Eyes: one eye per person, CNV in one eye and not in the fellow eye. The fellow eye was the "study eye." 
Source of funding: "Supported in part by the Austrian Foundation for the Propagation of Scientific Research (Ostetreichischer Fonds zur Forderung der xuissenschaftlichen Forschung), Project 7215-MED." and "The authors thank the staff at Astra GmbH, Linz, Austria, for providing the coded doses of zinc sulfate and placebo."

Declaration of interest: "Proprietary interest category: No"

Date study conducted: March 1990 to June 1992

Trial registration number: unknown

\section{Risk of bias}

Bias Authors' judgement Support for judgement

\section{Random sequence genera- Low risk} tion (selection bias)
Quote: "This was a double-masked, randomised, placebo-controlled study conducted at a single center. The randomization between zinc and placebo was performed in a ratio $1: 1 "$

Judgement comment: No details provided of method of sequence generation, however, since coding provided by sponsor, this is unlikely to be a source of bias.

\begin{tabular}{ll}
\hline $\begin{array}{l}\text { Allocation concealment } \\
\text { (selection bias) }\end{array}$ & Quote: "Coded doses of zinc sulfate and placebo were prepared by the spon- \\
& sor (Astra, Linz, Austria). All doses were lemon-flavored effervescent tablets \\
& made of citric acid that provided improved gastrointestinal absorption and \\
& contained saccharine and sorbitol. Treatment group doses contained an ad- \\
ditional $200 \mathrm{mg}$ of zinc sulfate. (This preparation is identical to a zinc sulfate & preparation registered in Austria and other European countries under the \\
name Solvezink; Astra, Wedel, Germany.) Tablets were bottled in identical con- \\
tainers."
\end{tabular}

Blinding of participants Low risk and personnel (performance bias)

Visual acuity
Quote: "Coded doses of zinc sulfate and placebo were prepared by the sponsor (Astra, Linz, Austria). All doses were lemon-flavored effervescent tablets made of citric acid that provided improved gastrointestinal absorption and contained saccharine and sorbitol. Treatment group doses contained an additional $200 \mathrm{mg}$ of zinc sulfate. (This preparation is identical to a zinc sulfate preparation registered in Austria and other European countries under the name Solvezink; Astra, Wedel, Germany.) Tablets were bottled in identical containers."

Blinding of participants Low risk
and personnel (perfor-
mance bias)
Progression AMD

Blinding of participants Low risk mance bias)

Progression AMD
Quote: "Coded doses of zinc sulfate and placebo were prepared by the sponsor (Astra, Linz, Austria). All doses were lemon-flavored effervescent tablets made of citric acid that provided improved gastrointestinal absorption and contained saccharine and sorbitol. Treatment group doses contained an additional $200 \mathrm{mg}$ of zinc sulfate. (This preparation is identical to a zinc sulfate preparation registered in Austria and other European countries under the name Solvezink; Astra, Wedel, Germany.) Tablets were bottled in identical containers."

\section{Blinding of outcome as- Low risk} sessment (detection bias) Visual acuity

\begin{abstract}
Quote: "Coded doses of zinc sulfate and placebo were prepared by the sponsor (Astra, Linz, Austria). All doses were lemon-flavored effervescent tablets made of citric acid that provided improved gastrointestinal absorption and contained saccharine and sorbitol. Treatment group doses contained an additional $200 \mathrm{mg}$ of zinc sulfate. (This preparation is identical to a zinc sulfate preparation registered in Austria and other European countries under the name Solvezink; Astra, Wedel, Germany.) Tablets were bottled in identical containers."
\end{abstract}


Stur 1996 (Continued)

Blinding of outcome as- Low risk Quote: "Coded doses of zinc sulfate and placebo were prepared by the sponsessment (detection bias)

Progression AMD sor (Astra, Linz, Austria). All doses were lemon-flavored effervescent tablets made of citric acid that provided improved gastrointestinal absorption and contained saccharine and sorbitol. Treatment group doses contained an additional $200 \mathrm{mg}$ of zinc sulfate. (This preparation is identical to a zinc sulfate preparation registered in Austria and other European countries under the name Solvezink; Astra, Wedel, Germany.) Tablets were bottled in identical containers."
Incomplete outcome data High risk

(attrition bias)

All outcomes
Quote: "One hundred twelve patients were enrolled between March 1, 1990 and June 30, 1992. Six patients (four in the treatment group, two in the placebo group) could not tolerate the medication because of gastrointestinal side effects and had to be withdrawn from the study. Fourteen patients did not return for the scheduled follow-up visits or decided to withdraw from the study because of personal reasons. The withdrawal of these 14 patients was not connected to any side effects of the study medication. The rest of the recruited patients (92 patients) returned for all required visits."

Quote: "During the treatment period, a CNV developed in the study eye in 14 patients (nine in the treatment group, five in the placebo group). Ten of these patients underwent laser treatment and were withdrawn from the study."

Selective reporting (re- Unclear risk

porting bias)

Difficult to assess with the information available

VECAT 2002

Methods

Parallel group RCT

Method of allocation: coded bottles

Masking: participant - yes; provider - yes; outcome - yes

Losses to follow-up: 11 participants excluded after randomisation

\section{Participants}

Country: Australia

Number of people randomised: 1204 (eyes unknown) randomised, but 11 participants excluded after randomisation, and reported 1193 (eyes unknown) randomised by group

Number of people followed up: 1179 (98\%)

Average age (range): 66 years ( 55 to 80 )

Percentage women: $56 \%$

Ethnic group: unknown

Baseline visual acuity: $99 \% \geq 40$ letters on logMAR chart

Comorbidities affecting the eye: only $19 \%$ with AMD; $4 \%$ with diabetes; approximately $20 \%$ with lens opacity

Percentage current smokers: $2 \%$

Inclusion criteria:

- lens and retina of at least 1 eye available for documentation

Exclusion criteria:

- previous cataract surgery or advanced cataract in both eyes 
VECAT 2002 (Continued)

- steroid or anticoagulation use

- serious disease

- regular use or sensitivity to vitamin $\mathrm{E}$

\begin{tabular}{|c|c|}
\hline \multirow[t]{3}{*}{ Interventions } & $\begin{array}{l}\text { Intervention: } \\
\text { - vitamin E } 500 \text { IU per day: natural vitamin E in soybean oil medium } \\
\text { ○ } 595 \text { people randomised (eyes unknown) } \\
\circ 587 \text { (99\%) people followed up (eyes unknown) }\end{array}$ \\
\hline & $\begin{array}{l}\text { Comparator: } \\
\text { - placebo of soybean oil medium } \\
\text { ○ } 598 \text { people randomised (eyes unknown) }\end{array}$ \\
\hline & ○ 592 (99\%) people followed up (eyes unknown) \\
\hline
\end{tabular}

Duration: 4 years

Similarity between intervention and comparator: Quote: "Vitamin E and placebo capsules were of identical appearance and taste."

Primary:
Outcomes
Secondary:
- $\quad$ progression of early AMD
- development of late AMD
- changes in visual acuity (the number of letters read on the logMAR chart)
Follow-up: annual follow-up for 4 years
Eyes: Quote: "Participants were categorised by their worse eye."

Notes

Source of funding: "The VECAT study was funded in part by grants from the National Health and Medical Research Council, Jack Brockhoff Foundation, the Eirene Lucas Foundation, the Stoicesco Foundation, the Carleton Family Charitable Trust, Je Hope Knell Trust Fund, Smith and Nephew, Australia, and Henkel Australia."

Declaration of interest: no competing interests declared

Date study conducted: January 1995 to January 2000

Trial registration number: unknown

\section{Risk of bias}

Bias Authors' judgement Support for judgement

Random sequence genera- Low risk tion (selection bias)

Quote: "Participants were then randomly allocated to treatment group. This random allocation was performed by using a "permuted blocks" allocation scheme."

$\begin{array}{ll}\begin{array}{l}\text { Allocation concealment } \\ \text { (selection bias) }\end{array} & \text { Low risk } \\ & \begin{array}{l}\text { Quote: "Study numbers were allocated sequentially by the study coordinator } \\ \text { as participants were enrolled in the study." }\end{array} \\ & \begin{array}{l}\text { Quote: "Bulk medications were dispensed into labelled jars by a person not in- } \\ \text { volved in the study. Vitamin E and placebo were dispensed on different days to }\end{array}\end{array}$


avoid confusion. Identical containers were used. The jars were packed in numerical order and then dispensed by study personnel."

\begin{tabular}{|c|c|c|}
\hline $\begin{array}{l}\text { Blinding of participants } \\
\text { and personnel (perfor- } \\
\text { mance bias) } \\
\text { Visual acuity }\end{array}$ & Low risk & $\begin{array}{l}\text { Quote: "Vitamin E and placebo capsules were of identical appearance and } \\
\text { taste. Neither study staff nor examiners or participants were aware of the treat- } \\
\text { ment allocation, although all knew that participants would be randomly as- } \\
\text { signed to receive either vitamin E or placebo." }\end{array}$ \\
\hline $\begin{array}{l}\text { Blinding of participants } \\
\text { and personnel (perfor- } \\
\text { mance bias) } \\
\text { Progression AMD }\end{array}$ & Low risk & $\begin{array}{l}\text { Quote: "Vitamin E and placebo capsules were of identical appearance and } \\
\text { taste. Neither study staff nor examiners or participants were aware of the treat- } \\
\text { ment allocation, although all knew that participants would be randomly as- } \\
\text { signed to receive either vitamin E or placebo." }\end{array}$ \\
\hline
\end{tabular}

Blinding of outcome as- Low risk sessment (detection bias)

Visual acuity
Quote: "Vitamin E and placebo capsules were of identical appearance and taste. Neither study staff nor examiners or participants were aware of the treatment allocation, although all knew that participants would be randomly assigned to receive either vitamin E or placebo."

\section{Blinding of outcome as- Low risk} sessment (detection bias) Progression AMD

Quote: "Vitamin E and placebo capsules were of identical appearance and taste. Neither study staff nor examiners or participants were aware of the treatment allocation, although all knew that participants would be randomly assigned to receive either vitamin E or placebo."

Quote: "At the end of the study we reassessed the initial and final photographs for any change with a "side by side" comparison in a masked and randomised fashion."

\begin{tabular}{|c|c|c|}
\hline $\begin{array}{l}\text { Incomplete outcome data } \\
\text { (attrition bias) } \\
\text { All outcomes }\end{array}$ & Low risk & $\begin{array}{l}\text { Judgement comment: } 78 / 595(13 \%) \text { participants in vitamin E group and } \\
72 / 598(12 \%) \text { of placebo group withdrew over the course of the study. Reasons } \\
\text { for withdrawal reported in table form. }\end{array}$ \\
\hline $\begin{array}{l}\text { Selective reporting (re- } \\
\text { porting bias) }\end{array}$ & High risk & $\begin{array}{l}\text { Judgement comment: For visual acuity, trial report states that outcome was } \\
\text { analysed but only reports that result was not significant. }\end{array}$ \\
\hline
\end{tabular}

\section{Veterans LAST study 2004}

$\begin{array}{ll}\text { Methods } & \text { Parallel group RCT } \\ & \text { Method of allocation: coded bottles } \\ & \text { Masking: participant - yes; provider - yes; outcome - yes } \\ & \text { Losses to follow-up: } 7 \text { withdrew, } 4 \text { lost to follow-up, } 3 \text { died. Slightly lower } \% \text { follow-up in group } 2 \\ & \text { (lutein or antioxidant), } 80 \% \text { compared with other } 2 \text { groups (lutein alone } 86 \%, \text { placebo } 87 \% \text { ). }\end{array}$

Participants

Country: USA

Number of people randomised: 90 (eyes unknown)

Number of people followed up: 76 (84\%) (eyes unknown)

Average age (range): approximate 75 years

Percentage women: $4 \%$

Ethnic group: unknown

Baseline visual acuity: average ranged from 0.279 to 0.445 logMAR by eye and treatment group

Comorbidities affecting the eye: unknown 
Veterans LAST study 2004 (Continued)

Percentage current smokers: unknown

Inclusion criteria:

- atrophic AMD diagnosed by ophthalmoscopy

- at least one visual abnormality reduced contrast sensitivity, photo-stress glare recovery deficit or deficit on Amsler grid

- clear ocular media

- free of any other ocular/systemic disease that could affect central or parafoveal macular visual function.

Exclusion criteria:

- cataract or retinal surgery within 6 months

- photosensitising drugs

- taken lutein supplements within the previous 6 months

- lutein 10 mg non-esterified lutein (FloraGlo from Kemin Foods International, Des Moines, lowa)

- 29 people randomised (eyes unknown)

- 25 (86\%) people followed up (eyes unknown)

- lutein plus additional antioxidants and nutrients (OcuPower, Nutraceutical Sciences Institute (NSI), Boynton Beach, Florida)

- 30 people randomised (eyes unknown)

- 24 (80\%) people followed up (eyes unknown)

Comparator:

- placebo, maltodextrin

- 31 people randomised (eyes unknown)

○ 27 (87\%) people followed up (eyes unknown)

Duration: 12 months

Ocupower had a range of nutrients including lutein, vitamin A, beta-carotene, vitamins C, D3, E, B1, B2, B3, B5, B6, B12, folic acid, biotin, calcium, magnesium, iodine, zinc copper, manganese, selenium, chromium, molybdenum, lycopene, bilberry extract, alpha lipoic acid, $\mathrm{N}$-acetyl cysteine, quercetin, rutin, citrus bioflavonoids, plant enzymes, black pepper extract, malic acid, taurine, L-glycine, L-glutathione, boron

Similarity between intervention and comparator: "Subjects were provided with opaque capsules of identical appearance in numbered containers taken as three capsules twice per day with food"

Outcomes

Primary:

- macular pigment optical density

Secondary:

- not specified

The following clinical measurements were made:

- lens opacity

- retinal images

- Macular Pigment Optical Density (MPOD)

- visual acuity (Snellen) distance and near

- glare testing

- glare recovery

- contrast sensitivity 
Veterans LAST study 2004 (Continued)

- VFQ-14 (activities of daily living, night driving, glare recovery symptoms)

- Amsler grid

- self reported vision

It was difficult to extract data on outcomes of relevance to this review: i.e. visual acuity and progression of AMD.

Follow-up: 12 month

Eyes: reported right and left eyes separately

Notes

Source of funding: "This material is based on work supported by the DVA Medical Center, North Chicago, Illinois and the Department of Veteran's Affairs, Hines, Illinois." and "Grant sponsors are Kemin Foods, Inc. (Des Moines, lowa); L/itacost.com, with its subsidiary Nutraceutical Sciences Institute (NSI: Boynton Beach, Florida); and Great Smokies Diagnostic Laboratory (Asheville, North Carolina). FloraGloB non-esterified lutein is a product of Kemin Foods. The FloraGloB lutein antioxidant supplement evaluated is known as OcuPower@, U.S. Patent \#6,103,756-Wayne Gorsek, inventor; L/itacost.com assignee."

Declaration of interest: unknown

Date study conducted: August 1999 to May 2001

Trial registration number: unknown

\section{Risk of bias}

Bias Authors' judgement Support for judgement

Random sequence genera- Unclear risk tion (selection bias)

Quote: "... were randomly assigned to one of three capsule groups by consecutive random card-3-choice, allocation sequence"

Allocation concealment Low risk (selection bias)
Quote: "Nutraceutical Sciences Institute prepared the lutein capsules, the L/A capsules, and the $P$ capsules and also maintained and concealed the blinding and four-digit allocation codes."

"All personnel at the DVA Medical Center were unaware of the masked allocation codes during the 12-month clinical study."

\begin{tabular}{|c|c|c|}
\hline $\begin{array}{l}\text { Blinding of participants } \\
\text { and personnel (perfor- } \\
\text { mance bias) }\end{array}$ & Low risk & $\begin{array}{l}\text { Quote: "All personnel at the DVA Medical Center were unaware of the maske } \\
\text { allocation codes during the } 12 \text {-month clinical study." }\end{array}$ \\
\hline Visual acuity & & $\begin{array}{l}\text { "Subjects were provided with opaque capsules of identical appearance in } \\
\text { numbered containers taken as three capsules twice per day with food." }\end{array}$ \\
\hline
\end{tabular}

\begin{tabular}{ll}
\hline $\begin{array}{l}\text { Blinding of participants } \\
\text { and personnel (perfor- }\end{array}$ & Low risk \\
$\begin{array}{l}\text { mance bias) } \\
\text { Progression AMD }\end{array}$ & $\begin{array}{l}\text { Quote: "All personnel at the DVA Medical Center were unaware of the masked } \\
\text { allocation codes during the 12-month clinical study." }\end{array}$ \\
& $\begin{array}{l}\text { Quote: "Subjects were provided with opaque capsules of identical appearance } \\
\text { in numbered containers taken as three capsules twice per day with food." }\end{array}$
\end{tabular}

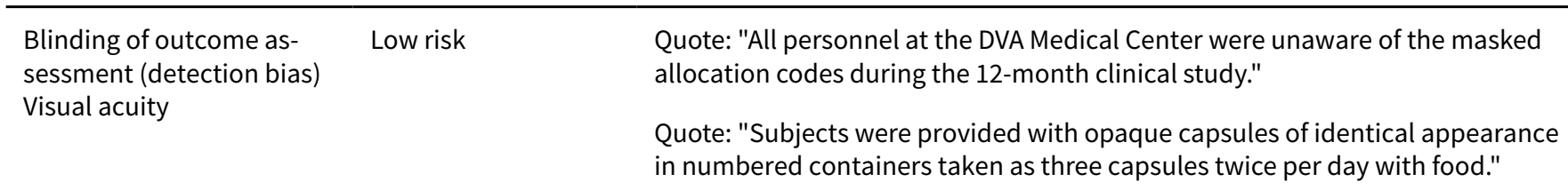

$\begin{array}{ll}\begin{array}{l}\text { Blinding of outcome as- } \\ \text { sessment (detection bias) }\end{array} & \text { Low risk }\end{array}$

Progression AMD 
Quote: "Subjects were provided with opaque capsules of identical appearance in numbered containers taken as three capsules twice per day with food."

Incomplete outcome data High risk
(attrition bias)

All outcomes
Lutein $10 \mathrm{mg}$ group $\mathrm{N}=29$
- 1 person lost to follow-up
- 1 person died
- 2 other withdrawals

Judgement comment: Loss to follow-up 14/90:

Lutein $10 \mathrm{mg}$ and antioxidant group $\mathrm{N}=30$

- 2 persons lost to follow-up

- 4 other withdrawals

Placebo group $\mathrm{N}=31$

- 1 persons lost to follow-up

- 1 person died

- 1 other withdrawals

Members of placebo group removed from analysis due to the fact that they had taken lutein

Selective reporting (re- Unclear risk Judgement comment: Difficult to assess with the information available.
porting bias)

\section{Wang 2004}

Methods

Parallel group RCT

Method of allocation: unknown

Masking: participant - unknown; provider - unknown; outcome - unknown

Losses to follow-up: unknown

Country: China
Number of people randomised: 400 (400 eyes)
Number of people followed up: unknown
Average age (range): 65 years (52 to 76)
Percentage women: $53 \%$
Ethnic group: unknown
Baseline visual acuity: unknown
Comorbidities affecting the eye: unknown
Percentage current smokers: unknown

Interventions Intervention:

- zinc oxide $80 \mathrm{mg}$ daily, vitamin C, vitamin $\mathrm{E}$

- unknown number people randomised (eyes unknown)

- unknown number (\%) people followed up (eyes unknown) 
Wang 2004 (Continued)

\section{Comparator:}

- placebo

- unknown number people randomised (eyes unknown)

○ unknown number (\%) people followed up (eyes unknown)

Duration: 24 to 32 months

Similarity between intervention and comparator: unknown

\begin{tabular}{l} 
Primary: \\
Outcomes not specified \\
Secondary: \\
Outcomes: \\
- not specified \\
- early and late AMD \\
Follow-up: every 6 months for 24 to 32 months \\
Eyes: one eye per person, worse eye was selected \\
Limited information available on this trial. AMD participants were stratified into early and late-stage \\
disease \\
Source of funding: unknown \\
Declaration of interest: unknown \\
Date study conducted: unknown \\
Trial registration number: unknown \\
\hline
\end{tabular}

\section{Risk of bias}

\begin{tabular}{|c|c|c|}
\hline Bias & Authors' judgement & Support for judgement \\
\hline $\begin{array}{l}\text { Random sequence genera- } \\
\text { tion (selection bias) }\end{array}$ & Unclear risk & Not reported \\
\hline $\begin{array}{l}\text { Allocation concealment } \\
\text { (selection bias) }\end{array}$ & Unclear risk & Unclear \\
\hline $\begin{array}{l}\text { Blinding of participants } \\
\text { and personnel (perfor- } \\
\text { mance bias) } \\
\text { Visual acuity }\end{array}$ & Unclear risk & Not reported \\
\hline $\begin{array}{l}\text { Blinding of participants } \\
\text { and personnel (perfor- } \\
\text { mance bias) } \\
\text { Progression AMD }\end{array}$ & Unclear risk & Not reported \\
\hline $\begin{array}{l}\text { Blinding of outcome as- } \\
\text { sessment (detection bias) } \\
\text { Visual acuity }\end{array}$ & Unclear risk & Not reported \\
\hline
\end{tabular}


Wang 2004 (Continued)
Blinding of outcome as-
Unclear risk
Not reported sessment (detection bias)

Progression AMD

\begin{tabular}{lll}
\hline $\begin{array}{l}\text { Incomplete outcome data } \\
\text { (attrition bias) } \\
\text { All outcomes }\end{array}$ & Unclear risk & Unclear \\
\hline $\begin{array}{l}\text { Selective reporting (re- } \\
\text { porting bias) }\end{array}$ & Unclear risk & $\begin{array}{l}\text { Visual acuity was measured but not reported, possibly because of non-signifi- } \\
\text { cant results }\end{array}$ \\
\hline
\end{tabular}

AMD: age-related macular degeneration

AREDS: Age-Related Eye Disease Study

ARM: Age-related maculopathy

CNV: Choroidal neovascularisation

ERG: electroretinogram

ETDRS: Early Treatment Diabetic Retinopathy Study

GA: Geographic atrophy

LOCF: last observation carried forward

logMAR: logarithm of the minimal angle of resolution

mfERG: multifocal electroretinogram

MPOD: macular pigment optical density

NEI: National Eye Institute

$\mathrm{RCT}$ : randomised controlled trial

RDA: recommended dietary allowance

RPE: retinal pigment epithelium

SD: standard deviation

VFQ: Visual function questionnaire

ZMC: zinc-monocysteine

Characteristics of excluded studies [ordered by study ID]

\begin{tabular}{ll}
\hline Study & Reason for exclusion \\
\hline Akuffo 2015 & No placebo or untreated group in the study \\
\hline Anonymous 2015 & Review \\
\hline Bahrami 2006 & Not AMD \\
\hline Barakat 2006 & Not antioxidant vitamin \\
\hline Benzie 2006 & Bioavailability study \\
\hline Bone 2007 & Bioavailability study \\
\hline Cangemi 2007 & No control group \\
\hline Christen 2007 & $\begin{array}{l}\text { RCT in healthy population group. Included in Cochrane review on prevention of AMD with antioxi- } \\
\text { dant supplements. }\end{array}$ \\
\hline Connolly 2011 & No AMD outcomes \\
\hline CREST 2014 & $\begin{array}{l}\text { Lutein and zeaxanthin compared to placebo with the aim of enhancing vision in healthy people. } \\
\text { Some of the participants had AMD but they were all given supplementation i.e. no control group. }\end{array}$ \\
\hline
\end{tabular}




\begin{tabular}{|c|c|}
\hline Study & Reason for exclusion \\
\hline Cumurcu 2006 & Not an RCT \\
\hline Falsini 2010 & Trial of saffron \\
\hline Franciose 2006 & Bioavailability study \\
\hline Goodrow 2006 & Bioavailability study \\
\hline \multirow[t]{2}{*}{ ISRCTN35481392 } & Participants had no ocular pathology \\
\hline & www.controlled-trials.com/ISRCTN35481392/ISRCTN35481392 \\
\hline \multirow[t]{2}{*}{ ISRCTN57556290 } & No comparator group \\
\hline & www.biomedcentral.com/1471-2415/7/3 \\
\hline ISRCTN81595685 & Comparison of two active formulations \\
\hline Kamburoglu 2006 & Not an RCT, not antioxidant \\
\hline Khachik 2006 & Bioavailability study \\
\hline Kolber 2013 & Review \\
\hline Kopsell 2006 & Bioavailability study \\
\hline Landrum 2012 & Pilot study of effects of lutein supplementation on serum and macular pigment \\
\hline $\operatorname{Lim} 2006$ & Not antioxidant \\
\hline LUNA 2007 & Bioavailability study \\
\hline LUTEGA 2013 & Antioxidants combined with omega- 3 fatty acids \\
\hline LUXEA 2006 & only MPOD measured; no clinical outcomes \\
\hline Meagher 2013 & Conference abstract reporting MPOD only \\
\hline Moeller 2006 & Not an RCT \\
\hline NCT00006202 & Dose ranging study for lutein supplementation. No control group. \\
\hline NCT00121589 & Phase I study only. Looking at changes in plasma levels and macular pigment density only. \\
\hline NCT00563979 & Active comparator (omega-3) \\
\hline NCT00564902 & Active comparator (lutein) \\
\hline NCT00718653 & Effect on macular pigments only, not on AMD \\
\hline NCT00800995 & Not antioxidant vitamin or mineral (superoxide dismutase) \\
\hline NCT00893724 & Antioxidants combined with inosine \\
\hline NCT02264938 & No control group \\
\hline
\end{tabular}




\begin{tabular}{|c|c|}
\hline Study & Reason for exclusion \\
\hline Nolan 2006 & Not a RCT \\
\hline Nolan 2007 & Not a RCT \\
\hline Nolan 2012 & Effect on macular pigments in healthy people only, not on AMD \\
\hline Nussenblatt 2006 & Not AMD \\
\hline Owsley 2006 & Not antioxidant \\
\hline PHS II 2012 & $\begin{array}{l}\text { RCT in healthy population group. Will be included in Cochrane Review on prevention of AMD with } \\
\text { antioxidant supplements. }\end{array}$ \\
\hline Rosenthal 2006 & $\begin{array}{l}\text { Small dose ranging study. Data on vision only collected for nine months and not possible to extract } \\
\text { from report. }\end{array}$ \\
\hline Sabour-Pickett 2014 & No control group \\
\hline Sasamoto 2011 & Not an RCT \\
\hline Scalinci 2002 & Antioxidants combined with omega-3 \\
\hline Scorolli 2002 & Antioxidants combined with PDT \\
\hline Souied 2013 & Not an antioxidant supplement (omega-3) \\
\hline Told 2014 & Small study of physiological effects in healthy volunteers \\
\hline Told 2015 & Small study of physiological effects in healthy volunteers \\
\hline Vannas 1958 & Allocation concealment inadequate \\
\hline Vidal 2011 & $\begin{array}{l}\text { RCT in healthy population group. Will be included in Cochrane review on prevention of AMD with } \\
\text { antioxidant supplements. }\end{array}$ \\
\hline Wang 2007 & Bioavailability study \\
\hline Wenzel 2006 & Bioavailability study \\
\hline Wolf-Schnurrbusch 2015 & Antioxidant compared to antioxidant plus omega-3 \\
\hline Wong 2010 & Phase II open-label study in 10 participants only \\
\hline Zhao 2006 & Bioavailability study \\
\hline
\end{tabular}

AMD: age-related macular degeneration

MPOD: macular pigment optical density

$\mathrm{RCT}$ : randomised controlled trial

Characteristics of ongoing studies [ordered by study ID]

\section{NCT01694680}

Trial name or title

Intervention trial in early age-related macular degeneration 
NCT01694680 (Continued)

Methods $\quad$ Parallel group RCT

\begin{tabular}{ll}
\hline Participants & $\mathrm{N}=120$ \\
\hline Interventions & $\begin{array}{l}\text { Dietary Supplement: Lutein-enriched-egg beverage (NWT-02) } \\
\text { Dietary Supplement: Placebo }\end{array}$ \\
\hline Outcomes & $\begin{array}{l}\text { from clinicaltrials.gov } \\
\text { "Primary Outcome Measures: Visual function (time frame: } 12 \text { months; designated as safety issue: } \\
\text { No) } \\
\text { Secondary Outcome Measures: Carotenoid levels (time frame: } 12 \text { months; designated as safety is- } \\
\text { sue: No); Levels of lutein and Zeaxanthin" }\end{array}$ \\
\hline Starting date & October 2012 to April 2016 \\
\hline Contact information & EJ Johnson PhD Jean Mayer USDA Human Nutrition research Centyer on Aging (HNRCA), Boston \\
\hline Notes & \\
\hline
\end{tabular}

\section{NCT02625376}

\begin{tabular}{|c|c|}
\hline Trial name or title & Resveratrol for exudative age-related macular degeneration \\
\hline Methods & Parallel group RCT \\
\hline Participants & $N=489$ \\
\hline \multirow[t]{2}{*}{ Interventions } & $\begin{array}{l}\text { Dietary Supplement: Resvega } \\
\text { Dietary Supplement: Trans-Resveratrol }\end{array}$ \\
\hline & Dietary Supplement: placebo \\
\hline \multirow[t]{3}{*}{ Outcomes } & from clinical trials.gov \\
\hline & $\begin{array}{l}\text { "Primary Outcome Measures: Comparaison of incidence of choroidal neovascularization between } \\
\text { resveratrol group and placebo group at } 24 \text { months (time frame: } 24 \text { months; designated as safety is- } \\
\text { sue: Yes) What is the influence of the daily intake of } 500 \mathrm{mg} \text { of resveratrol on the incidence of neo- } \\
\text { vascularization of the second eye? }\end{array}$ \\
\hline & $\begin{array}{l}\text { Secondary Outcome Measures: Comparaison of incidence of choroidal neovascularization be- } \\
\text { tween Resvega group and placebo group at } 24 \text { months (time frame: } 24 \text { months; designated as safe- } \\
\text { ty issue: Yes) What is the influence of the daily intake resvega on the incidence of neovasculariza- } \\
\text { tion of the second eye?" }\end{array}$ \\
\hline Starting date & August 2015 to August 2019 \\
\hline Contact information & Nicolas LEVEZIEL, MD, Ph Dpt of Ophthalmology, University Hospital of Poitiers, France \\
\hline Notes & \\
\hline
\end{tabular}

\section{DATA AND ANALYSES}


Comparison 1. Antioxidant multivitamin and mineral supplement versus placebo

\begin{tabular}{|c|c|c|c|c|}
\hline Outcome or subgroup title & No. of studies & $\begin{array}{l}\text { No. of partici- } \\
\text { pants }\end{array}$ & Statistical method & Effect size \\
\hline $\begin{array}{l}1 \text { Progression to late AMD (neovas- } \\
\text { cular AMD or geographic atrophy) }\end{array}$ & 3 & 2445 & Odds Ratio (Fixed, 95\% Cl) & $0.72[0.58,0.90]$ \\
\hline 2 Progression to neovascular AMD & 1 & & Odds Ratio (Fixed, 95\% Cl) & Totals not selected \\
\hline 3 Progression to geographic atrophy & 1 & & Odds Ratio (Fixed, 95\% Cl) & Totals not selected \\
\hline $\begin{array}{l}4 \text { Progression to visual loss (loss of } 3 \\
\text { or more lines on logMAR chart) }\end{array}$ & 1 & & Odds Ratio (Fixed, 95\% Cl) & Totals not selected \\
\hline 5 Mean visual acuity & 5 & 595 & $\begin{array}{l}\text { Mean Difference (IV, Fixed, } \\
95 \% \mathrm{CI})\end{array}$ & $0.02[-0.03,0.07]$ \\
\hline $\begin{array}{l}5.1 \text { Mean visual acuity at end of } \\
\text { study }\end{array}$ & 1 & 59 & $\begin{array}{l}\text { Mean Difference (IV, Fixed, } \\
95 \% \mathrm{CI})\end{array}$ & $0.04[-0.13,0.21]$ \\
\hline 5.2 Change in visual acuity & 4 & 536 & $\begin{array}{l}\text { Mean Difference (IV, Fixed, } \\
95 \% \mathrm{CI} \text { ) }\end{array}$ & $0.02[-0.03,0.07]$ \\
\hline 6 Quality of life & 1 & & $\begin{array}{l}\text { Mean Difference (IV, Fixed, } \\
95 \% \mathrm{CI} \text { ) }\end{array}$ & Totals not selected \\
\hline
\end{tabular}

Analysis 1.1. Comparison 1 Antioxidant multivitamin and mineral supplement versus placebo, Outcome 1 Progression to late AMD (neovascular AMD or geographic atrophy).

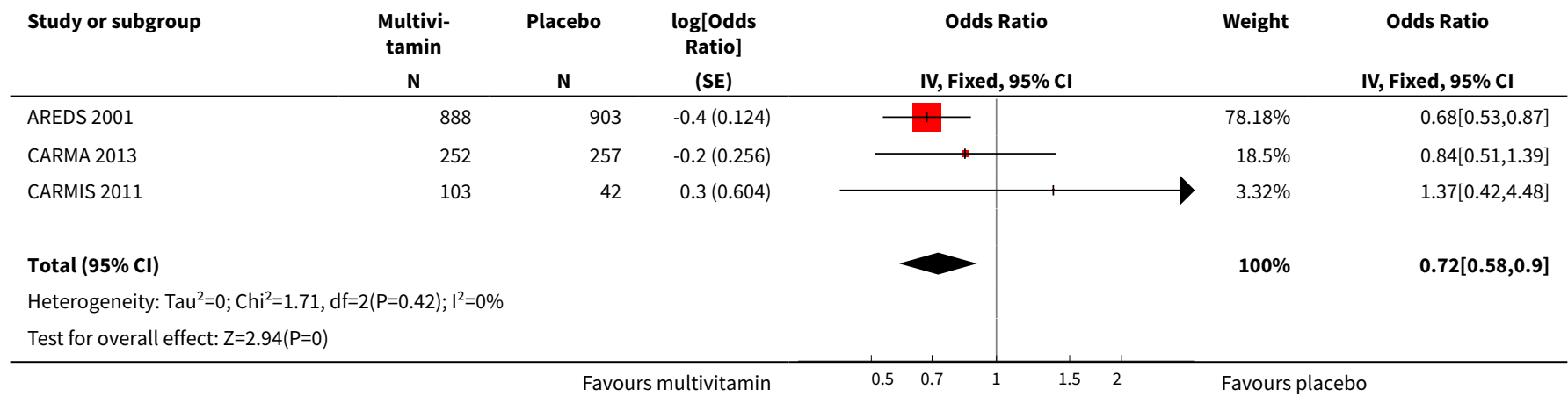

Analysis 1.2. Comparison 1 Antioxidant multivitamin and mineral supplement versus placebo, Outcome 2 Progression to neovascular AMD.

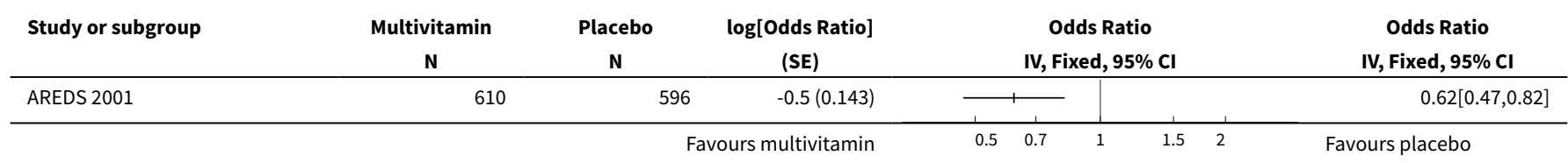


Analysis 1.3. Comparison 1 Antioxidant multivitamin and mineral supplement versus placebo, Outcome 3 Progression to geographic atrophy.

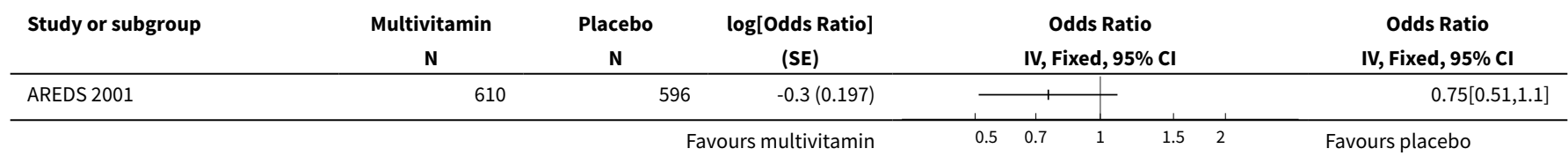

Analysis 1.4. Comparison 1 Antioxidant multivitamin and mineral supplement versus placebo, Outcome 4 Progression to visual loss (loss of 3 or more lines on logMAR chart).

\begin{tabular}{|c|c|c|c|c|c|c|}
\hline \multirow{2}{*}{$\begin{array}{l}\text { Study or subgroup } \\
\text { AREDS } 2001\end{array}$} & \multirow{2}{*}{$\begin{array}{l}\text { Multivitamin } \\
\qquad \mathbf{N} \\
\\
888\end{array}$} & \multirow{2}{*}{$\begin{array}{l}\text { Placebo } \\
\qquad \begin{array}{r}\text { N } \\
903\end{array}\end{array}$} & \multirow{2}{*}{$\begin{array}{c}\log \text { [Odds Ratio] } \\
\text { (SE) } \\
-0.3(0.112)\end{array}$} & \multicolumn{2}{|c|}{$\begin{array}{c}\text { Odds Ratio } \\
\text { IV, Fixed, } 95 \% \text { CI }\end{array}$} & \multirow{2}{*}{$\begin{array}{c}\begin{array}{c}\text { Odds Ratio } \\
\text { IV, Fixed, 95\% Cl }\end{array} \\
0.77[0.62,0.96\end{array}$} \\
\hline & & & & 1 & & \\
\hline
\end{tabular}

\section{Analysis 1.5. Comparison 1 Antioxidant multivitamin and mineral supplement versus placebo, Outcome 5 Mean visual acuity.}

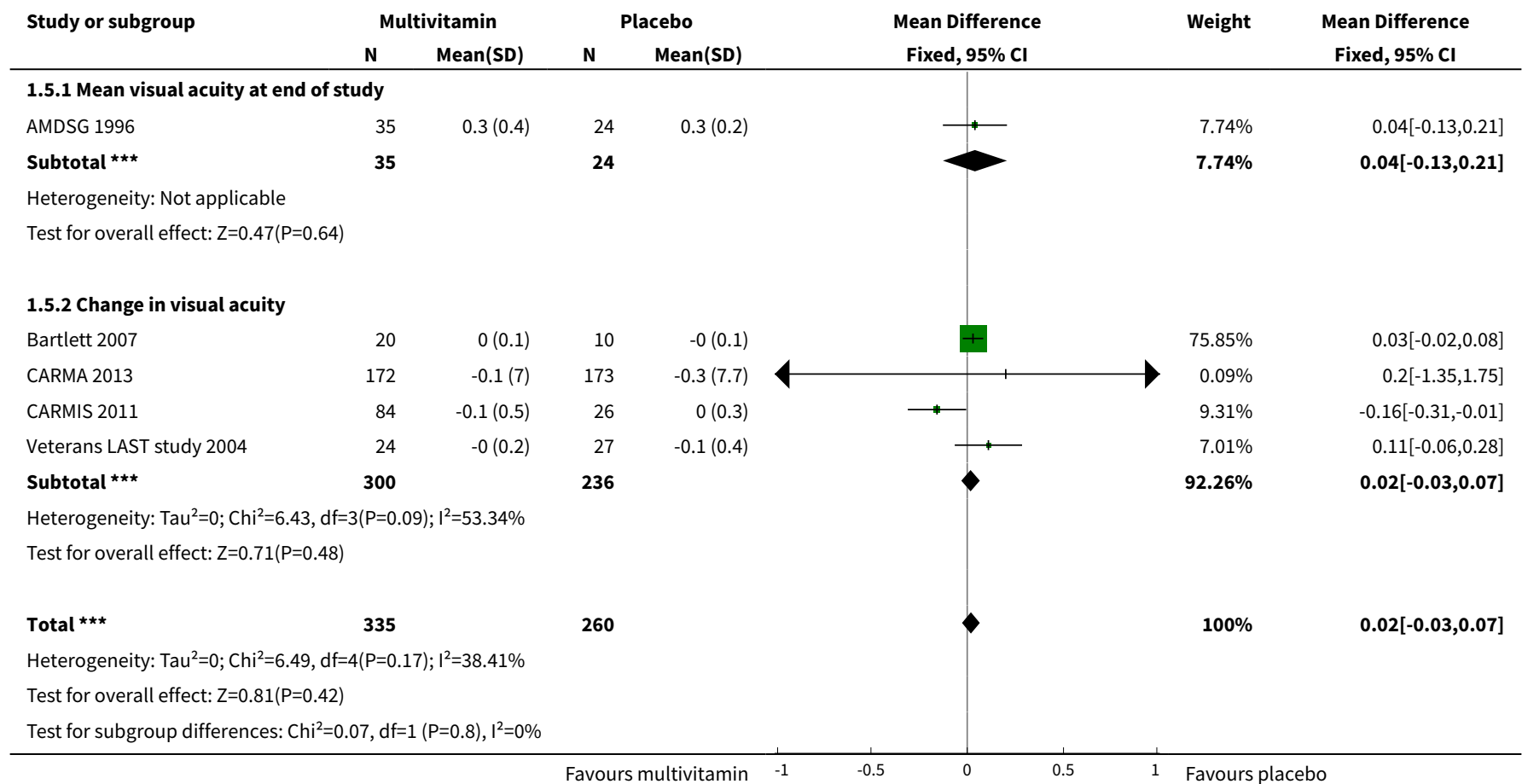


Analysis 1.6. Comparison 1 Antioxidant multivitamin and mineral supplement versus placebo, Outcome 6 Quality of life.

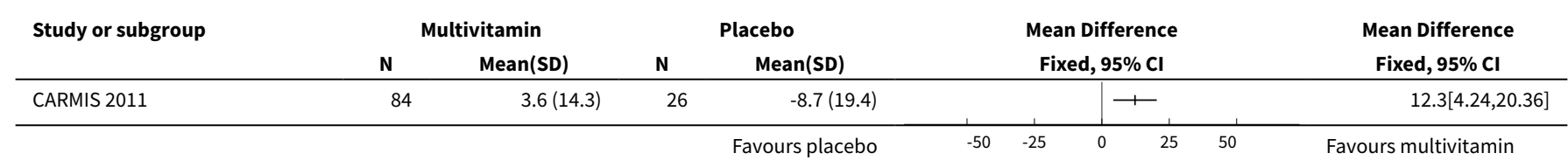

\section{Comparison 2. Lutein and/or zeaxanthin versus placebo}

\begin{tabular}{|c|c|c|c|c|}
\hline Outcome or subgroup title & No. of studies & $\begin{array}{l}\text { No. of partici- } \\
\text { pants }\end{array}$ & Statistical method & Effect size \\
\hline $\begin{array}{l}1 \text { Progression to late AMD (neovas- } \\
\text { cular AMD and/or geographic atro- } \\
\text { phy }\end{array}$ & 1 & & Risk Ratio (IV, Fixed, 95\% Cl) & Totals not selected \\
\hline 2 Progression to neovascular AMD & 1 & & Risk Ratio (IV, Fixed, 95\% CI) & Totals not selected \\
\hline 3 Progression to geographic atrophy & 1 & & Risk Ratio (IV, Fixed, 95\% CI) & Totals not selected \\
\hline $\begin{array}{l}4 \text { Progression to visual loss (loss of } 3 \\
\text { or more lines on logMAR chart) }\end{array}$ & 1 & & Risk Ratio (IV, Fixed, 95\% CI) & Totals not selected \\
\hline 5 Distance visual acuity: mean & 3 & 231 & $\begin{array}{l}\text { Mean Difference (IV, Fixed, } \\
95 \% \mathrm{Cl})\end{array}$ & $-0.00[-0.05,0.05]$ \\
\hline $\begin{array}{l}5.1 \text { Mean visual acuity at end of } \\
\text { study }\end{array}$ & 1 & 72 & $\begin{array}{l}\text { Mean Difference (IV, Fixed, } \\
95 \% \mathrm{Cl})\end{array}$ & $0.0[-0.06,0.06]$ \\
\hline 5.2 Change in visual acuity & 2 & 159 & $\begin{array}{l}\text { Mean Difference (IV, Fixed, } \\
95 \% \mathrm{CI})\end{array}$ & $-0.01[-0.09,0.08]$ \\
\hline 6 Visual Function Quality (VFQ) & 1 & & $\begin{array}{l}\text { Mean Difference (IV, Fixed, } \\
95 \% \mathrm{CI})\end{array}$ & Totals not selected \\
\hline
\end{tabular}

Analysis 2.1. Comparison 2 Lutein and/or zeaxanthin versus placebo, Outcome 1 Progression to late AMD (neovascular AMD and/or geographic atrophy.

\begin{tabular}{|c|c|c|c|c|}
\hline Study or subgroup & $\begin{array}{c}\text { Lutein/zeaxanthin } \\
n / N\end{array}$ & $\begin{array}{l}\text { Placebo } \\
n / N\end{array}$ & $\begin{array}{c}\text { Risk Ratio } \\
\text { IV, Fixed, 95\% CI }\end{array}$ & $\begin{array}{c}\text { Risk Ratio } \\
\text { IV, Fixed, 95\% CI }\end{array}$ \\
\hline AREDS2 2013 & $940 / 3451$ & $1000 / 3440$ & 1 & $0.94[0.87,1.01]$ \\
\hline
\end{tabular}


Analysis 2.2. Comparison 2 Lutein and/or zeaxanthin versus placebo, Outcome 2 Progression to neovascular AMD.

\begin{tabular}{|c|c|c|c|c|}
\hline Study or subgroup & $\begin{array}{c}\text { Lutein/zeaxanthin } \\
\mathrm{n} / \mathrm{N}\end{array}$ & $\begin{array}{c}\text { Placebo } \\
\mathbf{n} / \mathbf{N}\end{array}$ & $\begin{array}{c}\text { Risk Ratio } \\
\text { IV, Fixed, 95\% CI }\end{array}$ & $\begin{array}{c}\text { Risk Ratio } \\
\text { IV, Fixed, 95\% CI }\end{array}$ \\
\hline AREDS2 2013 & $607 / 3451$ & $655 / 3440$ & $\ldots$ & $0.92[0.84,1.02]$ \\
\hline
\end{tabular}

Analysis 2.3. Comparison 2 Lutein and/or zeaxanthin versus placebo, Outcome 3 Progression to geographic atrophy.

\begin{tabular}{|c|c|c|c|c|}
\hline Study or subgroup & $\begin{array}{c}\text { Lutein/zeaxanthin } \\
\qquad / \mathbf{N}\end{array}$ & $\begin{array}{c}\text { Placebo } \\
n / N\end{array}$ & $\begin{array}{c}\text { Risk Ratio } \\
\text { IV, Fixed, 95\% CI }\end{array}$ & $\begin{array}{c}\text { Risk Ratio } \\
\text { IV, Fixed, 95\% CI }\end{array}$ \\
\hline AREDS2 2013 & $367 / 3451$ & $398 / 3440$ & $\longrightarrow$ & $0.92[0.8,1.05]$ \\
\hline
\end{tabular}

Analysis 2.4. Comparison 2 Lutein and/or zeaxanthin versus placebo, Outcome 4 Progression to visual loss (loss of 3 or more lines on logMAR chart).

\begin{tabular}{|c|c|c|c|c|}
\hline Study or subgroup & $\begin{array}{c}\text { Lutein/zeaxanthin } \\
\mathrm{n} / \mathrm{N} \\
\end{array}$ & $\begin{array}{c}\text { Placebo } \\
n / N\end{array}$ & $\begin{array}{c}\text { Risk Ratio } \\
\text { IV, Fixed, 95\% CI }\end{array}$ & $\begin{array}{c}\text { Risk Ratio } \\
\text { IV, Fixed, 95\% CI }\end{array}$ \\
\hline AREDS2 2013 & $1015 / 3332$ & $1034 / 3324$ & $一$ & $0.98[0.91,1.05]$ \\
\hline
\end{tabular}

Analysis 2.5. Comparison 2 Lutein and/or zeaxanthin versus placebo, Outcome 5 Distance visual acuity: mean.

\begin{tabular}{|c|c|c|c|c|c|c|c|}
\hline \multirow[t]{2}{*}{ Study or subgroup } & \multicolumn{2}{|c|}{ Lutein/zeaxanthin } & \multicolumn{2}{|c|}{ Placebo } & \multirow{2}{*}{$\begin{array}{c}\text { Mean Difference } \\
\text { Fixed, } 95 \% \mathrm{Cl} \\
\end{array}$} & \multirow[t]{2}{*}{ Weight } & \multirow{2}{*}{$\begin{array}{c}\text { Mean Difference } \\
\text { Fixed, } 95 \% \mathrm{Cl}\end{array}$} \\
\hline & $\mathbf{N}$ & Mean(SD) & $\mathbf{N}$ & $\operatorname{Mean}(S D)$ & & & \\
\hline \multicolumn{8}{|c|}{ 2.5.1 Mean visual acuity at end of study } \\
\hline CLEAR 2013 & 36 & $0.1(0.1)$ & 36 & $0.1(0.1)$ & & $64 \%$ & $0[-0.06,0.06]$ \\
\hline Subtotal $* \star \star$ & 36 & & 36 & & & $64 \%$ & $0[-0.06,0.06]$ \\
\hline \multicolumn{8}{|c|}{ Heterogeneity: Not applicable } \\
\hline \multicolumn{8}{|c|}{ Test for overall effect: Not applicable } \\
\hline \multicolumn{8}{|c|}{ 2.5.2 Change in visual acuity } \\
\hline Ma 2012 & 80 & $-0(0.2)$ & 27 & $0(0.2)$ & - & $27.85 \%$ & $-0.02[-0.11,0.07]$ \\
\hline Veterans LAST study 2004 & 25 & $-0.1(0.2)$ & 27 & $-0.1(0.4)$ & & $8.15 \%$ & $0.04[-0.13,0.21]$ \\
\hline Subtotal $* \star \star$ & 105 & & 54 & & & $36 \%$ & $-0.01[-0.09,0.08]$ \\
\hline \multicolumn{8}{|c|}{ Heterogeneity: $\mathrm{Tau}^{2}=0 ; \mathrm{Chi}^{2}=0.35, \mathrm{df}=1(\mathrm{P}=0.55) ; \mathrm{I}^{2}=0 \%$} \\
\hline \multicolumn{8}{|c|}{ Test for overall effect: $\mathrm{Z}=0.15(\mathrm{P}=0.88)$} \\
\hline 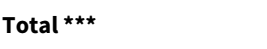 & 141 & & 90 & & & $100 \%$ & $-0[-0.05,0.05]$ \\
\hline \multicolumn{8}{|c|}{ Heterogeneity: $\operatorname{Tau}^{2}=0 ; \mathrm{Chi}^{2}=0.36, \mathrm{df}=2(\mathrm{P}=0.83) ; \mathrm{I}^{2}=0 \%$} \\
\hline \multicolumn{8}{|c|}{ Test for overall effect: $Z=0.09(P=0.93)$} \\
\hline \multicolumn{8}{|c|}{ Test for subgroup differences: $\mathrm{Chi}^{2}=0.01, \mathrm{df}=1(\mathrm{P}=0.9), \mathrm{I}^{2}=0 \%$} \\
\hline
\end{tabular}


Analysis 2.6. Comparison 2 Lutein and/or zeaxanthin versus placebo, Outcome 6 Visual Function Quality (VFQ).

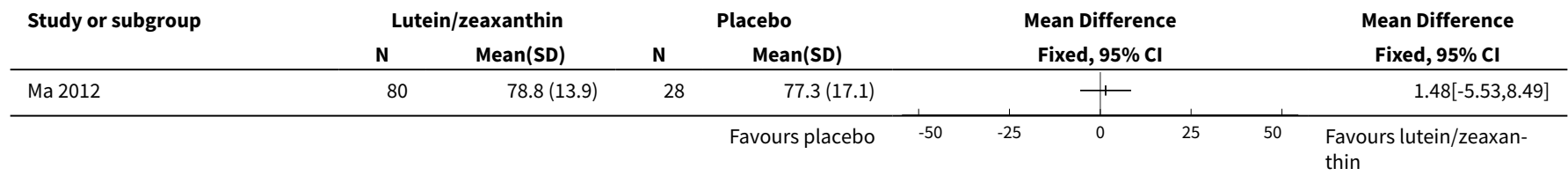

Comparison 3. Vitamin E versus placebo

\begin{tabular}{lllll}
\hline Outcome or subgroup title & No. of studies & $\begin{array}{l}\text { No. of partici- } \\
\text { pants }\end{array}$ & Statistical method & Effect size \\
\hline $\begin{array}{l}1 \text { Progression to late AMD (neovascular AMD } \\
\text { and/or geographic atrophy }\end{array}$ & 1 & & $\begin{array}{l}\text { Risk Ratio (IV, Fixed, } \\
95 \% \mathrm{Cl})\end{array}$ & $\begin{array}{l}\text { Totals not select- } \\
\text { ed }\end{array}$ \\
\hline $\begin{array}{l}2 \text { Progression to visual loss (loss of 3 or more } \\
\text { lines on logMAR chart) }\end{array}$ & 1 & Risk Ratio (IV, Fixed, & $\begin{array}{l}\text { Totals not select- } \\
\text { ed }\end{array}$ \\
\hline
\end{tabular}

Analysis 3.1. Comparison 3 Vitamin E versus placebo, Outcome 1 Progression to late AMD (neovascular AMD and/or geographic atrophy.

\begin{tabular}{lcrrr} 
Study or subgroup & $\begin{array}{c}\text { Vitamin E } \\
\mathbf{n} / \mathbf{N}\end{array}$ & $\begin{array}{c}\text { Placebo } \\
\mathbf{n} / \mathbf{N}\end{array}$ & $\begin{array}{c}\text { Risk Ratio } \\
\text { IV, Fixed, 95\% Cl }\end{array}$ & $\begin{array}{c}\text { Risk Ratio } \\
\text { IV, Fixed, 95\% Cl }\end{array}$ \\
\hline VECAT 2002 & & $4 / 494$ & $3 / 504$ & $1.36[0.31,6.05]$ \\
\hline
\end{tabular}

Analysis 3.2. Comparison 3 Vitamin E versus placebo, Outcome 2 Progression to visual loss (loss of 3 or more lines on logMAR chart).

\begin{tabular}{lccc|c|c} 
Study or subgroup & $\begin{array}{c}\text { Vitamin E } \\
\mathbf{n} / \mathbf{N}\end{array}$ & $\begin{array}{c}\text { Placebo } \\
\mathbf{n} / \mathbf{N}\end{array}$ & $\begin{array}{c}\text { Risk Ratio } \\
\text { IV, Fixed, 95\% Cl }\end{array}$ & $\begin{array}{c}\text { Risk Ratio } \\
\text { IV, Fixed, 95\% Cl }\end{array}$ \\
\hline VECAT 2002 & & $59 / 587$ & $57 / 592$ & $1.04[0.74,1.47]$ \\
\hline
\end{tabular}

\section{Comparison 4. Zinc versus placebo}

\begin{tabular}{lllll}
\hline Outcome or subgroup title & No. of studies & $\begin{array}{l}\text { No. of partici- } \\
\text { pants }\end{array}$ & Statistical method & Effect size \\
\hline $\begin{array}{l}\text { 1 Progression to late AMD (neovascu- } \\
\text { lar AMD or geographic atrophy) }\end{array}$ & 3 & 3790 & Odds Ratio (Fixed, 95\% Cl) & $0.83[0.70,0.98]$ \\
\hline 2 Progression to neovascular AMD & 1 & & Odds Ratio (Fixed, 95\% Cl) & Totals not selected \\
\hline 3 Progression to geographic atrophy & 1 & Odds Ratio (Fixed, 95\% Cl) & Totals not selected \\
\hline
\end{tabular}




\begin{tabular}{|c|c|c|c|c|}
\hline Outcome or subgroup title & No. of studies & $\begin{array}{l}\text { No. of partici- } \\
\text { pants }\end{array}$ & Statistical method & Effect size \\
\hline $\begin{array}{l}4 \text { Progression to visual loss (loss of } 3 \\
\text { or more lines on logMAR chart) }\end{array}$ & 2 & 3791 & Odds Ratio (Fixed, 95\% Cl) & $0.87[0.75,1.00]$ \\
\hline 5 Distance visual acuity: mean & 2 & 155 & $\begin{array}{l}\text { Mean Difference (IV, Fixed, } \\
95 \% \mathrm{CI})\end{array}$ & $-0.01[-0.05,0.04]$ \\
\hline 5.1 Mean visual acuity at end of study & 1 & 78 & $\begin{array}{l}\text { Mean Difference (IV, Fixed, } \\
95 \% \mathrm{CI})\end{array}$ & $0.02[-0.04,0.08]$ \\
\hline 5.2 Change in visual acuity & 1 & 77 & $\begin{array}{l}\text { Mean Difference (IV, Fixed, } \\
95 \% \mathrm{Cl} \text { ) }\end{array}$ & $-0.06[-0.14,0.02]$ \\
\hline
\end{tabular}

Analysis 4.1. Comparison 4 Zinc versus placebo, Outcome 1 Progression to late AMD (neovascular AMD or geographic atrophy).

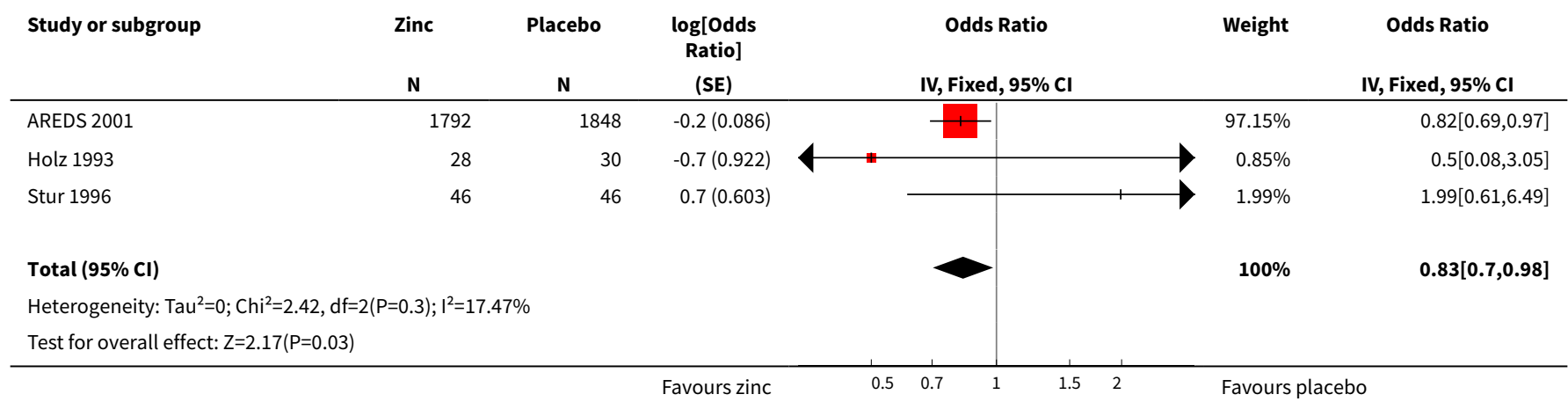

Analysis 4.2. Comparison 4 Zinc versus placebo, Outcome 2 Progression to neovascular AMD.

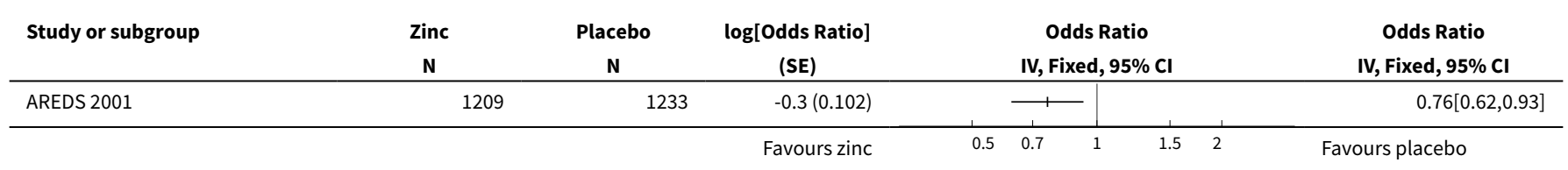

Analysis 4.3. Comparison 4 Zinc versus placebo, Outcome 3 Progression to geographic atrophy.

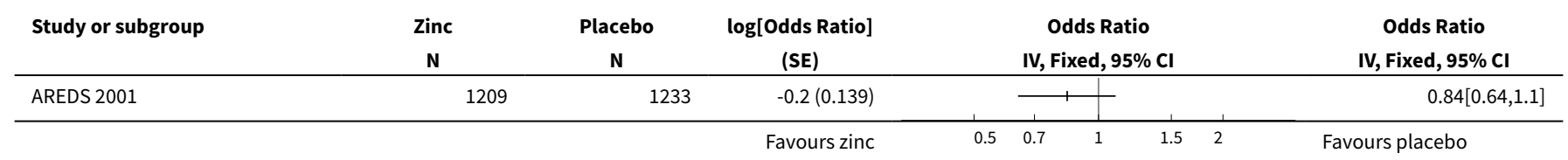


Analysis 4.4. Comparison 4 Zinc versus placebo, Outcome 4

Progression to visual loss (loss of 3 or more lines on logMAR chart).

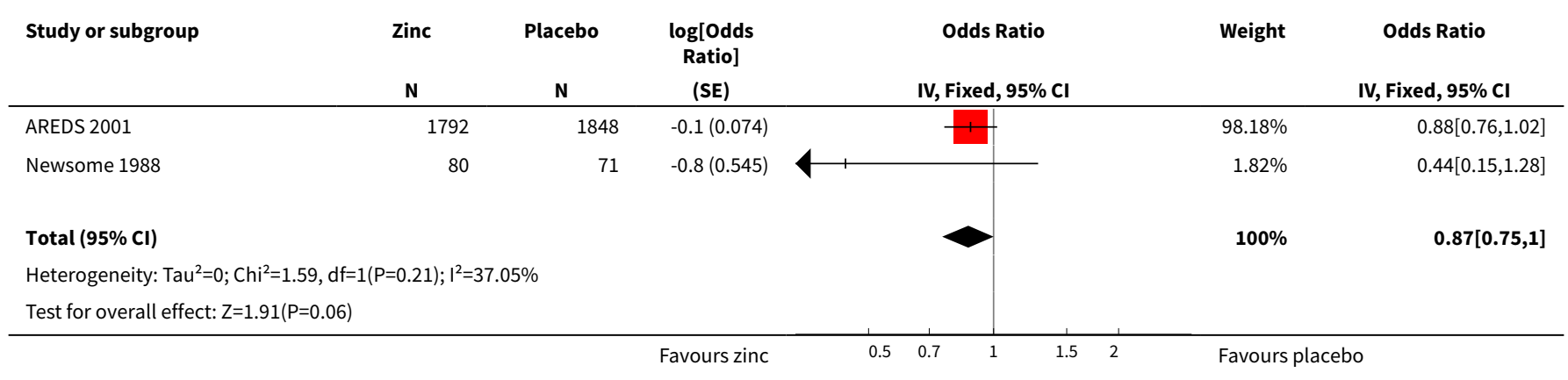

Analysis 4.5. Comparison 4 Zinc versus placebo, Outcome 5 Distance visual acuity: mean.

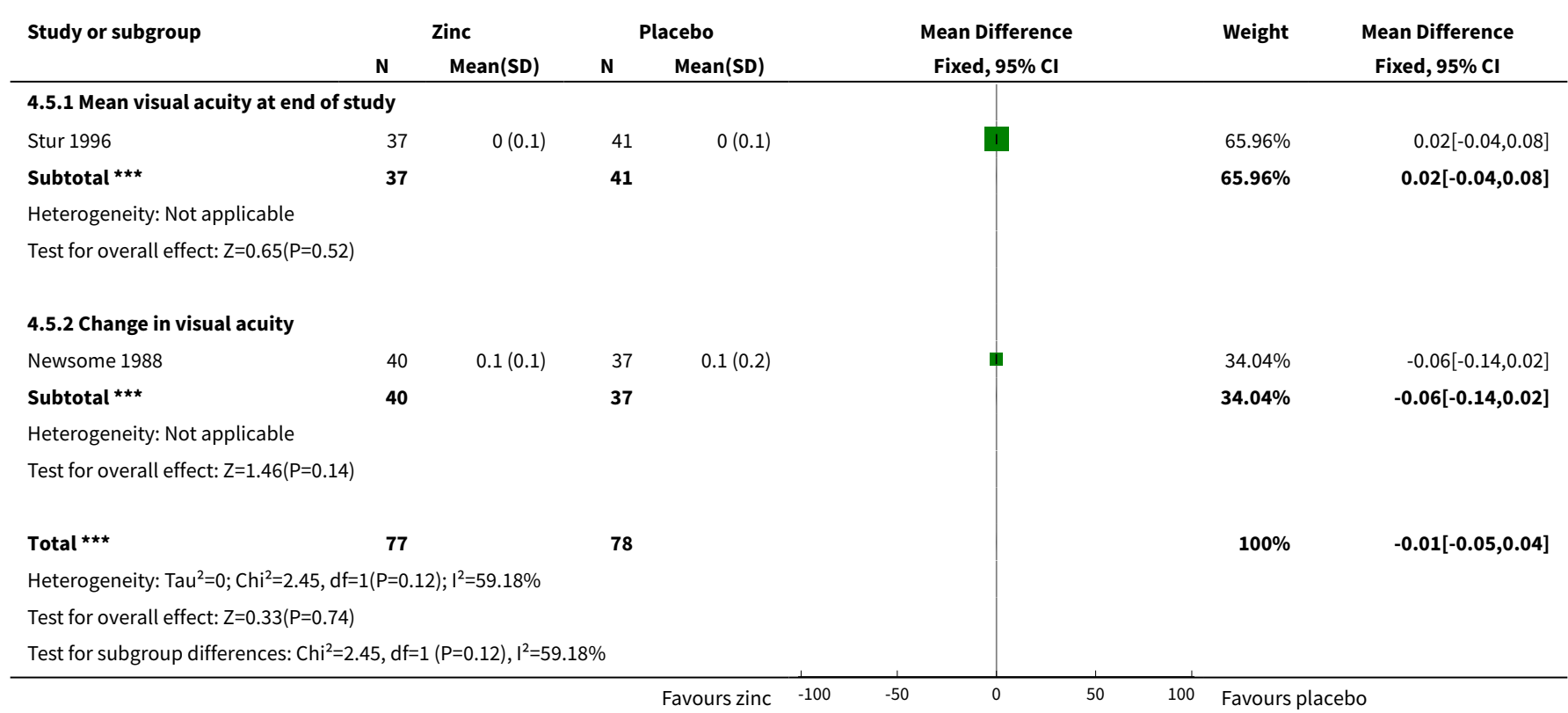




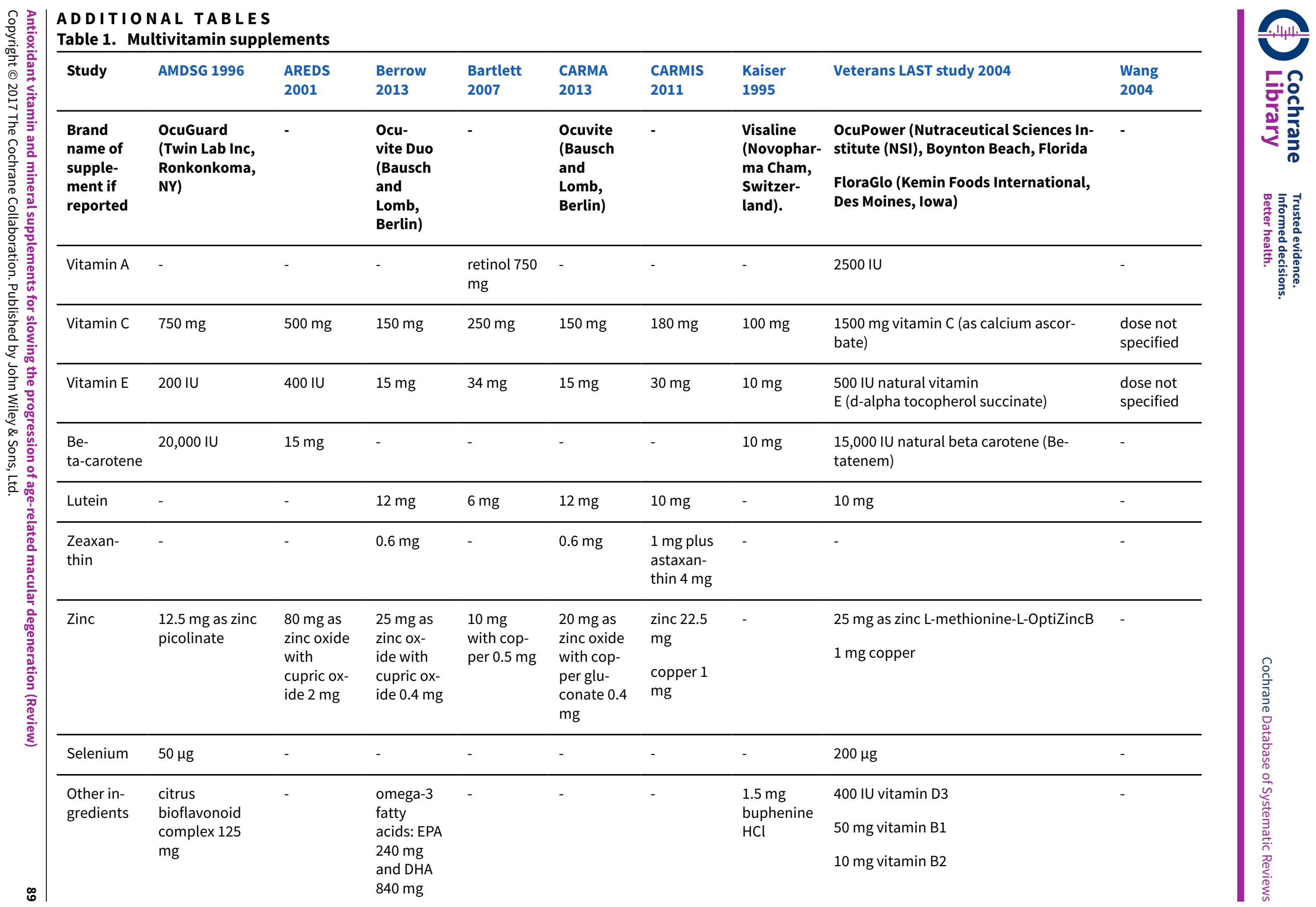




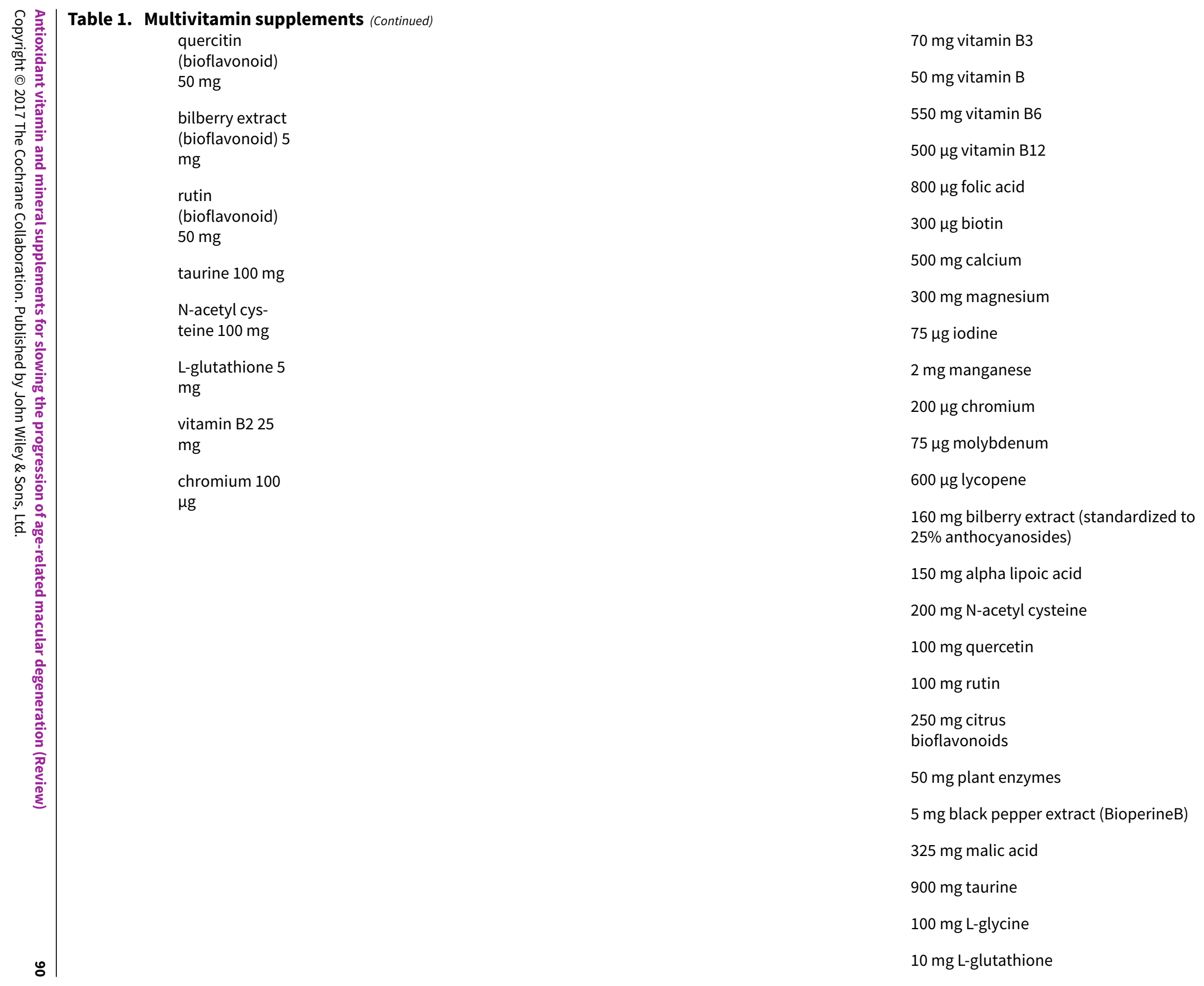




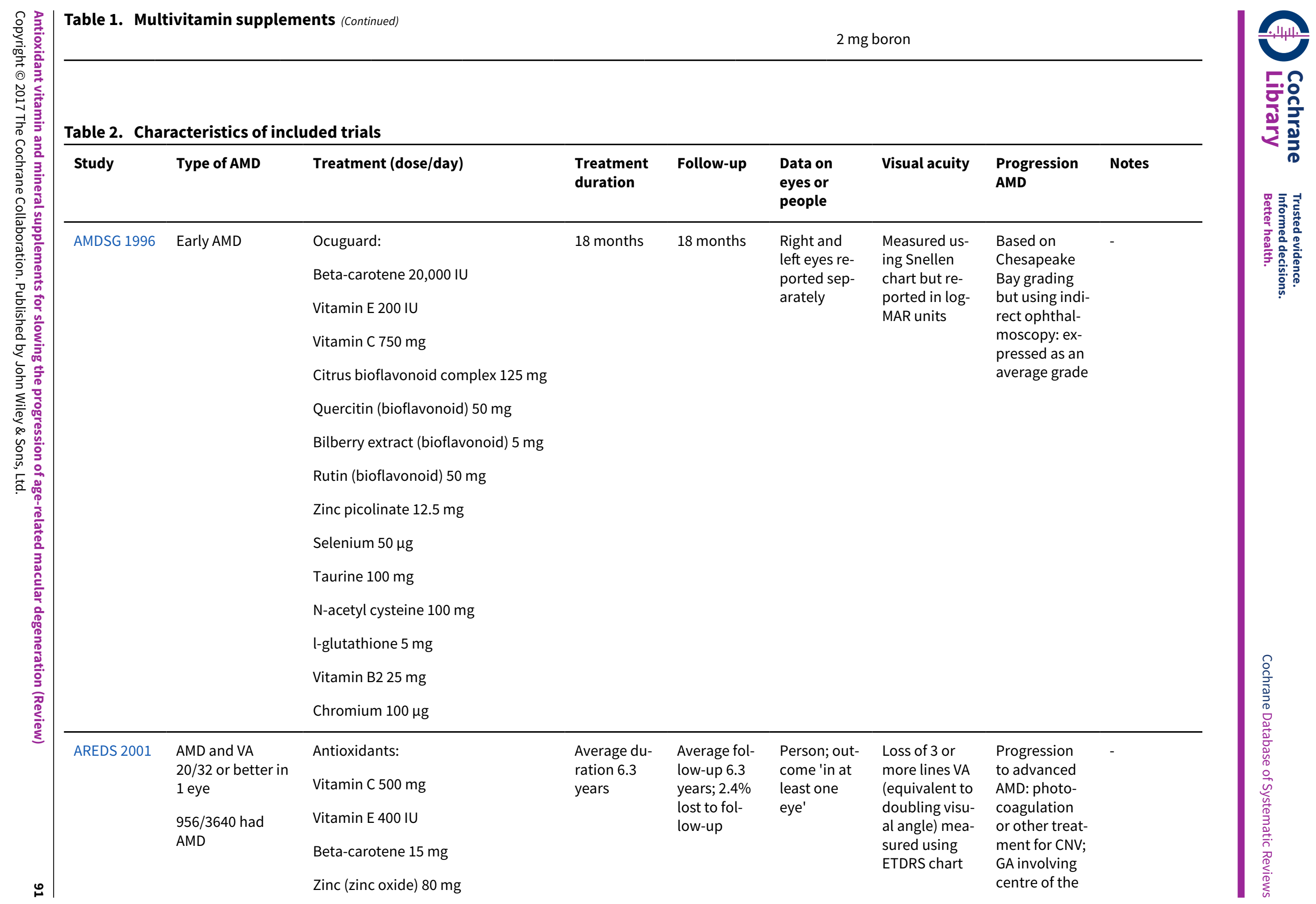




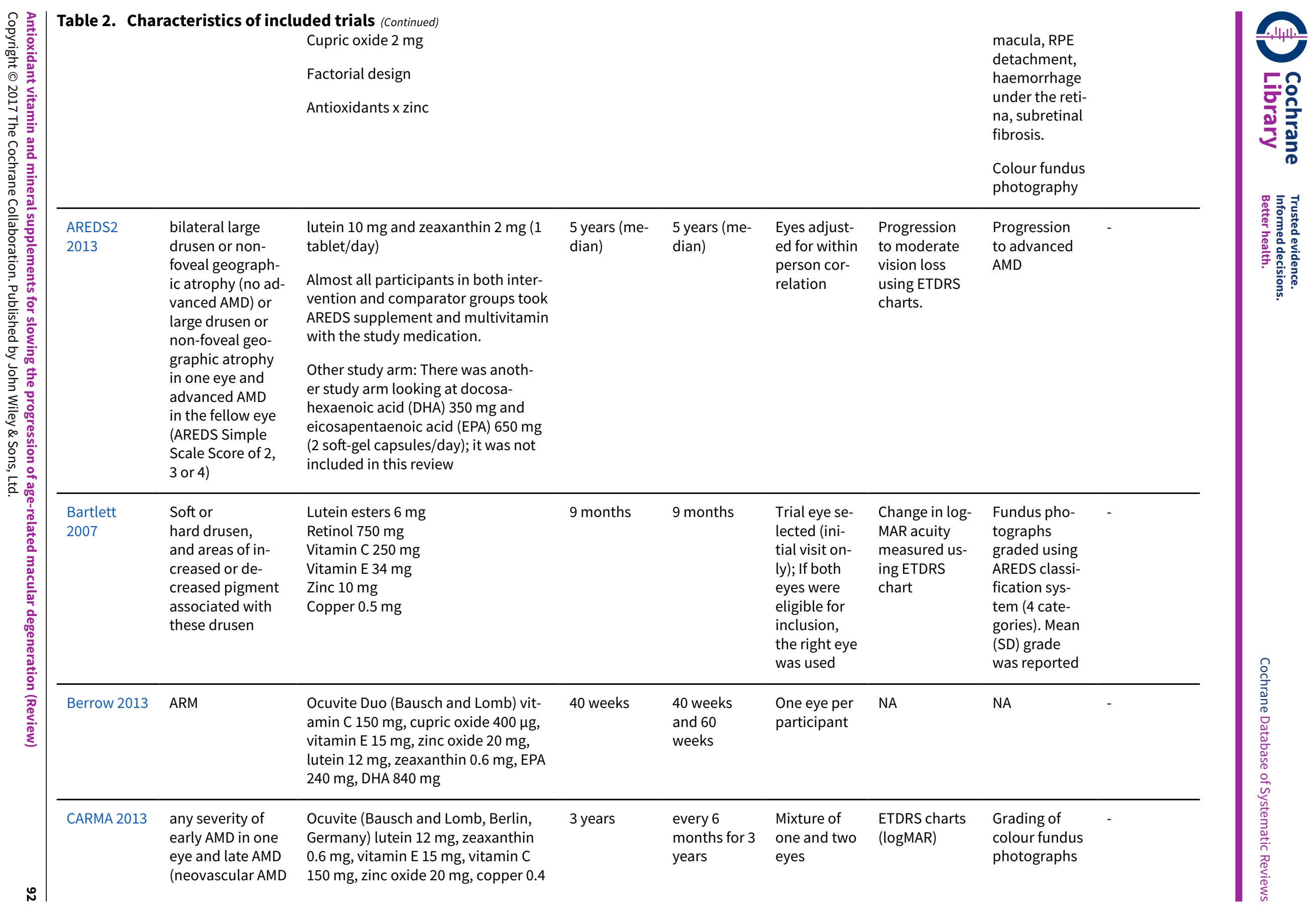




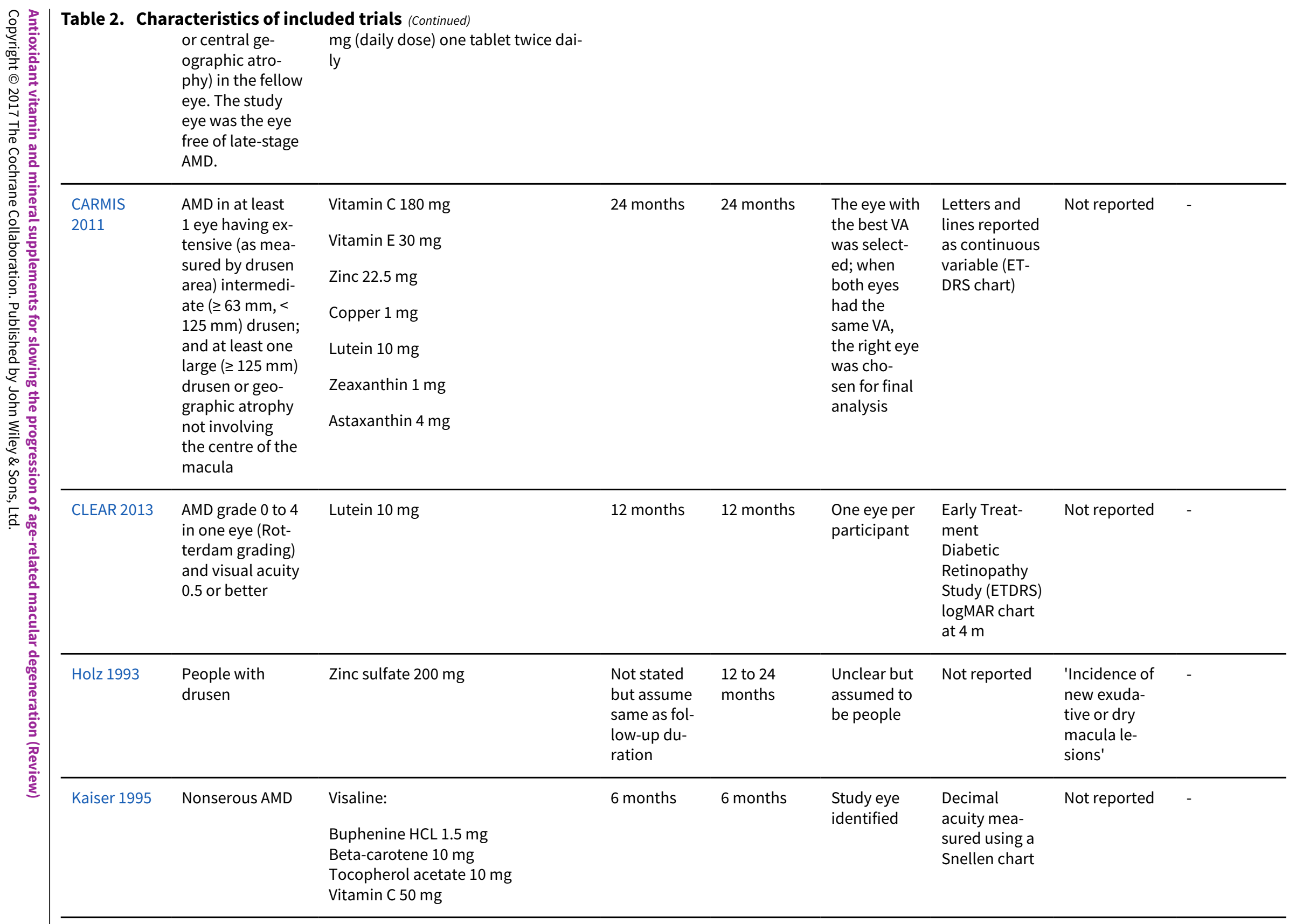




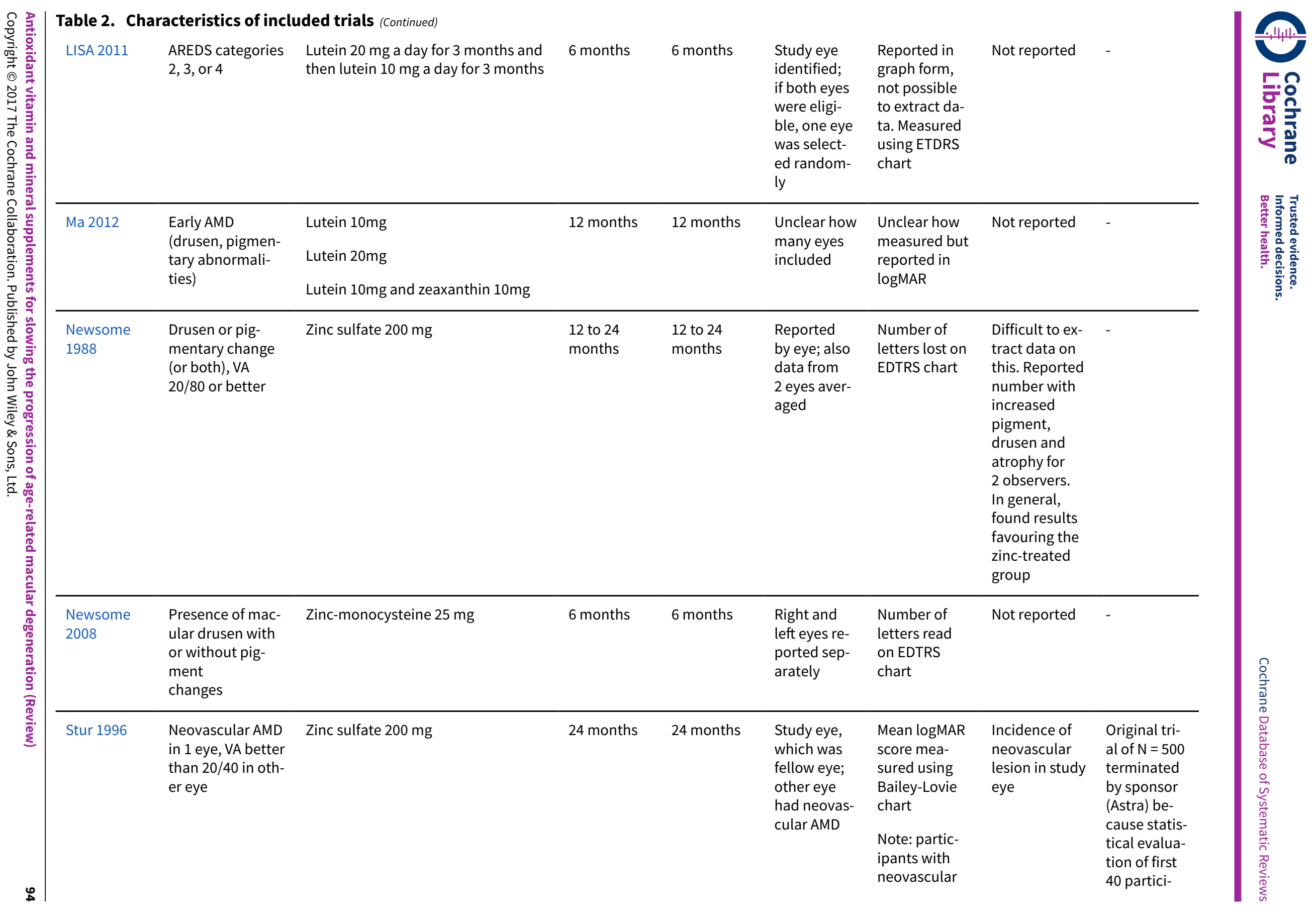




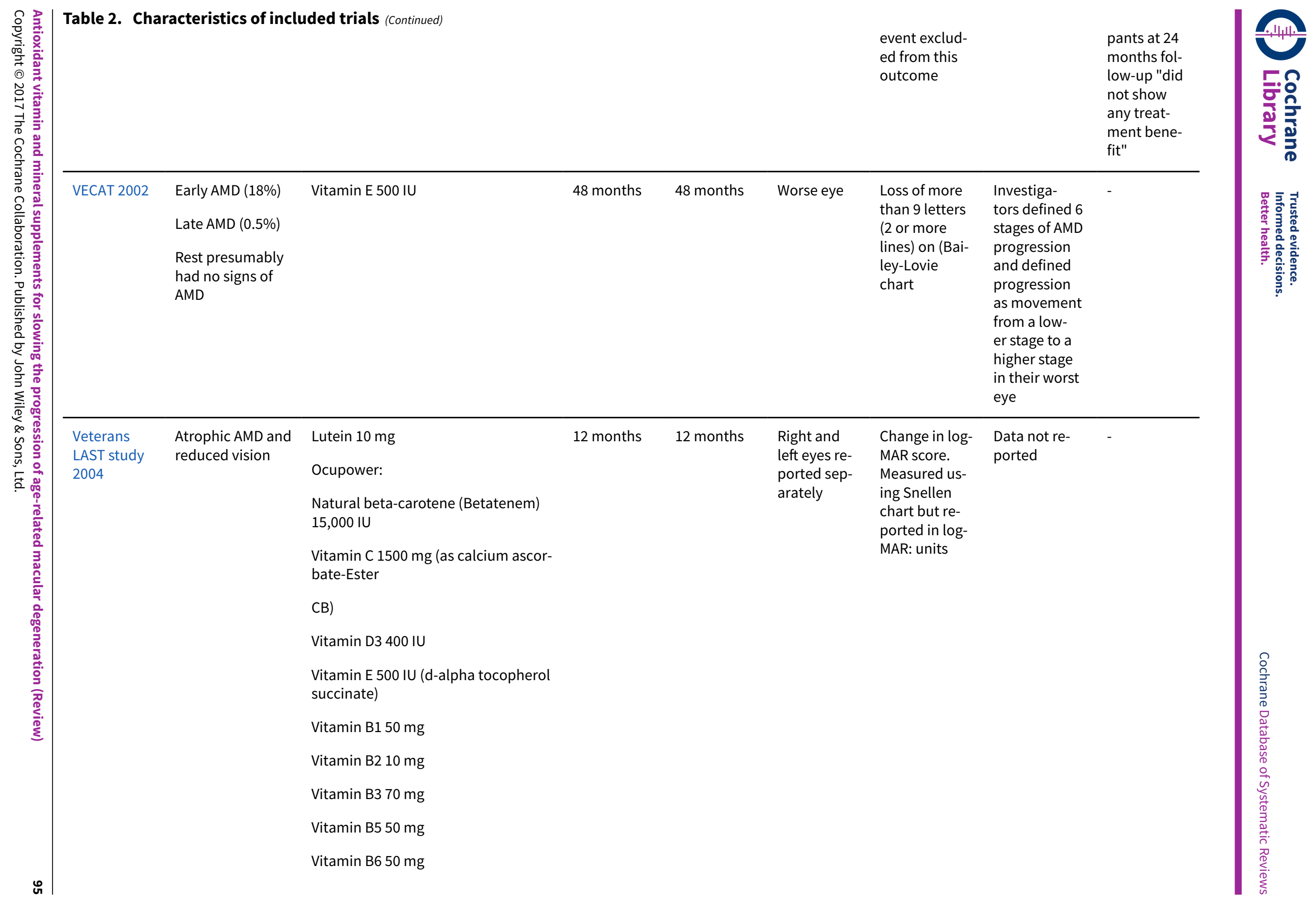




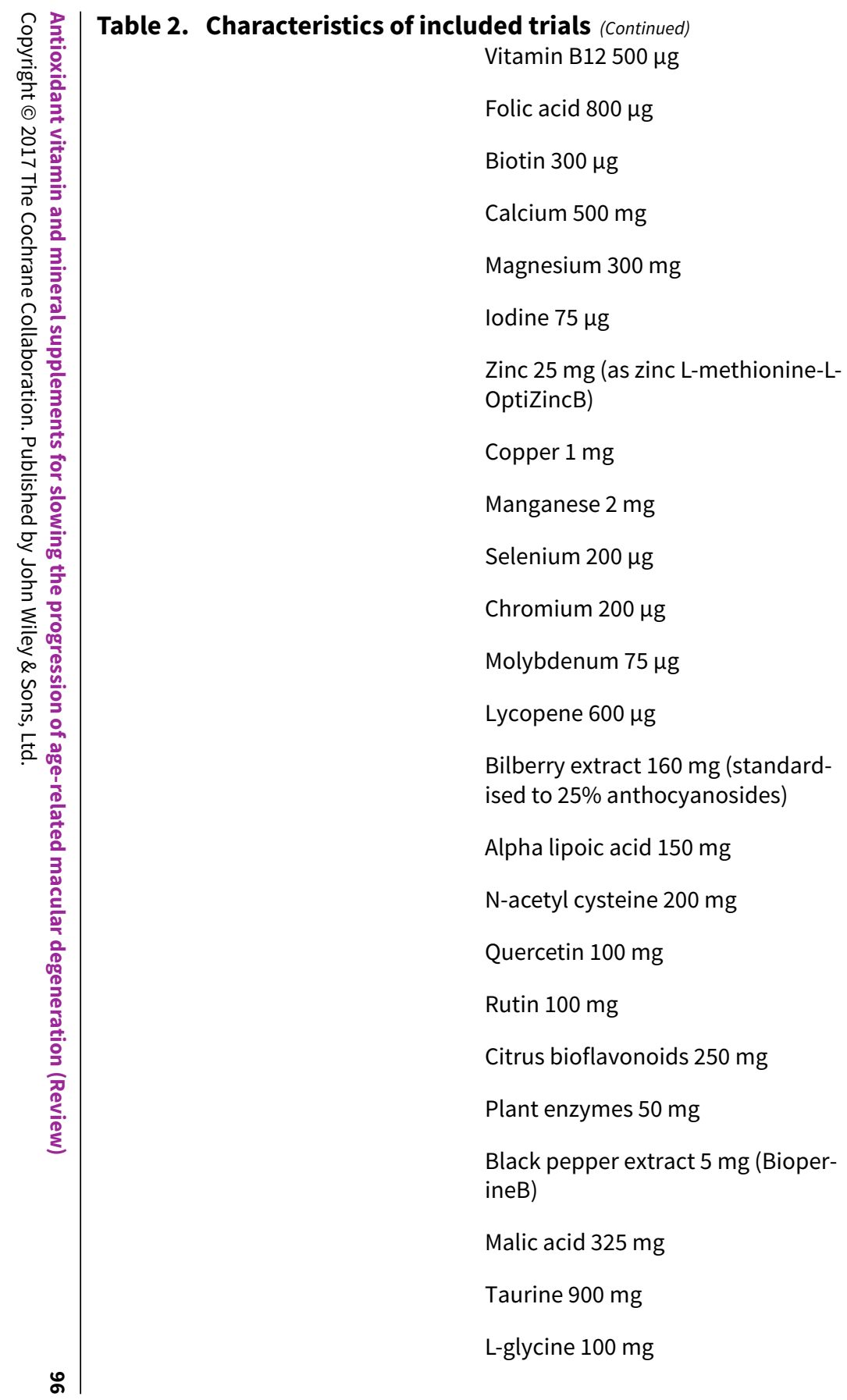




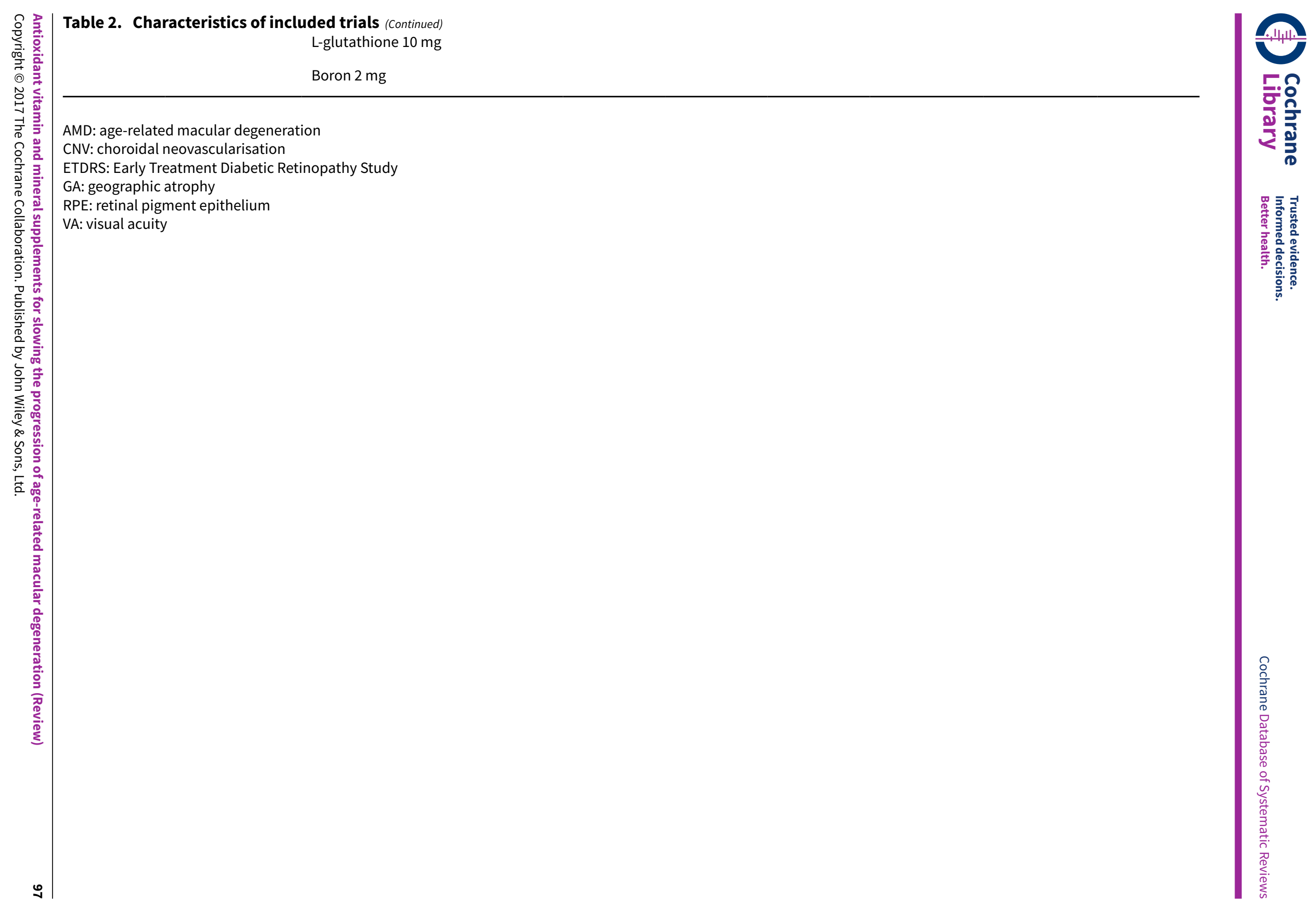


Table 3. Adverse effects in the included studies.

\begin{tabular}{|c|c|c|c|}
\hline Study number & Study name & Intervention & Adverse effects \\
\hline 1 & AMDSG 1996 & $\begin{array}{l}\text { Multivitamin (Ocu- } \\
\text { guard) }\end{array}$ & $\begin{array}{l}\text { One person developed an "allergic reaction", although it was } \\
\text { not clear whether or not this was related to the treatment. }\end{array}$ \\
\hline 2 & AREDS 2001 & $\begin{array}{l}\text { Multivitamin and } \\
\text { zinc }\end{array}$ & $\begin{array}{l}\text { Over } 100 \text { comparisons of zinc versus no zinc and antioxidants } \\
\text { versus no antioxidants. Participants in the antioxidant arms } \\
\text { more frequently reported yellow skin ( } 8.3 \% \text { versus } 6.0 \%, \mathrm{P}= \\
0.008) \text {. No important effect on mortality associated with mul- } \\
\text { tivitamin use (hazard ratio for mortality } 0.87,95 \% \mathrm{Cl} 0.60 \text { to } \\
1.25) \text {. } \\
\text { Participants in the zinc arms reported more anaemia ( } 13.2 \% \\
\text { versus } 10.2 \%, \mathrm{P}=0.004) \text {, however, serum haematocrit levels } \\
\text { were the same. They found that participants taking zinc had } \\
\text { a lower mortality. Later follow-up of the cohort of people tak- } \\
\text { ing part in the AREDS study found that there was a significant } \\
\text { increase in hospital admissions due to genitourinary diseases } \\
\text { in people taking zinc supplements ( } 11.1 \% \text { versus } 7.6 \%, \mathrm{P}= \\
0.0003 \text { ). }\end{array}$ \\
\hline
\end{tabular}

$\begin{array}{ll}\text { AREDS2 } 2013 & \begin{array}{l}\text { Lutein and zeaxan- } \\ \text { thin }\end{array}\end{array}$

Quote "No clinically or statistically significant differences in reported serious adverse events, including rates of development of neoplasms, were noted across the treatment groups in the primary randomization. However, secondary randomization excluding participants who were smokers showed more lung cancers in the beta carotene group than in the no beta carotene group (23 [2.0\%] vs 11 [0.9\%]) (nominal P=.04)." and "Rates of reported gastrointestinal disorders and hospitalizations for genitourinary diseases were similar in the 2 randomly assigned groups (high-dose zinc, low-dose zinc) in AREDS2" "The HR for mortality comparing lutein zeaxanthin vs no lutein zeaxanthin was $1.06(95 \% \mathrm{Cl}, 0.87-1.31 ; \mathrm{P}=.56)$ for lutein zeaxanthin vs no lutein zeaxanthin"

\begin{tabular}{|c|c|c|c|}
\hline 4 & Bartlett 2007 & Multivitamin & $\begin{array}{l}\text { "There were no reported adverse effects from any of the study } \\
\text { participants." }\end{array}$ \\
\hline 5 & Berrow 2013 & $\begin{array}{l}\text { Multivitamin (Ocu- } \\
\text { vite) }\end{array}$ & Did not report adverse effects. \\
\hline 6 & CARMA 2013 & $\begin{array}{l}\text { Multivitamin (Ocu- } \\
\text { vite) }\end{array}$ & Did not report adverse effects. \\
\hline 7 & CARMIS 2011 & Multivitamin & $\begin{array}{l}\text { Quote "There were no significant systemic or ocular adverse } \\
\text { events related to the nutritional supplementation." }\end{array}$ \\
\hline 8 & CLEAR 2013 & Lutein & $\begin{array}{l}3 / 42 \text { in the lutein group and } 1 / 42 \text { in the placebo group "discon- } \\
\text { tinued due to medical reasons", but it was unclear if these were } \\
\text { complications, per se. }\end{array}$ \\
\hline 9 & France 1998 & Zinc & Unpublished study, no data available. \\
\hline 10 & Holz 1993 & Zinc & Quote "the zinc therapy was well-tolerated". \\
\hline 11 & Kaiser 1995 & Multivitamin & Did not report adverse effects. \\
\hline
\end{tabular}


Table 3. Adverse effects in the included studies. (Continued)

$\begin{array}{ll}\text { LISA } 2011 \quad \text { Lutein (Lutamax) } & \begin{array}{l}\text { Quote "In two subjects, the withdrawal was due to serious ad- } \\ \text { verse events. One subject had a myocardial infarction, and the } \\ \text { other subject developed CNV in the study eye." }\end{array}\end{array}$

\begin{tabular}{|c|c|c|c|}
\hline 13 & Ma 2012 & $\begin{array}{l}\text { Lutein and zeaxan- } \\
\text { thin }\end{array}$ & $\begin{array}{l}\text { Quote "No adverse events were observed or reported." and } \\
\text { "No significant adverse events or changes in biochemical or } \\
\text { hematologic profiles were observed or reported in any subject } \\
\text { throughout the study. No subject developed or reported occa- } \\
\text { sional skin pigmentation (carotenodermia)." }\end{array}$ \\
\hline 14 & Newsome 1988 & Zinc & Did not report adverse effects. \\
\hline 15 & Newsome 2008 & Zinc mono-cysteine & $\begin{array}{l}\text { Quote "ZMC (zinc mono-cysteine) appeared to be well tolerat- } \\
\text { ed"; } 1 / 40 \text { had gastrointestinal symptoms attributable to treat- } \\
\text { ment. }\end{array}$ \\
\hline 16 & Stur 1996 & Zinc & $\begin{array}{l}4 / 56 \text { in the zinc-treated group and } 2 / 56 \text { in the placebo group } \\
\text { withdrew because of gastrointestinal symptoms. }\end{array}$ \\
\hline 17 & VECAT 2002 & Vitamin E & $\begin{array}{l}11 \text { in the vitamin } E \text { and } 7 \text { in the control group died; } 16 \text { in the vi- } \\
\text { tamin E group and } 17 \text { in the control group had an adverse reac- } \\
\text { tion. }\end{array}$ \\
\hline 18 & $\begin{array}{l}\text { Veterans LAST } \\
\text { study } 2004\end{array}$ & $\begin{array}{l}\text { Multivtamin } \\
\text { (OcuPower) and } \\
\text { lutein (FloraGlo) }\end{array}$ & $\begin{array}{l}\text { The number of adverse effects were tabulated, but the study } \\
\text { was underpowered to detect any differences. }\end{array}$ \\
\hline 19 & Wang 2004 & $\begin{array}{l}\text { Multivitamin and } \\
\text { zinc }\end{array}$ & Did not report adverse effects. \\
\hline
\end{tabular}

\section{AP PEN DICES}

\section{Appendix 1. CENTRAL search strategy}

\#1 MeSH descriptor Macular Degeneration

\#2 MeSH descriptor Retinal Degeneration

\#3 MeSH descriptor Retinal Neovascularization

\#4 MeSH descriptor Choroidal Neovascularization

\#5 MeSH descriptor Macula Lutea

\#6 macula* near lutea*

\#7 (( macul $^{\star}$ OR retina* OR choroid ${ }^{\star}:$ TI) AND (degener ${ }^{\star}$ OR neovasc $\left.\left.{ }^{\star}: T I\right)\right)$

\#8 ((macul ${ }^{\star}$ OR retina* OR choroid ${ }^{\star}:$ AB) AND (degener ${ }^{\star}$ OR neovasc $\left.\left.{ }^{\star}: A B\right)\right)$

\#9 maculopath*

\#10 (\#1 OR \#2 OR \#3 OR \#4 OR \#5 OR \#6 OR \#7 OR \#8 OR \#9)

\#11 MeSH descriptor Vitamins

$\# 12$ vitamin*

\#13 MeSH descriptor Vitamin A

$\# 14$ retinol $^{*}$

\#15 MeSH descriptor beta Carotene

\#16 caroten $^{*}$

\#17 MeSH descriptor Ascorbic Acid

$\# 18$ ascorbic next acid

\#19 MeSH descriptor Vitamin E

\#20 MeSH descriptor alpha-Tocopherol

\#21 alpha tocopherol*

\#22 MeSH descriptor Vitamin B 12 
\#23 cobalamin*

\#24 MeSH descriptor Antioxidants

\#25 antioxidant* or anti oxidant ${ }^{\star}$

\#26 MeSH descriptor Carotenoids

\#27 carotenoid*

\#28 MeSH descriptor Zinc

\#29 zinc*

\#30 MeSH descriptor Riboflavin

\#31 riboflavin*

\#32 MeSH descriptor Selenium

\#33 selenium*

\#34 MeSH descriptor Lutein

\#35 lutein*

\#36 MeSH descriptor Xanthophylls

\#37 xanthophyll*

\#38 zeaxanthin*

\#39 (\#11 OR \#12 OR \#13 OR \#14 OR \#15 OR\#16 OR \#17 OR \#18 OR \#19 OR \#20 OR \#21 OR \#22 OR \#23 OR \#24)

\#40 (\#25 OR \#26 OR \#27 OR \#28 OR \#29 OR \#30 OR \#31 OR \#32 OR \#33 OR \#34 OR \#35 OR \#36 OR \#37 OR \#38)

\#41 (\#39 OR \#40)

\#42 (\#10 AND \#41)

\section{Appendix 2. MEDLINE Ovid search strategy}

1. randomized controlled trial.pt.

2. (randomized or randomised).ab,ti.

3. placebo.ab,ti.

4. dt.fs.

5. randomly.ab,ti.

6. trial.ab,ti.

7. groups.ab,ti.

8. or/1-7

9. exp animals/

10. exp humans/

11. 9 not (9 and 10)

12. 8 not 11

13. exp macular degeneration/

14. exp retinal degeneration/

15. exp retinal neovascularization/

16. exp choroidal neovascularization/

17. exp macula lutea/

18. (macula\$ adj2 lutea).tw.

19. ((macul\$ or retina\$ or choroid\$) adj4 degener\$).tw.

20. ((macul\$ or retina $\$$ or choroid\$) adj4 neovasc\$).tw.

21. (AMD or ARMD or CNV).tw.

22. maculopath\$.tw.

23. or $/ 13-22$

24. exp vitamins/

25. $\exp$ vitamin $\mathrm{A} /$

26. vitamin A.tw.

27. retinol\$.tw.

28. exp beta carotene/

29. (caroten\$ or betacaroten\$).tw.

30. exp ascorbic acid/

31. ascorbic acid\$.tw.

32. vitamin C.tw.

33. exp Vitamin E/

34. exp alpha tocopherol/

35. alpha?tocopherol\$.tw.

36. alpha tocopherol\$.tw.

37. vitamin E.tw.

38. exp Vitamin B12/

39. vitamin B12.tw. 
40. cobalamin\$.tw.

41. exp antioxidants/

42. ((antioxidant\$ or anti) adj1 oxidant\$).tw.

43. exp carotenoids/

44. carotenoid\$.tw.

45. exp zinc/

46. zinc\$.tw.

47. exp riboflavin/

48. riboflavin\$.tw.

49. exp selenium/

50. selenium\$.tw.

51. exp lutein/

52. lutein\$.tw.

53. exp xanthophylls/

54. xanthophyll.tw.

55. zeaxanthin\$.tw.

56. or/24-55

57.23 and 56

58. 12 and 57

The search filter for trials at the beginning of the MEDLINE strategy is from the published paper by Glanville 2006.

\section{Appendix 3. Embase Ovid search strategy}

1. exp randomized controlled trial/

2. exp randomization/

3. exp double blind procedure/

4. exp single blind procedure/

5. random\$.tw.

6. or/1-5

7. (animal or animal experiment).sh.

8. human.sh.

9. 7 and 8

10.7 not 9

11.6 not 10

12. exp clinical trial/

13. (clin\$ adj3 trial\$).tw.

14. ((singl\$ or doubl\$ or trebl\$ or tripl\$) adj3 (blind\$ or mask\$)).tw.

15. exp placebo/

16. placebo\$.tw.

17. random\$.tw.

18. exp experimental design/

19. exp crossover procedure/

20. exp control group/

21. exp latin square design/

22. or $/ 12-21$

23. 22 not 10

24. 23 not 11

25. exp comparative study/

26. exp evaluation/

27. exp prospective study/

28. (control\$ or prospectiv\$ or volunteer\$).tw.

29. or $/ 25-28$

30.29 not 10

31. 30 not ( 11 or 23 )

32. 11 or 24 or 31

33. exp retina macula degeneration/

34. exp retina degeneration/

35. exp retina neovascularization/

36. exp subretinal neovascularization/

37. (AMD or ARMD or CNV).tw.

38. ((macul\$ or retina\$ or choroid\$) adj4 degener\$).tw. 
39. ((macul\$ or retina\$ or choroid\$) adj4 neovasc\$).tw.

40. exp retina macula lutea/

41. (macula\$ adj2 lutea\$).tw.

42. maculopath\$.tw.

43. or/33-42

44. exp vitamins/

45. exp Retinol/

46. vitamin A.tw.

47. retinol\$.tw.

48. exp beta carotene/

49. (caroten\$ or betacaroten\$).tw.

50. exp ascorbic acid/

51. ascorbic acid\$.tw.

52. vitamin C.tw.

53. exp alpha tocopherol/

54. alpha?tocopherol\$.tw.

55. alpha tocopherol\$.tw.

56. vitamin E.tw.

57. vitamin B12.tw.

58. exp cyanocobalamin/

59. cobalamin\$.tw.

60. exp antioxidants/

61. ((antioxidant\$ or anti) adj1 oxidant\$).tw.

62. exp carotenoid/

63. exp zinc/

64. zinc\$.tw.

65. exp riboflavin/

66. riboflavin\$.tw.

67. exp selenium/

68. selenium\$.tw.

69. exp zeaxanthin/

70. zeaxanthin\$.tw.

71. lutein\$.tw.

72. xanthophyll.tw.

73. or/44-72

74.43 and 73

75.32 and 74

\section{Appendix 4. AMED Ovid search strategy}

1. exp eye disease/

2. exp vision disorders/

3. exp retinal disease/

4. maculopath\$.tw.

5. ((macul\$ or retina\$ or choroid\$) adj3 degenerat\$).tw.

6. ((macul\$ or retina\$ or choroid\$) adj3 neovasc\$).tw.

7. or/1-6

8. exp vitamins/

9. vitamin A.tw.

10. retinol\$.tw.

11. exp carotenoids/

12. caroten\$.tw.

13. exp ascorbic acid/

14. ascorbic acid\$.tw.

15. vitamin C.tw.

16. vitamin E.tw.

17. alpha tocopherol\$.tw.

18. vitamin B12.tw.

19. cobalamin\$.tw.

20. exp antioxidants/

21. ((antioxidant\$ or anti) adj1 oxidant\$).tw.

22. zinc/ 
23. zinc\$.tw.

24. riboflavin\$.tw.

25. selenium/

26. selenium\$.tw.

27. lutein\$.tw.

28. xanthophylls.tw.

29. zeaxanthin\$.tw.

30. or/8-29

31.7 and 30

\section{Appendix 5. OpenGrey search strategy}

(macular degeneration OR AMD) AND (antioxidant OR vitamin OR carotene OR selenium OR tocopherol)

\section{Appendix 6. ISRCTN search strategy}

(macular degeneration OR AMD) AND (antioxidant OR vitamin OR carotene OR selenium OR tocopherol)

\section{Appendix 7. ClinicalTrials.gov search strategy}

(Macular Degeneration OR AMD) AND (Antioxidant OR Vitamin OR Carotene OR Selenium OR Tocopherol)

\section{Appendix 8. ICTRP search strategy}

Macular Degeneration OR AMD = Condition AND Antioxidant OR Vitamin OR Carotene OR Selenium OR Tocopherol = Intervention

\section{Appendix 9. MEDLINE Ovid adverse effects search strategy}

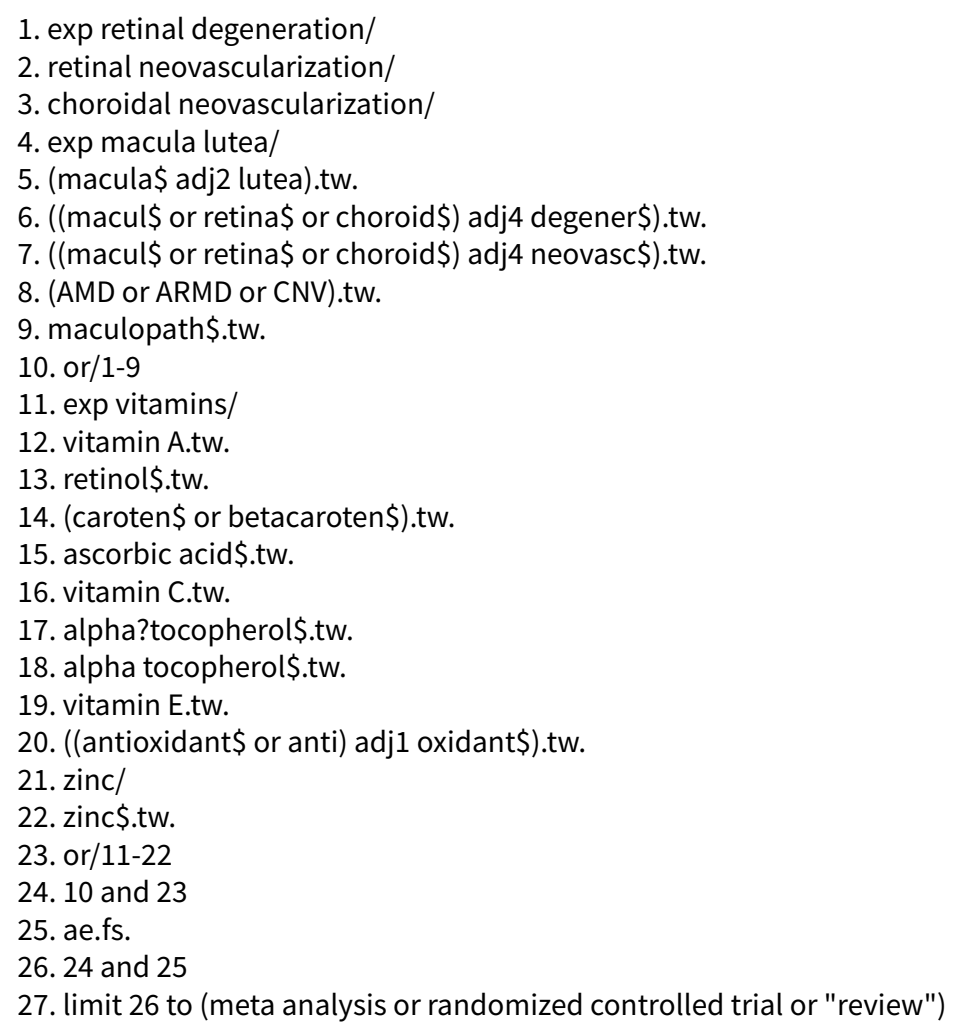

\section{WHAT'S NEW}

\begin{tabular}{lll}
\hline Date & Event & Description \\
\hline 22 September 2017 & Amended & $\begin{array}{l}\text { Correction of discrepancy between Analysis 1.5 and text in Ef- } \\
\text { fects of interventions section. Sources of support and Acknowl- } \\
\text { edgements updated. }\end{array}$ \\
\hline \hline
\end{tabular}




\section{HISTORY}

Protocol first published: Issue 3, 1997

Review first published: Issue 1, 1998

\begin{tabular}{|c|c|c|}
\hline Date & Event & Description \\
\hline 29 March 2017 & New search has been performed & Issue 7, 2017: Electronic searches were updated. \\
\hline 29 March 2017 & $\begin{array}{l}\text { New citation required but conclusions } \\
\text { have not changed }\end{array}$ & $\begin{array}{l}\text { Issue 7, 2017: Six new trials (AREDS2 2013; Berrow 2013; CARMA } \\
\text { 2013; CLEAR 2013; France 1998; Ma 2012) were included in this } \\
\text { update }\end{array}$ \\
\hline 11 July 2012 & $\begin{array}{l}\text { New citation required but conclusions } \\
\text { have not changed }\end{array}$ & $\begin{array}{l}\text { Issue 9, 2012: Update searches were conducted and } 3 \text { new trials } \\
\text { have been added to the review. }\end{array}$ \\
\hline 11 July 2012 & New search has been performed & Issue 9, 2012: John Lawrenson assisted with this review update. \\
\hline 28 August 2008 & Amended & Converted to new review format. \\
\hline 12 August 2007 & New search has been performed & $\begin{array}{l}\text { Issue } 1 \text { 2008: Results of trial from China (Wang et al) added. Re- } \\
\text { port from AREDS study on risk of hospital admission due to geni- } \\
\text { tourinary complications in people taking high-dose zinc. } \\
\text { Graphs with only one trial have been deleted and results have } \\
\text { been reported in the text. }\end{array}$ \\
\hline 19 January 2006 & $\begin{array}{l}\text { New citation required and conclusions } \\
\text { have changed }\end{array}$ & Substantive amendment \\
\hline
\end{tabular}

\section{CONTRIBUTIONS OF AUTHORS}

JE wrote the protocol and completed the first published version of this review.

JGL checked all the data in the originally published review.

For the 2012 and 2017 updates, both authors searched for new studies, did 'Risk of bias' assessment, and extracted data. JE cut and pasted data into RevMan and updated the text. JGL checked the data and provided comments on the text.

\section{DECLARATIONS OF INTEREST}

None known.

\section{SOURCES OF SUPPORT}

\section{Internal sources}

- Moorfields Eye Hospital NHS Trust, UK.

\section{External sources}

- Guide Dogs for the Blind Association, UK.

- National Institute for Health Research (NIHR), UK.

- Richard Wormald, Co-ordinating Editor for Cochrane Eyes and Vision (CEV) acknowledges financial support for his CEV research sessions from the Department of Health through the award made by the NIHR to Moorfields Eye Hospital NHS Foundation Trust and UCL Institute of Ophthalmology for a Specialist Biomedical Research Centre for Ophthalmology.

- This review was supported by the NIHR, via Cochrane Infrastructure funding to the CEV UK editorial base which funds part of Jennifer Evans's salary. 
The views and opinions expressed therein are those of the authors and do not necessarily reflect those of the Systematic Reviews Programme, NIHR, NHS or the Department of Health.

\section{DIFFERENCES BETWEEN PROTOCOLANDREVIEW}

The original protocol was published in 1999. Since that time, there have been methodological improvements within Cochrane, and the methods have been updated to include assessment of risk of bias, 'Summary of findings' tables, GRADE assessment, and better consideration of unit of analysis issues.

Previous versions of this review have included a comparison "Any multivitamin or single component antioxidant supplement versus placebo". We have dropped this comparison for the current review because the majority of the data for this review come from AREDS 2001 and AREDS2 2013. Given that all participants in AREDS2 2013 received the supplements trialled in AREDS 2001 it did not make much sense to pool these data.

For the update in 2017, we modified the outcome measures to ensure they were in line with those being used as part of the macular degeneration guidelines being prepared by NICE (NICE 2016). We also applied the default minimum important difference interval for dichotomous outcomes of 0.8 to 1.25 for downgrading for imprecision.

Table: Comparing outcome measures in current review with outcome measures in last published version

\begin{tabular}{ll}
\hline Current review (2017)* & Last published version (2012) \\
\hline Progression to late AMD (neovascular AMD, geographic atrophy, or both) & Progression of the disease (secondary) \\
Progression to neovascular AMD & - as defined by study investigators \\
Progression to geographic atrophy & \\
\hline Progression to visual loss & Visual acuity (primary) \\
- loss of 3 or more lines & - loss of 3 or more lines \\
\hline continuous & continuous \\
\hline Resource use and costs & Quality of life (secondary) \\
\hline Adverse effects & Adverse effects \\
\hline
\end{tabular}

* In the current review no primary / secondary outcomes are specified.

\section{INDEX TERMS}

\section{Medical Subject Headings (MeSH)}

Antioxidants [^therapeutic use]; Dietary Supplements; Disease Progression; Geographic Atrophy [prevention \& control]; Lutein [therapeutic use]; Macular Degeneration [*prevention \& control]; Minerals [*therapeutic use]; Quality of Life; Randomized Controlled Trials as Topic; Vitamin E [therapeutic use]; Vitamins [ ${ }^{\star}$ therapeutic use]; Zeaxanthins [therapeutic use]; Zinc [therapeutic use]

\section{MeSH check words}

Aged; Humans 